\title{
Kurt Glaser
}

\section{Kriegsgefangener auf drei Kontinenten}

\author{
Samstag, 8. 5. 43
}

Wir sind früh aufgestanden vor lauter Kälte. Der Chef kommt mit dem Pkw vorbeigefahren. Ich mache Meldung. Ich bekomme den Befehl, um 12.00 Uhr die Geschütze zu sprengen, da wir uns nicht mehr bewegen können. Es wären keine Fahrzeuge vorhanden. Ich habe mich mit dem Zug geschlossen nach El Alaia durchzuschlagen. Gegen 11.00 Uhr haben wir alles vorbereitet. Unser Gepäck verkleinert. Araber sind Abnehmer für alles, was wir „über Bord“" werfen. Die Geschützführer haben die Sprengladung an den Geschützen angebracht. Die Sprengkapseln hatte ich bis dahin unter Verschluß. Wir sind alle recht niedergeschlagen, jetzt ist es soweit, daß hier der Feldzug zu Ende geht. Eine Gruppe Pioniere schließt sich uns an. Die Zündschnüre brennen, wir laufen in Deckung und warten zwei Minuten ab. Zwei Geschütze gehen auf einen Schlag hoch, das dritte etwas später. Ich kann nicht mehr zurückschauen, das Herz möchte mir fast brechen. Unsere Handwaffen, unser Gepäck haben wir aufgenommen und erreichen die erste Höhe. Dort hinten sehen wir die weiße Stadt am Hang. Wir kommen nicht weit, das Gepäck ist uns zu schwer, und wir müssen uns erleichtern. Schweren Herzens nehmen wir von manchem Stück Abschied, das uns etwas wert erscheint. Als erstes lassen wir unsere Schaftstiefel zurück und ziehen unsere Schnürschuhe an. Die Araber, wie die Hyänen, stürzen sich auf die zurückgelassenen Stücke. Am Nachmittag erreichen wir unser Ziel. Dort wird gerade ein Kasino leer gemacht. Es gibt Wein, Likör und Schnaps. Hier müssen wir uns wieder erleichtern. Wir halten einen Lkw an, der uns geschlossen, d. h. meinen I. Zug, mitnimmt. Nächstes Ziel ist die Küste, von der wir uns so viel erhoffen. Gegen 14.00 Uhr erreichen wir den Divisions-Stab der 19. Flak-Division. Auch hier kann ich nichts erfahren. Ich fasse den Entschluß, mich mit dem Zug nach Porto Farina durchzuschlagen. Mit einem leeren Lkw geht die Fahrt los. Wie von einem Magnet angezogen, eilen die Fahrzeuge dorthin. Am Hafen angekommen, sehen wir, wie schon an organisierten Kähnen fleißig gearbeitet wird. Viele wollen ihr Glück mit einer Überfahrt nach Sizilien machen. Für uns sieht es hoffnungslos aus. Am Abend fahren wir bis zur Landzunge hinaus. Dort ist ein Heerlager am Strand aufgefahren. Am Strand schlagen wir unser Lager auf und schlafen hier. Ein Gerücht geht um, daß heute nacht Schnellboote und "Siebel-Fähren“ 
kommen, um uns zu holen. Mit welch großen Hoffnungen liegen wir hier an der See. „Eine Armee wartet auf Schiffe", sage ich halb im Scherz. Lichter tauchen während der Nacht in gewissen Abständen auf. Es gibt wieder neue Hoffnung, doch sie kommen nicht näher. Wahrscheinlich sind es feindliche Schiffe, die die Bucht absperren. So verbringen wir die Nacht im Hoffen, doch es sollte vergeblich sein. Völlig durchfroren haben wir die Nacht durchgebracht. Am Vormittag ist am Strand ein eifriges Schaffen, alles baut Flöße. Zum Teil sind sie gut, zum Teil recht primitiv. Wir haben uns am Berghang ein schattiges Plätzchen gesucht.

Wir organisieren uns etwas zum Essen. Unten am Strand sind uns sämtliche Fahrzeuge zugänglich. Zum Teil brennen bereits Fahrzeuge, zum Teil Munition. Ich besorge mir 1 Paar Hosen, 1 Paar Safari-Stiefel, was ich später bereuen sollte. Meine Schnürstiefel hätten mir einen besseren Dienst erwiesen. Später schnitt ich den Schaft der Safari-Stiefel ab. Verpflegung gibt es in Hülle und Fülle, doch leider kann man nicht alles tragen.

\section{Sonntag, 9. 5.43}

Gegen Mittag rücken die Amerikaner näher. Etliche Unentwegte wagen die Ausfahrt mit ihren Flößen zu einer Fahrt nach Sizilien. Doch sind bereits etliche Kreuzer in der Bucht erschienen und fangen so alle ab. Feindliche Artillerie und Spitfire schießen auf die Flöße und Boote. Am Strand ein Bild der Zerstörung, alles brennt. Von unseren Gewehren haben wir die Schlösser entfernt und in das Meer geworfen. Meine Pistole und mein schönes Doppelglas $(8 \times 30)$ fliegen ebenfalls in das Wasser. Gegen 15.00 Uhr erscheinen die ersten Amerikaner, es sind Offiziere im Fahrzeug (wir sehen die ersten Jeeps) und fordern die Truppe zur Übergabe auf. Jetzt ist es soweit, der Marsch in die Kriegsgefangenschaft. Wir hatten inzwischen unser Gepäck geordnet, nur das Notwendigste wird mitgenommen. Wir ordnen uns zum Abmarsch in die Gefangenschaft. So endete unser Feldzug in Afrika. Es ist unheimlich heiß. Bald wird uns der Rucksack zu schwer. Nach einer Stunde Marsch halten wir und werfen wieder etwas über Bord. Unser Weg führt uns am Strand entlang zur Stadt. Bald kommen uns die ersten schweren Panzer entgegen. Auf den Panzern die Besatzung, zum Teil mit grinsendem Gesicht, zum Teil mit frecher Gebärde; sie spielen mit ihren Pistolen in der Hand. Ich marschiere mit meinem Zug geschlossen. Einige der Kameraden hatten meine Warnung nicht ernstgenommen, ihre Armbanduhren zu verstecken und nicht offen zu tragen, und müssen es nun büßen. Die Uhren werden ihnen mit ,,sanfter Gewalt" abgenommen. Wir sehen amerikanische Soldaten, die ihre Hemdsärmel aufgekrempelt hatten und die abgenommenen Armbanduhren aufgestreift. Dem Obergefreiten Darrenberg wurde das Erdkampfabzeichen ab- 
gerissen. Hinter der Stadt lagern wir im Freien in einem grünen Haferfeld, eingerahmt von Stacheldraht. Hier verbringen wir die Nacht.

\section{Montag, 10. 5.43}

Die Nacht war wieder sehr kalt. Wir haben den größten Teil der 9. Batterie Flak-Regiment 5 getroffen und haben uns ihnen angeschlossen. Ein Mann von meinem Zug, der jüngste, Kanonier Huyung, hat die Überfahrt mit einem Floß gewagt. Von seinem Schicksal ist mir nichts bekannt. Wir warten auf unseren Abtransport. Am Nachmittag erscheinen die ersten Fahrzeuge. Die Fahrt geht an fast sämtlichen Stellungen vorbei, ein schmerzlicher Anblick, wenn man bedenkt, daß wir vor noch kurzer Zeit hier die „Herren“ waren. Die Fahrt geht nach Mateuer, und wir werden in ein großes Sammellager gebracht. Hier mögen wohl ca. 15000-20000 Mann untergebracht sein.

\section{Dienstag, 11. 5.43}

Wir sind froh, daß wir alle unsere Zeltbahn behalten haben. Wir werden in Hundertschaften eingeteilt. Ursprünglich als 11./V. werden wir zur 9./5 zugeteilt und gehören nun zur 13./V. Unser Chef, Oblt. Handy, hat sich nicht viel sehen lassen. Die 9. Batterie Flak-Regiment 5 marschierte geschlossen mit ihrem Chef in die Gefangenschaft. Es ist furchtbar heiß. Die Kost sehr schmal. Aufklärer fliegen ganz tief über uns, ein sehr billiger Triumph. Unsere Südfront soll noch kämpfen. Laut Gerüchten sollen die Türkei und Spanien in den Krieg eingetreten sein. Japan soll in Rußland einmarschiert sein. ${ }^{1}$ Eine russische Armee bereits vernichtet und eingeschlossen sein. Wenn das alles wahr sein sollte! Die Stimmung im Lager ist gut. Am Abend wird alles wieder lebendig, und man singt. Die Amerikaner können unsere Stimmung nicht verstehen.

\section{Donnerstag, 13. 5.43}

Wir sind seit gestern in einem Luftwaffenlager untergebracht worden. In einem Haferfeld haben wir unsere Zelte aufgeschlagen. Es gehen schon laufend Transporte zu den Häfen. Auch wir sollen wegkommen. Es heißt nach Bizerta und von dort nach Bône. Am Nachmittag wurde unser Gepäck untersucht. Ich habe meinen Fotoapparat und Filme versteckt und kann alles durchbringen. Die Amerikaner verhalten sich sehr gut. Am Stacheldraht stehen unsere Landser, man kann sie auch Lumpen nennen, die ihre Uhren, Fotoapparate, Eheringe und dergleichen verkaufen bzw. gegen Zigaretten eintauschen. Für eine Leica gibt es 1000 Camels. 
Freitag, 14. 5.43

Um 9.00 Uhr werden wir verladen, es soll nach Bône gehen. Es geht über steile Gebirgsstraßen durch eine herrliche Landschaft. Bei der Fahrt durch die Städte steht das ganze Volk an der Straße und zeigt uns die lange Nase oder wie ein Offizier die Zunge. Jetzt haben wir unsere Feinde hassen gelernt, insbesondere aber die Franzosen. Gegen 18.00 Uhr erreichen wir ca. $27 \mathrm{~km}$ vor Bône ein englisches Durchgangslager. Heute bekommen wir das erste Weißbrot. Wir müssen hier einige Tage bleiben, entlaust und sollen dann verschifft werden.

Samstag, 15. 5.43

Es ist heute den ganzen Tag furchtbar heiß. Wir haben keine Zeltstangen, um unser Zelt aufzustellen, so liegen wir in der prallen Sonne. Zu essen gibt es fast nichts. Erst am Spätnachmittag gibt es $1 / 6$ Brot, $1 / 3$ Büchse Fleisch, etwas Tee, Milch und Zucker. Jetzt am Abend, wo die Sonne untergeht und nicht mehr so brennt, erwacht das Lager. Jetzt steht alles in Gruppen zusammen. Die neuesten Latrinengerüchte machen ihre Runde. Unsere Befürchtung, daß wir nun in englische Kriegsgefangenschaft kommen, hat sich nicht bewahrheitet, wir bleiben bei den Amerikanern. Die Stimmung ist trotz allem wunderbar. Es gibt etliche, die eine Harmonika spielen, Heimatlieder erklingen. Es gibt Humoristen, die einige Witze zum besten geben. Mitten im Lager steht ein hoher Turm, auf dem ein Tommy Posten steht. Ab und zu läßt er einen Schuß in die Luft los, wenn ein Araber von draußen zu dicht an den Zaun herangeht. Jetzt am Abend ist es unserem Albert gelungen, eine Stange zu besorgen, und wir können somit unser Zelt aufstellen. Wie in der letzten Nacht, so erfolgt auch heute wieder ein Großangriff auf den Hafen Bône. Die Engländer haben eine unverschämte Luftabwehr (Flak $2 \mathrm{~cm}$ ). Der Angriff mag ungefähr eine Stunde gedauert haben. Das Aufblitzen der Bomben sagt uns, daß unsere genug abgeworfen haben.

Sonntag, 16. 5. 43

Am Vormittag haben wir uns von einer Büchse Kohl und Fleisch ein fabelhaftes Essen zubereitet. Anschließend etwas Tee, die Raucher eine $\mathbf{Z i -}$ garette, wir schätzen uns glücklich. Heute ist der Himmel bedeckt und daher nicht so heiß. Wir sollen bald entlaust werden, obwohl nichts vorhanden, und haben dann Aussicht, bald eingeschifft zu werden. Es soll nach Amerika gehen. Heute ist Muttertag, und noch immer haben wir unsere Angehörigen nicht verständigen können. Der Tommy läßt sich auch damit Zeit. 
Montag, 17. 5.43

Um 7.15 Uhr stehen wir, der I. und II. Zug, abmarschbereit. Das Ziel ist unbekannt. Der Abmarsch verzögert sich etwas. Wir sind froh, daß wir endlich aus diesem Lager kommen. Hier mögen etwa 4000 bis 5000 Gefangene liegen. Die vorgesehene Entlausung entfällt, und wir steigen in eine Kleinbahn ein. Die Fahrt geht über Bône. Wir nahmen schon an, daß wir verschifft werden sollten.

Doch es geht weiter. Unsere Marschverpflegung ist ausgezeichnet. Die Fahrt ist sehr schön. Es geht durch algerisches Gebiet, jetzt erst können wir eine fruchtbare Landschaft bewundern. Riesige Weiden, große Viehherden, alles zeigt eine gewisse Wohlhabenheit. Wir legen eine Strecke von $90 \mathrm{~km}$ mit der Bahn zurück. In Sankt Charles verlassen wir die Bahn und werden in Fahrzeuge umgeladen. Die Fahrt geht über eine Talstraße. Rechts und links große Weinfelder, der Wein steht fast in der Blüte. Großartige Farmen lassen einen gewissen Reichtum des Landes vermuten. Die Berghänge sind mit Olivenbäumen bewachsen. Die Fahrt geht an großen Verpflegungslagern vorbei. Nach 20 km Fahrt erreichen wir ein Sammellager, es liegt in der Nähe eines Hafens, und zwar Philippeville. Es ist ein Naturhafen, steil fallen die Felsen in das Meer, der Hafen ist durch einige Fessel-Ballone geschützt (gegen Tiefflieger). Das Lager ist sauber eingerichtet, das beste bisher. Bei Mondschein beziehen wir unser Nachtquartier und müssen diese Nacht im Freien zubringen.

\section{Dienstag, 18. 5.43}

Wir sind in Gruppen zu 25 Mann eingeteilt. Meinen Zug habe ich noch immer beisammen. Es gibt Weißbrot und Tee zum Frühstück. Im Laufe des Tages erhalten wir große Zelte, jeweils für 50 Mann. Wir stellen noch einige Vierer-Zelte auf, da es sonst zu eng wäre. Ein herrliches Klima, Seeklima, es weht stets eine frische Brise. Die Verpflegung ist jetzt seit gestern ausreichend. Wir werden dem Lagerarzt vorgestellt und müssen Personalbogen ausfüllen. Es heißt, daß wir vielleicht in vierzehn Tagen noch hier sein können. Heute wurden Italiener eingeschifft, so können wir auch jeden Tag wegkommen, vielleicht nach Kanada, aber man weiß nichts Genaues.

Samstag, 22. 5.43

Seit Mittwoch, 19. 5. 43, können wir jeden Tag zum Strand zum Baden gehen. Es ist herrlich, das Wasser nicht zu kalt und nicht zu warm. Wunderbar die Nacht, ein herrlicher Sternenhimmel. Am Donnerstag hatten wir unseren ersten bunten Abend aufgezogen. Es waren Stunden netter Unterhaltung. Die Verpflegung ist bisher immer ziemlich einseitig geblieben. Es 
gibt zum Frühstück zehn Scheiben Keks und etwas Butter. Zu Mittag eine Büchse Corned beef und ein Viertel Weißbrot. Dreimal am Tag Tee mitMilch. Wir sind soweit zufrieden. Es kann nun jeden Tag fortgehen. Wir haben Zuwachs bekommen und sind jetzt 750 Mann im Lager.

\section{Dienstag, 25. 5.43}

Es hatte geheißen, daß am Mittwoch ein Transport wegginge, heute am Vormittag wird wider Erwarten ein Transport von 10 Offizieren und 39 Mann zusammengestellt. Von meinem Zug bzw. Batterie sind es leider nur 6 Mann. Gestern abend wurde Wachtm. Kimmel, mein z. b. V., in das Lazarett eingeliefert, wahrscheinlich Malaria. Es wird höchste Zeit, daß wir von diesem Lager wegkommen. Seit den letzten Tagen herrscht eine unverschämte Hitze, kaum zu ertragen. Fast schutzlos liegen wir den ganzen Tag in der prallen Sonne. Das schönste Vergnügen ist für uns jeden Tag das Baden. Wir sind alle der Meinung, daß es nach Kanada geht. - Unsere Marschgruppe setzt sich in Bewegung mit einem frischen Gesang. Die italienische Marschgruppe macht einen jämmerlichen Eindruck. Vornweg geht ein englischer Offizier (Major). Es sind immerhin $8 \mathrm{~km}$ zu marschieren. Es geht durchwegs an der Küste entlang, eine frische Brise verschafft uns ein wenig Kühlung. Wir erfahren, daß wir nicht nach Kanada, sondern nach England kommen. Teils Vorteile, teils Nachteile. Endlich haben wir den Hafen erreicht und können uns in einem Schuppen waschen, dann geht es auf das Schiff. Wir werden von den Offizieren getrennt und müssen mit den Italienern das Zwischendeck beziehen. Nach fünf Tagen Fahrt werden wir für eine Nervenheilanstalt reif sein. Ich habe für meine Gruppe Verpflegung empfangen, und wir haben unser Lager hergerichtet. Wahrscheinlich werden wir in den Abendstunden den Hafen verlassen.

\section{Mittwoch, 26. 5. 43}

Gegen 4.00 Uhr in der Frühe treten wir unsere Fahrt an. Es geht sehr langsam voran. Es herrscht ein Riesenkrach, verursacht von den Italienern. An Schlaf ist nicht zu denken. Im Laufe des Vormittags fordert "Neptun“ auch unser Opfer. Ich selbst habe furchtbare Magenkrämpfe und muß auch mein Opfer bringen. Wir liegen alle lang, keiner traut sich aufzustehen, da sonst einem das Essen beschleunigt aus dem Gesicht fällt. Am Nachmittag dürfen wir für 10 Minuten an Deck spazierengehen. Im Laufe des Tages laufe ich wohl sieben- bis achtmal auf den Lokus. Ich kann nichts essen. Gegen Abend geht es mir etwas besser. Gegen 17.00 Uhr werfen wir Anker und liegen vor der Bucht von Bougie, $150 \mathrm{~km}$ ostwärts von Algier. Morgen früh soll es weiter nach Algier gehen. Wenn das Fahrttempo so weitergeht, dann sind wir in Tagen vor Gibraltar. 
Donnerstag, 27. 5.43

Das Gefühl der Seekrankheit hat uns verlassen, aber ich muß immer noch laufen. Es herrscht unter Deck eine furchtbare Luft (ca. $35^{\circ} \mathrm{C}$ ) von der Latrine, ein Bretterverschlag mitten unter uns, offene Blechkübel sind randvoll und laufen zum Teil über, ein fürchterlicher Gestank, ein ständiges Brechgefühl im Hals! Wir liegen während der ganzen Fahrt, weil wir sonst Gefahr laufen, daß einem das Essen aus dem Gesicht fällt. Am Tage können wir 10 Minuten von der Einstiegluke, sitzend am Rand, frische Luft tanken und sehen dabei die nahe Küste. Es ist eine herrliche Landschaft, zum Teil fällt das Ufer steil zur Küste ab. In herrlichem Grün prangt die Landschaft. Am Abend erreichen wir den Hafen von Algier und bleiben vor Anker. Es ist eine sternenklare Nacht, über uns spielen die Scheinwerfer, man kann sie nicht zählen. Wir glauben anfangs an einen Fliegeralarm, aber es ist nur eine Übung.

Freitag, 28. 5. 43

In der Frühe machen wir uns fertig zum Verlassen des Schiffes. Mir ist elend zu Mute, so schlecht ging es mir noch nie! Seit zwei Tagen habe ich nur Weißbrot gegessen und Tee getrunken. Vom Tommy bekomme ich eine Büchse Milch und $1 / 3$ Büchse Obst. Gegen Mittag verlassen wir das Schiff. Eine große Bedeckung ist angetreten, ca. 30 Mann. Durch ein Spalier mit aufgepflanztem Seitengewehr marschieren wir zum Hafenausgang. Hier schart sich die Bevölkerung zusammen. Zwei amerikanische Offiziere und eine extravagante Frau stehen dort. Endlich geht es zum nahen Bahnhof, und wir werden dort verladen. Wir können feststellen, daß der Hafen mit Schiffseinheiten vollgepfropft ist. Es herrscht hier ein großer Betrieb. Mit der Bahn geht es ca. 49 km nach Osten, ein kleines Städtchen, Korso (?), und wir gehen hier noch $3 \mathrm{~km}$ zu Fuß. Das Lager sieht ganz gut aus, es sind feststehende Zelte vorhanden. Auf dem Marsch wird unsere kleine Abteilung Deutscher scharf bewacht, auf vier Mann von uns je ein Posten. Die italienische Gruppe hat dagegen nur drei Posten zur Bedeckung. Wieder werden wir beim Eintritt in das Lager gezählt. Wir können feststellen, daß der Stacheldrahtzaun immer höher wird.

\section{Mittwoch, 1. 6. 43}

In den letzten drei Tagen haben wir es sehr gut gehabt. Das Essen war hier bisher am besten. Es gab täglich Milch und Rosinen, Erbsen mit Fleisch oder Bohnengemüse, für drei Mann ein Brot. Heute müssen wir überraschend das Lager verlassen. Mein I. Zug mit 20 Mann fährt gegen 10.00 Uhr ab, und wir kommen in die Nähe von Algier in ein deutsches Lager. Hier herrscht noch mehr Stacheldraht, und die Sicherung ist noch besser. Hier muß der Kommandant für uns mehr übrig haben. Im letzten Lager schienen nur Deutschenhasser zu herrschen. Inzwischen haben wir hier 
unser Lager bezogen. Ich kann einige gute Nachrichten hören, die auf Wahrheit beruhen sollen. Danach soll Leningrad gefallen sein, in Moskau vor ca. 14 Tagen Straßenkämpfe stattgefunden haben und Stalingrad im Süden umgangen worden sein. Der Japaner soll in Wladiwostok und eine bulgarisch/deutsche Armee unter Generalfeldmarschall List in die Türkei einmarschiert sein, nachdem die Türkei den Krieg an Bulgarien erklärt haben soll. ${ }^{2}$ Hier ging vor ca. sechs Tagen ein Transport mit 6000 Mann nach England. So ist anzunehmen, daß wir in den nächsten Tagen wegkommen werden.

Samstag, 12. 6.43

Endlich ist der Tag gekommen, auf den wir so lange gewartet haben, der Tag des Abmarsches nach Algier zur Einschiffung. Am Abend zuvor bin ich mit einigen Kameraden vom Stammlager zum Lager 7 gekommen. Seit 7.00 Uhr stehen wir auf dem Abmarschplatz, unser Rucksack ist unsere Sitzgelegenheit. Wir dürfen uns in der prallen Sonne nicht vom Fleck bewegen. Gegen 12.00 Uhr haben sich etwa 2000 Mann zum Abmarsch formiert. Es ist ein heißer Tag, seit dem Frühstück nichts mehr gegessen. Ich halte mit meinem Gepäck etwa eine Stunde durch, dann laß ich mich vom „Lumpensammler“ (Lkw) aufnehmen. Ich habe eine Wunde an der linken Ferse. Es wird alle Stunde eine kurze Rast gemacht. Gegen 18.00 Uhr haben wir endlich den Hafen erreicht und beziehen das Transportschiff. $25 \mathrm{~km}$ hatten wir in einer glühenden Hitze zurückgelegt und nichts im Magen, so sind viele Kameraden ausgefallen. Am Stadtrand passierten wir etliche Flakstellungen, wo die Amerikaner lässig an den Sandsäcken lehnten und sich eine Flasche Bier an den Mund hielten. Das einzige, was uns durchhalten läßt: Wasser.

Gegen 21.20 Uhr haben wir endlich die Schiffsplanken bestiegen, doch die Abfahrt soll erst am anderen Tage sein. Wir beziehen sofort die Ladeluken, in unserer befinden sich 230 Mann. Vor lauter Hitze weiß man nicht wohin, wir liegen auf den Planken in kurzer Hose ohne Hemd. An Schlaf ist nicht zu denken, gegen Mitternacht erhalten wir ein Stückchen Brot, zehn Mann ein Weißbrot. Wir haben eine ohnmächtige Wut im Leib.

\section{Pfingstsonntag, 13. 6. 43}

Wir befinden uns noch immer im Hafen. Im Laufe des Tages hat sich ein Geleitzug formiert, etwa 20 Schiffe können wir zählen. Vor dem Hafen, weit draußen, kreuzen etliche Zerstörer. Mit weiß aufzischenden Bugwellen durchpflügen sie das Meer. Wir können gruppenweise 15 Minuten an Deck. Ich habe die Ausgabe von Trinkwasser übernommen. Es herrscht ein herrliches Wetter. Vor uns liegt die weiße Stadt Algier. Weit zieht sich die Stadt an den Hängen hinauf. Es herrscht eine leichte Brise, weiße 
Schaumkronen tanzen auf den Wellen. Die Tommys sind zu uns soweit ganz anständig. Die Verpflegung ist heute etwas reichlicher ausgefallen. Am Morgen gab es etwas Tee, drei Mann ein Brot, Fleisch und Fett. Wir haben herausbekommen, $\mathrm{da} \beta$ wir um 17.00 $\mathrm{Uhr}$ abfahren sollen, und zwar nach Oran, dort umgeschifft werden und nach Westengland kommen sollen. Was wird nun stimmen? Es ist bereits $17.00 \mathrm{Uhr}$ vorüber. Wir dürfen an Deck kommen, der Geleitzug hat sich in Bewegung gesetzt. Wir fahren an der Spitze. Seitwärts von uns fahren Torpedo-Boote und sichern. Die hinteren Schiffe führen Fessel-Ballone. Inzwischen haben wir das offene Meer gewonnen. Die Stadt ist im Dunst verschwunden, zur Linken die nahe Küste. Delphine tummeln sich für kurze Zeit vor der Bugspitze.

\section{Pfingstmontag, 14. 6. 43}

Gestern wurden wir mit der Verpflegung sehr kurz gehalten. Am Vormittag dürfen wir an Deck, mir selbst geht es sehr schlecht. Ich habe immer wieder den Durchmarsch und muß sehr oft laufen. Sehr weit auseinandergezogen zieht der Geleitzug seine Bahn. Wir haben wieder ein sehr schönes Wetter. Ich kann an Deck bleiben. Die Kameraden müssen im Wechsel von 20 Minuten wieder unter Deck. Dort herrscht eine fürchterliche Luft, auf engstem Raum 220 Mann. In den Abendstunden erreichen wir den Hafen von Oran, erst gegen 24.00 Uhr verlassen wir das Schiff und werden von amerikanischen Posten übernommen. Unter starker Bedekkung erreichen wir einen nahen Steinbruch. Wir müssen erst die losen Steine wegräumen, um auf blanker Erde und ohne Zelt zu schlafen. Es gibt noch Verpflegung, was sehr viel Zeit in Anspruch nimmt. Es herrscht nicht gerade die beste Stimmung.

\section{Dienstag, 15. 6. 43}

Mir geht es elend. Ich laufe den ganzen Tag. An der offenen Latrine, einfache Kübel mit Holzbrille, muß man anstehen und versuchen, einen freien Platz zu bekommen, ehe es in die Hosen geht. Die Kübel sind voll bis zum Rand, ein fürchterlicher Zustand. Wir liegen hier in der prallen Sonne und haben keinen Schutz. Wasser gibt es sehr wenig. Ich koche mir einen Tee, kann aber nichts essen. Ich habe wahnsinnige Schmerzen im Unterleib und schlucke Tabletten, die ich vom Sani erhalten habe. In den Abendstunden heißt es, daß es wieder weitergehen soll. Verpflegung bekommen wir heute dreimal, und zwar je eine „Frühstücksdose“ (Inhalt: Kekse, Kaffeepulver und Bonbons) und Gemüsesuppe. Ich selbst kann nichts mehr essen, da mein Darm sofort reagiert. Mit Fahrzeugen verlassen wir das Lager. Durch die Stadt werden wir wieder mit Fäusten und Gejohle begrüßt. Etwa $15 \mathrm{~km}$ geht es an der Küste entlang durch den Hafen von Oran hindurch. Es ist eine schöne Stadt, die sich auf den Höhen 
erstreckt. Wunderbare Hochhäuser können wir sehen. Im Hafen liegen zahlreiche Schiffe, die schwach beleuchtet sind. In einem nahen Bahnhof werden wir verladen. In einen Viehwaggon müssen 50 Mann hinein. An liegen ist nicht zu denken, und wir können nur auf unserem Rucksack sitzen. Es herrschen unmögliche Zustände. Unterhalb der Decke sind einige Bohlen entfernt worden, wir machen einen Klimmzug und hängen unsern Hintern hinaus, um unsere Geschäfte zu erledigen. Die im Waggon für diese Zwecke aufgestellten offenen Kübel werden nicht benutzt. Die Amerikaner haben eine wahnsinnige Angst vor uns. Jeder Waggon ist durch zwei Posten abgesichert, sie sitzen auf dem Dach.

\section{Mittwoch, 16. 6. 43}

Gegen 10.00 Uhr erreichen wir den Eisenbahnknotenpunkt Sidi Bel-Abbès. Wir sind also erst sehr wenig gefahren, es geht ziemlich steil im Gelände, zwei Lokomotiven ziehen uns. Gegen 12.00 Uhr erreichen wir die Stadt Chancy und werden hier ausgeladen. Zu Fuß geht es in der prallen Mittagssonne in das $4 \mathrm{~km}$ entfernt gelegene Lager. Es ist ein amerikanisches Lager. Tolle Zustände herrschen hier, das schlechteste Lager wohl, das wir bisher angetroffen haben. Kleine Vier-Mann-Zelte (deutsche Herkunft) auf engstem Raum. Waschwasser gibt es vorerst nicht.

Es müssen sämtliche Messer, Eßbestecke und Scheren abgegeben werden. Am Abend ist mir so jämmerlich zu Mute, daß ich in das Krankenrevier einziehe.

\section{Mittwoch, 23. 6. 43}

Noch immer liege ich im Krankenrevier. Ich habe mich ganz gut erholt, der Durchfall hat inzwischen aufgehört. Bis jetzt habe ich Diät gegessen. Die Verpflegung ist sehr gut, nur zu wenig. Morgens gibt es für alle eine Milchsuppe und einen Liter Kaffee, den man allerdings nur warm genieBen kann, da das Wasser zu stark gechlort wurde. Zu Mittag gibt es abwechselnd eine Nudelsuppe, Gemüse oder eine Grießsuppe. Zu Abend wieder warmes Essen, im Grunde dasselbe wie zu Mittag, dazu einen halben Liter Kaffee. Wir sind hier in einem rein amerikanischen Lager untergebracht. Es sollen hier etwa 20000 Gefangene untergebracht sein. Wie wir in Erfahrung bringen konnten, sind unsere Offiziere noch hier, auch etliche Italiener. Das ganze Lager erscheint uns als Blendwerk. In einem Teillager sind drei Tausendschaften untergebracht. Die Wasserfrage ist eine sehr schlechte. Es muß mit dem Fahrzeug ca. $30 \mathrm{~km}$ hergefahren werden. Somit gibt es täglich nur ein Kochgeschirr voll Waschwasser. Wir haben einen Wasserdienst eingeteilt, der immer für zehn Mann Wasser empfängt. Es bestehen Wartezeiten bis zu drei Stunden. Die Unterbringung ist die schlechteste, die wir bisher hatten. Es stehen deutsche Viererzelte und 
sind im Durchschnitt mit fünf Mann belegt. Brot gibt es fast gar nicht zum Essen. Dafür zum Frühstück vier Kekse. Bereits früh am Abend, wenn noch die Sonne scheint, ist die Lagerbeleuchtung eingeschaltet. Es sind hier doppelte Zäune gezogen worden, dazwischen Stacheldrahtrollen ausgelegt. Ca. alle $75 \mathrm{~m}$ ein hoher Wachturm mit einem Posten besetzt und mit einem schweren Maschinengewehr ausgerüstet. Nachts leuchten hin und wieder Scheinwerfer auf und suchen die Zäune ab. Ein Entweichen ist hier unmöglich. Auf dem Transport mit der Bahn sollen ungefähr 50 Mann stiftengegangen sein. Tagsüber brütet eine unverschämte Hitze, es ist kaum noch zu ertragen. Feiner brauner Staub wirbelt auf und belegt alles mit einer feinen Staubschicht. Wir haben hier einen ewigen Hunger. Die Raucher stöhnen, denn sie haben nichts mehr zum Rauchen. Im letzten Lager bei Oran wurde von den Rauchern wohl alles eingetauscht, was noch einen Tauschwert hatte. Es gibt bereits Raucher, die trockenen Tee rauchen. Ich selbst schlafe viel und träume viel von der Vergangenheit und der Zukunft. Parolen ziehen auch hier ihre Bahn. Die tollsten Gerüchte werden schon verbreitet. So soll bereits im Osten Moskau gefallen sein, ein weißrussischer General soll eine Regierung gebildet haben, Waffenstillstand soll auch bereits sein. Alles fromme Wünsche, doch wann werden sie wahr sein? Das Lager selbst liegt in einem weiten Talkessel, rings von Bergen umgeben. In den nächsten drei Tagen soll es mit Fahrzeugen nach Oran gehen zur endgültigen Einschiffung. Hoffentlich bald, denn hier ist es nicht zum Aushalten.

\section{Donnerstag, 24. 6. 43}

Am Vormittag werde ich aus dem Revier entlassen und ziehe wieder in das Lager zu meinen Kameraden. Hier herrscht ein unverschämter Dreck und Staub. Die Wasserfrage tritt hier ganz kraß zutage. Man kann sich höchstens alle zwei Tage waschen. Tagsüber geht ein ständiger Wind daher und wirbelt Staub auf, alles ist mit einer braunen Staubschicht bedeckt. Die Stimmung ist auf dem Nullpunkt angekommen. Die Raucher jagen nach Zigaretten. Es kommen die unmöglichsten Dinge vor. Es werden bereits Auszeichnungen, so das EK I, und Trauringe gegen Rauchwaren vertauscht. Ein Bild des Jammers. Alles ödet und schreit sich an. Es ist die Hitze und es sind die schlechten Lebensbedingungen, die uns alle plagen. Man kann nur hoffen, daß wir hier bald wegkommen. Am Abend findet ein bunter Abend statt. Ich selbst bin erst am Schluß dabei und mache eine Aufnahme von den Wiener Sängern und bringe sogar einen Wachturm hinauf. Es war ja etwas schwierig, aber es klappte.

Montag, 28. 6. 43

Heute feierst du, liebe Mama, deinen 53. Geburtstag, und ich konnte dir 
keinen Brief schreiben, um dir, liebe Mama, meine Glückwünsche zum Ausdruck zu bringen. Aber im Geiste bin ich heute bei dir, und ich weiß, auch du wirst gerade an diesem Tage mehr als einmal an mich denken. Du wirst deinen Geburtstag nicht wie früher feiern können, da wir, deine Kinder, noch im Elternhause waren. Ich weiß nicht, ob Christel zu Hause sein wird. Ich aber hoffe, daß du dir über mein Schicksal im klaren bist und dir keine unnützen Gedanken machst. Ja, wenn ich zurückdenke, wie schön konnten wir diesen Tag feiern in den vergangenen Jahren, da ich noch im Elternhaus war. Ich sehe im Geiste einen herrlichen RosenstrauB auf dem Tische stehen. Das Zimmer voll herrlichem Rosenduft. Wenn wir bei der Geburtstagstafel beisammensaßen, die herrliche Torte, und dann gab es die erste Erdbeerbowle. Ja, und nun ist es einsam um euch geworden, liebe Eltern! So muß ich diesen Tag in Gefangenschaft verbringen. Nicht frei, denn wir sitzen hinter Stacheldraht auf afrikanischem Boden. Es ist heute wieder ein heißer Tag, es mögen wohl $40^{\circ} \mathrm{C}$ im Schatten sein. Wir sitzen in unserem Zelt mit vier Mann beisammen. Man weiß nicht, wohin. Das Beste ist noch, sich im Freien zu bewegen, denn im Zelt ist es vor Hitze nicht zum Aushalten. Die Verpflegungszuteilung ist weniger geworden. Heute morgen gab es nur ein halbes Kochgeschirr Kaffee und vier Stück Kekse. Zu Mittag gab es Kartoffelsuppe, am Abend eine Maissuppe und ein Stückchen Brot. Alles ist überreizt durch die Hitze und durch den Hunger, jeder sieht sich selber nicht mehr gern. Die kleinsten Anlässe sind Grund zum Streit. Was soll noch werden? Man könnte verzweifeln, und doch darf man es nicht. - Es ist Abend geworden, noch immer steht die Sonne im Westen, obwohl es schon 20.00 Uhr ist. Wir sind zum Appell angetreten. Das gesamte Lager 5, zum Gedenken des heutigen Tages, der so oft zum Schicksal des deutschen Volkes wurde. Zwei Kameraden sprechen zu uns. Der erste spricht in kernigen Worten zu uns, wir sollten nicht verzweifeln, sondern aufrechte Deutsche bleiben, die auch in der Not eisern dastehen, daran zu denken, daß Brüder für uns kämpfen. Manch einer mag durch diese Worte aufgerüttelt worden sein und sich seiner besinnen. Der zweite Kamerad führt uns die Bedeutung dieses Tages vor Augen. Er gedenkt des 28. Juni 1914, da dieser Tag Anlaß wurde für den Ausbruch des Ersten Weltkrieges, am 28. Juni 1919 das Schanddiktat in Versailles unterschrieben und wir gezwungen wurden, eine Schuld einzugestehen, die nicht bestand. Im gleichen Saale, da einst am 18. Januar 1871 die Schaffung des II. Reiches seine Krönung fand. Er gedachte des 28. Juni 1940, da im Wald von Compiègne an der gleichen Stelle durch den Führer erklärt wurde, daß die Schande von Versailles für immer gelöscht sei. Und heute, am 28. Juni 1943, stehen deutsche Soldaten auf afrikanischem Boden hinter Stacheldraht und gedenken dieses Tages. Wir wissen, daß Kameraden für uns kämpfen und daß eines Tages der Sieg unser sein wird. Der Lagerführer gedenkt am Schluß des Führers, Volk und Vaterland. Wir bringen ein donnerndes Sieg Heil aus, das sich an den 
Berghängen bricht und wieder zurückschallt. Als Abschluß des Abends werden die Nationalhymnen gesungen. Der Abend ist beendet.

\section{Samstag, 24. 7. 43}

Es war wohl die unruhigste Nacht während der ganzen Fahrt. Lange wird noch erzählt, es ist eine gewisse Aufregung vorhanden. Gegen Mitternacht rasseln mit großem Getöse die Ankerketten. Das Schiff liegt still. Irgendwo auf dem Schiff läuft noch eine Maschine, man kann nicht einschlafen. Schon früh, wohl gegen 6.00 Uhr, wird die Ladeluke geöffnet, und wir steigen mit großer Erwartung an Deck. Der Blick schweift nach rechts und links. Wir liegen in einer großen Bucht. Wir werden von einem Arzt untersucht, der an Bord kam. Endlich gegen $12.00 \mathrm{Uhr}$ legt ein Fährschiff an, wir sollen noch heute mit der Bahn 600 Meilen fahren. Wir richten uns auf eine lange Fahrt ein, da heißt es schon wieder aussteigen. Nun haben wir amerikanischen Boden betreten. In einer großen Halle marschieren wir in Reihe auf, jetzt beginnt wieder eine Durchsuchung. Wir passieren Laufgassen, abgeteilt durch gespannte Seile, hin und wieder stehen offene Zinktonnen. Hier müßten noch etwa vorhandene militärische Ausrüstungsgegenstände hineingeworfen werden. So etwa Kompaß, Waffen, Feldflaschen und dergleichen. Jetzt muß ich blitzschnell handeln, denn in meiner zweiten Feldflasche befindet sich meine $6 \times 9$ Zeiss Ikon Rollfilmkamera. Ich gebe mir drei Sekunden Bedenkzeit: entweder die Feldflasche samt Inhalt in den Kübel oder hinaus damit und mitgenommen. Ich knie nieder, hole aus meinem Rucksack die Feldflasche heraus, geöffnet, die Kamera in ein Stück Fallschirmseide (Halstuch) eingewickelt und in meine Seitentasche vom Uniformrock gesteckt. Obwohl überall Posten stehen und Offiziere alles überwachen, kann ich diese Aktion unbeobachtet ausführen. Nur ruhig bleiben, hieß meine Devise. Meine zwei Feldflaschen fliegen in die Tonne, und weiter geht es im Gänsemarsch. In einem geschlossenen Raum müssen wir uns splitternackt ausziehen. Unsere Kleidungsstücke wandern in einen blauen Sack und landen in einem Dampfkessel zur Entlausung, obwohl wir kein Ungeziefer haben. Für meinen Rucksack und die übrigen Bekleidungsstücke bekomme ich eine Nummer und soll diese Dinge in unserem künftigen Lager wieder erhalten. Mein Rucksack hat auch sein Geheimnis. Denn im Wäschefach hatte ich am Boden liegend meine belichteten Filme eingenäht. Mit dieser Taktik kam ich bisher durch alle Filzungen. Denn in der Regel mußten wir bei einer Filzung unseren Rucksack entleeren und ihn ausschütteln. Ob wir das Abgegebene noch einmal wiedersehen werden? - Unsere sog. Wertsachen, Brieftasche, Bilder usw. müssen wir ebenfalls in einen kleinen Beutel stecken, schnell stecke ich meine Kamera hinein und gebe alles am Schalter $a b$, wo uns ein netter farbiger Soldat die Sachen abnimmt. Ich kann noch sehen, wie er mit Läusepulver den Inhalt bestreut und alles in 
einem Fach landet. Auch hierfür gibt es eine „Garderobenmarke“. In den Wertsachenbeutel kann ich auch mein Waschzeug und Alu-Büchse, hier befanden sich getarnt meine unbelichteten Filme, stecken. Ich hatte meine Zwirne und Stopfwolle dazu verwandt, um die Filme so zu tarnen. Weiter geht es im amerikanischen Tempo in den Duschraum. Nach dem Verlassen werden wir mit einer Art Spritzpistole unter den Armen abgesprüht. Schneeweiße Frotteetücher erhalten wir zum Abtrocknen, anschließend fliegen sie auf einen Haufen, um von dort in einer Wäscherei zu landen. In einem Warteraum werden unsere Nummern aufgerufen, und wir erhalten am Schalter unsere Beutel zurück. Ein Griff an den Wertsachenbeutel und ich kann mich überzeugen, daß sich meine Kamera noch darin befindet. Ich atme auf! Es geht weiter in die nächste Baracke. Wir betreten einen Mittelgang, zu beiden Seiten sitzen „Tippmädchen" vor ihrer Schreibmaschine. Wir sind beeindruckt von soviel Schönheit. Jeder sucht sich ein Mädchen aus, setzt sich vor sie, und sie tippt auf einem Personalbogen unsere Daten ein. Anschließend erfaßt sie unsere beiden Daumen nacheinander, drückt sie auf ein Stempelkissen und rollt jeden Daumen auf dem Formblatt an der dafür vorgesehenen Stelle ab. Jetzt sind wir registriert und landen wieder in der großen Ankunftshalle. Wir stehen am Eisenbahngleis, in einiger Entfernung von uns steht ein Pullmanzug. Meine Gedanken, sicher für die amerikanischen Soldaten bereitgestellt. Da heißt es Gepäck aufnehmen, und wir besteigen den vor uns stehenden PullmanZug (D-Zug). Unser Magen macht sich bemerkbar, wir haben einen fürchterlichen Kohldampf! Gegen 12.45 Uhr verläßt der Zug die Halle, was wir anfangs nicht für möglich hielten, wir sitzen nun in der Polsterklasse und werden nun etliche $1000 \mathrm{~km}$ nach Süden gefahren. Unser Waggon hat einen Mittelgang, rechts und links Viermannabteile. Die Abteile sind jeweils nur mit drei Mann besetzt. Am Ende des Waggons befindet sich jeweils ein Ventilator mit einer großen Luftschraube, der für Kühlung sorgen soll. Unsere Fenster können wir nicht öffnen. Es sind Doppelfenster, die von unten einen Spalt geöffnet sind, aber fest verriegelt. An jedem Waggonende befindet sich ein WC und eine Wasserbox mit Trinkbecherautomat. $\mathrm{Ja}$, kaum sind wir auf unseren Plätzen warm geworden, gibt ein Sergeant das Zeichen zur Filzung. Bewacht werden wir im Waggon natürlich auch. Es steht jeweils ein Posten mit einer MP bewaffnet am Waggonende. Jetzt heißt es schnell reagieren. Meine Kamera befindet sich noch in meiner Rocktasche. Wohin damit, sind meine Gedanken. Meine Augen schweifen in die Runde, von unten nach oben. Da entdecke ich, daß unsere Sitzpolster nur lose aufliegen. Blitzschnell habe ich meine Kamera unter meinen Sitz geschoben. Das flache, massive Metallgehäuse wird mein Gewicht schon aushalten, denke ich bei mir. Wir müssen nun einzeln vortreten und werden abgetastet. Wir müssen jeweils einen freiwerdenden Platz einnehmen. Mein Gedanke, hoffentlich kann ich wieder an meinen alten Platz zurück. Verstohlen schaue ich zurück, ob es nicht auffällt, daß die eine 
Ecke vom Polster sich vom anderen etwas nach oben abhebt. Da kommt das erlösende Wort: wieder an die alten Plätze zurück! Das haben wir überstanden. - Das Essen läßt nicht lange auf sich warten. Es gibt auf nüchternen Magen zwei Scheiben Weißbrot, eine dicke Scheibe frischgekühlte Wurst, eine dicke Scheibe Käse und einen Butterkeks mit Schokoladenüberzug. Ferner einen Becher schwarzen Kaffee. Man hätte ja das fünf Wochen früher vertragen können. Wir sind zufrieden! - Nun rasen wir schon etliche Stunden im D-Zug-Tempo durch die Landschaft. Hin und wieder durcheilen wir ein kleines Städtchen. Ein paar Mädchen winken uns zu. Es scheint eine Landschaft zu sein, die von Wochenendurlaubern bevorzugt wird. Was uns als erstes auffällt, das sind die vielen Autos, die auf parallel zur Bahn geführten Straßen an uns vorbeifahren. Alles schöne, große, moderne Fahrzeuge. Dazu viele Wohnwagen. Hin und wieder an einem kleinen Häuschen vorbei, so wechselt das Bild. Gegen Abend durchfahren wir eine herrliche Flußlandschaft. Rechts und links Steilufer, dahinter undurchdringlicher Wald, zum größten Teil Laubwald und später auch Tannenwald. Die Sonne steht im Westen, wir fahren ihr entgegen, bald verschwindet sie blutrot hinter den Bergen. Alles atmet heimatliche Landschaftsstimmung. - Im übrigen wurden wir vom Kochpersonal bedient. Das Essen wird uns an die Plätze gebracht. Wir durften einzig und allein nur aufstehen, wenn wir zum WC oder zum Trinkwasser wollten. Zum Abendessen gab es heute einen klassischen Maisbrei, eine Pellkartoffel, eine große Portion Hackfleisch, was ganz ausgezeichnet zubereitet war, als Nachspeise Ananas und einen Becher Kaffee. - Mitternacht ist wohl schon vorüber, der Zug rast durch die Landschaft. Da, auf einmal ein Lichtermeer, eine Großstadt muß es sein. Herrlich dieses Bild zu schauen, alles taghell erleuchtet, dazu die Lichtreklame, für uns ein ungewohntes Bild.

\section{Sonntag, 25. 7.43}

Die heutige Fahrt geht durch weite Ebenen. Hin und wieder kleine Ortschaften. Wir sind über den Baustoff der Häuser erstaunt. Hier ist alles in Holz gebaut. Immer wieder sind die vielen Autos auf den Straßen zu bewundern. Der Zug rast weiter ohne große Aufenthalte durch die Landschaft. Die Hitze ist fast unerträglich. Zum Frühstück gab es Kartoffelpüree, zwei Scheiben Brot, drei Pflaumen, Kaffee mit Milch und Zucker. Zu Mittag: zwei Scheiben Brot, eine Scheibe Kasseler, eine Kartoffel mit Butter, Erbsen und Zitrone. Zu Abend: zwei Scheiben Brot, eine Scheibe Käse, eine Scheibe Wurst. - Weite Flächen des Landes sind mit Mais bepflanzt. Wir passieren zweimal Öl-Förderpumpen. Auch hier sind die Ortschaften sehr klein. Ein paar Bretterbuden, ein paar Autos, das ist alles. Gegen 18.30 Uhr laufen wir in St. Louis ein, nachdem wir auf einer riesigen Brücke über den Fluß Mississippi gefahren sind. Hier gibt es in den 
Vorstädten sehr viele Fabriken. Die Luft ist diesig und dick. Etliche Wolkenkratzer sind auch zu sehen. In dieser Stadt haben wir einen sehr langen Aufenthalt bis etwa gegen 22.00 Uhr. Unser Zug steht einem amerikanischen Militärzug gegenüber. Zur Hälfte ist er mit Soldaten und zur Hälfte mit Helferinnen besetzt. Es sind alles junge Mädels, etwa mit unseren Nachrichtenhelferinnen zu vergleichen. Wir werden ziemlich kritisch gemustert. Aber bald merken wir, daß sie uns offene Sympathie entgegenbringen. Sie tragen alle eine weiße Bluse und einen blauen Rock. Sie reisen sehr bequem, soweit ich sehen konnte, befinden sich immer vier Mädels in einem Abteil. Ein Schlafabteil schließt sich an. Hier sind gerade Schwarze dabei, alles zum Schlaf herzurichten. Wir versuchen mit den Mädels ins Gespräch zu kommen, aber wir können unsere Fenster nicht öffnen.

Ehe wir uns vom Staunen erholen, sind schon Mädels in unser Abteil gestürmt, nachdem es ihnen nicht gelungen war, uns Zigaretten hinüberzureichen. Es kam nun ein reger Tauschhandel in Schwung. Sie fragten nach deutschen Münzen, natürlich mit Hakenkreuz. Ich selbst kam mit einem Mädchen ins Gespräch. Nachdem mein Englisch nicht ausreichte, ging es mit Französisch. Fragen hin und her, woher des Weges. Als Soldaten des Deutschen Afrika-Korps waren wir für sie die ,,supermen“. Über eine Frage mußte ich mich wundern, ob wir die Amerikaner lieben würden. Darauf konnte ich keine Antwort geben. Aber dieses Zusammentreffen konnte uns allen zeigen, daß für uns doch eine große Sympathie vorhanden war. Doch bald war die Invasion den Soldaten zu stark geworden, die Landser waren hilflos. Amerikanische Offiziere baten die Mädchen sehr höflich hinaus. Auf der ganzen Fahrt können wir Sympathiebeweise erleben. Überall winken uns heimfahrende Wochenendfahrer zu. Zum Teil halten die Fahrzeuge, als unser Zug an einer Autostraße hält. Auch die Behandlung hier im Zug ist sehr gut. Das Essen wird uns auf Papptellern serviert, wir dürfen nur aufstehen, wenn wir zum WC müssen. Ein Handzeichen zum Posten hin, ein Kopfnicken, und wir können gehen. Unsere Knie sind schon steif geworden, so geht es oft zum WC, unsere einzige Bewegung. Mit Anbruch der Dunkelheit flammen die vielen Reklamelichter in den Städten auf, hier merkt man nichts vom Krieg.

\section{Montag, 26. 7.43}

Sehr interessant, unser Zugabteil zu studieren, wie diese Waggons für die klimatischen Verhältnisse eingerichtet sind. An der Decke befinden sich vier Ventilatoren, die während der ganzen Fahrt für Kühlung sorgen. Auf Grund der großen Fahrtgeschwindigkeit ist es nicht möglich, die Fenster zu öffnen, da einem sofort Kohleteilchen in die Augen fliegen würden. So können die Fenster nur von unten her geöffnet werden und auch nur fast zur Hälfte. An jedem Ende die Toiletten mit Waschraum und davor ein 
Behälter mit Trinkwasser, das ständig eisgekühlt ist. Daneben ein Automat mit Einwegtrinkbechern. In gewissen Abständen während eines Aufenthaltes wurde der Zug versorgt, d.h. von außen die Scheiben abgesprüht, Trinkwasser nachgefüllt wie auch Eis aufgefüllt. All diese Arbeiten wurden von Schwarzen verrichtet. - Die Landschaft ist immer noch dieselbe geblieben. Hin und wieder eine kleine Ortschaft, ein paar Häuser aus Holz, die Fassaden mit aufgeschnittenen Konservendosen verkleidet, sie tragen alle ihre Rostfarbe. Davor winkt uns eine Schwarze zu, die gerade auf dem Bett ihr Schläfchen gehalten hat, bekleidet mit Rock und Büstenhalter. Gegen abend wird es plötzlich bekannt, daß wir gegen 21.30 Uhr unser Ziel erreichen werden. Wir fahren in der Nähe des Flusses Arkansas vorbei. Da sehen wir schon von weitem plötzlich Lichter, dort muß unser Lager sein. Nun sehen wir viele Baracken, ein Truppenlager. Wir steigen aus und formieren uns in Marschordnung. Nach einer halben Stunde sind wir im Lager angekommen. Die Bewachung ist wieder ganz fürchterlich. Zwei Lkw fahren hinter uns und strahlen uns an. Nun passieren wir die Lagertore, und sie schließen sich wieder einmal. Mächtige Wachtürme in gewissen Abständen geben dem Ganzen den Charakter eines Kriegsgefangenenlagers. Die Dienstgrade werden aus der Masse herausgezogen und müssen sich an die Spitze setzen. Unser Handgepäck müssen wir in einer Baracke niederlegen und sollen es morgen bei Tageslicht abholen. Am anderen Ende der Baracke geht es wieder hinaus. Da warten schon wieder die Amis, um uns wieder einmal zu filzen. Ich bin leider der dritte Mann, bin natürlich vollkommen überrascht. Ich kann meine Kamera nicht mehr tarnen, d. h., ich ziehe sie blitzschnell aus meiner Tasche und stecke sie in meine Uniformmütze. Ich erwische auch noch einen Soldaten, der nimmt es sehr genau und dreht mir sämtliche Taschen um. Sämtliche Bilder aus meiner Brieftasche werden angesehen. Es werden insbesondere Bilder vom Führer, Göring und Goebbels gesucht. Bei mir Mangelware. Da erwischt der Posten meinen Belichtungsmesser. Was ist das, fragt er seinen Kameraden, der langt zu meiner linken Hand mit der Mütze, und da haben sie mich erwischt. Auch mein Tagebuch, Eintragungen in Steno, erst recht verdächtig, mein Taschenkalender mit allen Adressen. Ich werde in die Baracke geschickt, dort empfängt mich ein Sergeant mit Bremer Dialekt. „Nun, Kamerad, was hast du da?“ ,Ja, meine Fotokamera“, war meine Antwort. „,Hast Du schon etwas abgegeben?" war die Frage. ,Ja, mein Handgepäck.“ „Leg es dazu“, war der Befehl, ,morgen erhältst du eine Quittung, und wenn der Krieg zu Ende ist, erhältst du alles zurück“. „,Denkste“, war meine Antwort. Nun war ich alles los, ein schwarzer Tag für mich. Wir werden in die Baracken eingewiesen, empfangen noch unser Bettzeug und können endlich unsere amerikanischen Feldbetten aufsuchen. Endlich können wir uns strecken, mit steifen Knien verließen wir den Zug. Drei Tage nur zu sitzen, Tag und Nacht, war beinahe eine Strafe. 
Dienstag, 27. 7.43

Wir sind der 11. Kompanie zugeteilt worden. Stabswachtmeister Stierschneider, übrigens ehemals Zugführer unserer Flakeinheit (10./5), macht den Kompanie-Führer, Oberfeldwebel Dr. Hausner Spieß und Dolmetscher, vier Zugfeldwebel, vier Dolmetscher, acht Mann Küchenpersonal, drei Handwerker und ein Friseur, das ist unser ,Stammpersonal". Alle erhalten einen Sold von 20 \$. Wir werden neu eingekleidet, und zwar: eine blaue Baumwollgarnitur, vier Unterhemden, vier Unterhosen, vier Paar Strümpfe, ein Paar Arbeitshandschuhe (Leder), ein Rasierapparat, Seife und dergleichen. Weiter erhalten wir eine vorgedruckte Karte zur Benachrichtigung unserer Angehörigen, daß wir uns in amerikanischer Kriegsgefangenschaft befinden. Wir können nach Erhalt unserer Kriegsgef.-Nr. in der Woche zwei Briefe und eine Karte schreiben. - Die Verpflegung ist sehr gut. Zum Frühstück gibt es zwei Tassen Kaffee oder Kakao, zwei Scheiben Weißbrot, eine Portion Rühreier, eine Tasse Milch, Cornflakes, einen Apfel. Wir waren überwältigt, als wir nach dem Eintreffen in diesem Lager das o. a. Frühstück einnahmen. Als wir unseren Speisesaal (Küchenbaracke) betraten und an den Tischen mit je acht Mann Platz nahmen. Unser erstes Mittagessen: Bratkartoffeln, Soße, Kraut, Rettichsalat, zwei Klopse, eine Portion Fleisch, Tomatensalat, als Vorspeise Nudelsuppe, eine Scheibe Brot, zwei Tassen Kakao.

Im Laufe des Vormittags werden wir in Gruppen von je 25 Mann eingeteilt, um unser Handgepäck aus der Baracke abzuholen, das wir bei unserer gestrigen Ankunft dort ablegen mußten. Auf dem Marsch dorthin habe ich plötzlich eine ,fixe Idee“. Ich ziehe mein deutsches Tropenhemd aus, falte es der Länge nach und rolle es zusammen. Auf dem großen Haufen finde ich meine Kartentasche, Alu-Büchse und daneben meine Kamera in Fallschirmseide eingewickelt. Draußen stehen natürlich wieder Posten, die nun unser Handgepäck filzen sollen. Ich schalte sofort und suche mir einen älteren Ami aus, ich tippe, es könnte ein Farmer sein. Nun stehe ich vor dem Posten und rolle mein Hemd auseinander und lege es auf den unebenen Grasboden. Aus meiner Brusttasche ziehe ich meine Brieftasche heraus und gebe sie dem Posten zur Überprüfung. Wie er nun meine Fotos eingehend studiert, schiebe ich blitzschnell meine Kamera unter das Hemd und zwar so, daß sie an die obere Hälfte zu liegen kommt. Anschließend entleere ich meine Kartentasche und Alu-Büchse mit meinem Nähzeug, Zwirn- und Wollerollen, getarnte Filmrollen $6 \times 9$. Nach dem Studium meiner Bilder überblickt der Posten das ausgebreitete Material, nickt mit dem Kopf und sagt $O$.K. Jetzt packe ich wieder alles zusammen, falte mein Hemd der Länge nach und rolle es von unten her zusammen, so daß meine Kamera mit eingerollt wird. Das alles in einer Seelenruhe, damit ich ja nicht auffalle. Nun klemme ich die Rolle unter meinen Arm und passiere das Lagertor, jeden Augenblick gewärtig, zurückgerufen zu werden, aber nichts dergleichen. Ich atme tief durch, wieder einmal geschafft. 
Samstag, 31. 7.43

Inzwischen hat sich alles eingelaufen. Die Verpflegung ist sehr gut. Langsam hat sich unser Magen wieder angefüllt. Die Stimmung ist wieder ruhiger geworden. Die Hitze dagegen unerträglich. Man schlägt sich den Bauch voll Wasser, wir sind direkt wassersüchtig geworden. Unser Durstgefühl ist nicht zu stillen. Duschen kann man sich mehrmals am Tag. Heute abend soll die Kantine geöffnet werden. Geld soll es auch bald geben.

\section{Mittwoch, 4.8. 43}

Gestern gab es Geld, d. h. Kantinenbons für 26. 7. - 31. $7.43=70$ Cents. Die Kantine wurde auch eröffnet. In den nächsten Tagen erhalten wir den Sold für den Monat August. Inzwischen sind wir alle ,ausgefressen ", die Verpflegung ist nach wie vor ausgezeichnet. So habe ich in den vergangenen vier Kriegsjahren selten gegessen, was uns hier täglich auf den Tisch gebracht wird. Mengenmäßig ist es nicht viel, es sind aber kräftige Speisen. Seit gestern rücken Arbeitskommandos aus. Die ersten POW ${ }^{3}$ haben im Sandberg gearbeitet. Mit der Zivilbevölkerung kommt niemand in Berührung. Man hat mir erzählt, daß die eingesetzten Fahrzeuge von Frauen gefahren werden, bei der Einfahrt zur Arbeitsstelle die Fahrzeuge aber von den Posten übernommen werden, mit Sand gefüllt, wieder hinausgefahren und dann von den Frauen wieder übernommen werden. Man hat mir erzählt, daß die Mädels für uns zu viele Sympathien entgegenbringen. Es soll schon vorgekommen sein, daß Frauen Zettel mit ihrer Adresse arbeitenden POW zugeworfen haben. - Das Lager ist in drei Teil-Lager aufgeteilt. In jedem Teil-Lager sind 12 Kompanien à 100 aufgestellt. Gemäß Genfer Konvention ${ }^{4}$ sind die Mannschaftsdienstgrade zur Arbeit verpflichtet, die Uffz.-Dienstgrade können zur Aufsicht als Gruppenführer eingeteilt werden, können sich aber freiwillig zur Arbeit verpflichten.

\section{Donnerstag, 5. 8. 43}

Heute kann ich meinen ersten Brief aus den USA nach Hause schreiben. Ich teile meinen Eltern mit, daß wir von Afrika gut hinübergekommen sind und nun in unserem Stammlager gut aufgehoben sind. Ich bitte Hilde um etliche Bücher. Es wird uns mitgeteilt, daß die Laufzeit der Post etwa 4-5 Monate dauern soll.

Montag, 9. 8. 43

Heute haben sich etwa 20 Unteroffiziere zusammengefunden zu einem Allgemein-Unterricht. Es wird Englisch, Deutsch, Rechnen und Stenografie gelehrt. Der Unterricht findet in den Morgenstunden statt. 
Freitag, 13. 8. 43

Gegen Mittag erhalten wir 34 Mann Zuwachs. Sie kamen aus Casablanca. Sie sollen es dort sehr schlecht gehabt haben. Während der Überfahrt gab es für sie nur zweimal am Tag etwas zum. Essen. Ihr Aussehen ist außerordentlich schlecht. Beim Duschen können wir feststellen, daß ihr Gesäß so stark eingefallen ist, daß man eine geballte Faust hineinlegen kann. So ähnlich müssen wir auch ausgesehen haben. Nach meiner eigenen Einschätzung muß ich während der Zeit in afrikanischer Gefangenschaft ca. 20 Pfund Gewicht verloren haben. Der erste Eindruck über das Essen ist auch für sie ein gewaltiger. Wir lächeln, als sie schweißgebadet aus dem Speisesaal herauskommen.

Donnerstag, 19.8. 43

Seit 9. 8. 43 führen wir täglich einen Schulunterricht durch. Er macht gute Fortschritte. Wir sind ca. 30 Schüler. Täglich haben wir eine Stunde Englisch, Deutsch, Rechnen und Steno. Es ist allerdings für die Lehrer schwierig, ohne Lehrmittel einen ausgewählten Unterricht zu geben. Ich selbst habe mir etliche Bücher bestellt, die mir von zu Hause geschickt werden sollen.

Samstag, 21. 8. 43

Für gestern abend war ein Konzert der Kapelle des Lagers II angesagt. Leider konnte es wegen eines Zwischenfalls nicht ausgeführt werden. Es hatte sich ein bayerischer Unteroffizier freiwillig zur amerikanischen Armee gemeldet, um dort für ein freies, katholisches, unabhängiges Königreich Bayern zu kämpfen. Daß der Geist der anderen Kameraden noch gut war, beweist die Tatsache, daß dieser gute Mann Zuflucht bei den Posten suchen mußte. In der Aufnahmebaracke mußte er Schutz vor seinen eigenen Kameraden suchen. Man erzählt sich, daß er noch eine gehörige Tracht Prügel bekommen haben soll. Bei den Amerikanern herrschte Alarmstimmung, alle Posten und Wachtürme wurden sofort verstärkt und die Lagertore zu den Teil-Lagern gesperrt. So mußten wir auf unser Konzert verzichten.

Sonntag, 22. 8.43

Heute ist der lang angekündigte Nachmittag mit Musik, Torte und $\mathrm{Ku}$ chen gekommen. Gegen 14.30 Uhr betreten wir den Speisesaal. Die Tische sind mit Grün geschmückt. Auf jedem Tisch steht eine Torte, Streuselkuchen und Pfannkuchen. Zur Freude und Überraschung, es spielt die Kapelle vom Lager II. Es sind fünf Kameraden, die Geige, Akkordeon, Gi- 
tarre, Kontrabaß und Cello spielen. Wir hören anfangs Unterhaltungsmusik, dann aber schmissige Tanzmusik. Der Beifall ist überwältigend. Wir lassen uns den Kuchen und die Torte ganz besonders schmecken, dazu gibt es eisgekühlten Kakao. Unser amerikanischer Chef ist auch gekommen und scheint von unserer Musik sehr erbaut zu sein. Gegen 16.00 Uhr spielen unsere Musiker den Schlußmarsch „Alte Kameraden“ auf, die Kaffeetafel ist damit beendet. - Am Abend mache ich mit dem Kameraden Henke einen Spaziergang durch die Lager I und II, dabei mache ich dort einige Aufnahmen.

\section{Mittwoch, 8. 9. 43}

Heute wird unser Fortbildungskurs in zwei Klassen eingeteilt. Es hat um diese Teilung Meinungsverschiedenheiten gegeben. Die Teilung wird jedoch vom Lehrpersonal befürwortet. Ich komme in die Klasse A mit insgesamt 15 Schülern. In die Klasse B sind sieben Schüler eingeteilt. Wir haben zum Lehrpersonal zwei Lehrer aus den Teil-Lagern I und II hinzubekommen. Studienrat Gehrke, ein Fachschullehrer, und Studienrat Trebenius. Wir haben nun folgende Fächer: Deutsch, Mathematik, Geschichte, Englisch, Erdkunde und Kurzschrift. Ein Kamerad hat sich durch die Einteilung in die Klasse B zurückgesętzt gefühlt und steigt aus.

\section{Donnerstag, 9. 9. 43}

Jetzt in den letzten Tagen hat sich die Nachricht verbreitet, daß Italien bedingungslos kapituliert hat. ${ }^{5}$ Der König hat das Angebot von General Eisenhower angenommen, unter der Bedingung, daß die Grenzen von 1919 garantiert werden, das wurde aber verweigert. General Eisenhower soll sich in einer Rundfunkrede geäußert haben, daß Italien zwar aufgegeben habe, nun seien aber noch die deutschen Truppen zu schlagen, die sich noch im Lande befinden. Die starken deutschen Verbände sollen sich in Mittel- und Nord-Italien befinden. Die Stimmung ist auf Grund dieser Nachrichten nicht die beste. Viele verlieren nun doch das Vertrauen zur deutschen Führung. Es ist traurig zu hören, wie Kameraden bereits in scharfer Form zum eigenen Regime Stellung nehmen. Man hätte ja diesen Krieg nicht vom Zaune brechen sollen, muß man hören. Weitere Nachrichten melden, daß von uns das Donez-Becken geräumt worden sei. Die Stadt Tangerog in russischen Händen sei. Ich selbst habe den felsenfesten Glauben an die eigene Sache, daß diese Nachrichten die Amerikaner zum Durchhalten beeinflussen sollen. Es wird einst die Zukunft lehren, was nun tatsächlich der Fall war.

Samstag, 11. 9.43

Jetzt in den letzten Tagen gingen wohl die tollsten Gerüchte durch das Lager. Es gingen die widerspruchvollsten Nachrichten und Parolen um. Die 
Stimmung ist ziemlich auf dem Nullpunkt wegen der schlechten Meldungen aus Italien bzw. der Kapitulation der italienischen Regierung. Heute ist nun der Bann gebrochen. Es war Kameraden möglich, aus einer amerikanischen Zeitung die Rede des Führers zu übersetzen. Jetzt in den Abendstunden ist die gesamte Kompanie in unserer Baracke versammelt, um die Übersetzung zu hören. Oberfeldwebel Hausner, der die Rede selbst übersetzt hat, verliest nun die Rede des Führers. Wir hören nun, daß der Zusammenbruch schon seit einiger Zeit erwartet wurde und eigentlich keine Überraschung bedeute. Wir hören, daß auf Grund der Verträge Italien bereits im September 1939 in den Krieg hätte treten müssen. Nach Überwindung der größten Schwierigkeiten gelang es dann Mussolini im Jahre 1940, die Kriegserklärung durchzubringen. Er hätte hierbei seine Gegner überwinden müssen. Diesen reaktionären Kreisen wäre es nun gelungen, da der Feind im Lande steht, den Staatschef Mussolini zu stürzen. Spätere Generationen werden mit Scham vernehmen müssen, wie einst Italiens größter Sohn, seit dem Zusammenbruch des römischen Imperiums, schmählich behandelt wurde. Die Gegenmaßnahmen, die nun gegen Italien ergriffen werden müssen, sind hart. Große Teile der Bevölkerung kämpfen an unserer Seite weiter. Er berichtet von Maßnahmen in der Heimat, die verhindern sollen, daß der Gegner weitere Terrormaßnahmen durchführen kann.

Mit dem Appell an Front und Heimat, jetzt erst recht fest zusammenzustehen, wird und muß der Sieg unser sein, schließt der Führer seine Rede. Oberfeldwebel Hausner gedenkt in diesem Augenblick des Führers, Volk und Vaterland. Diese Worte haben auch für uns in Gefangenschaft ihre Bedeutung. Mit einem Sieg Heil wird die Abendveranstaltung geschlossen. -

An weiteren Nachrichten erfahren wir, daß die Amerikaner ein Drittel von Italien besetzt haben, daß drei weitere Divisionen vom Norden her in Anmarsch seien. Genua und Rom wären in deutscher Hand, Mussolini Chef einer faschistischen Regierung in Norditalien. Der König hätte abgedankt. ${ }^{6}$ Die Generäle Rommel und Blaskowitz würden die deutschen Truppen führen. Die amerikanischen Flotteneinheiten wären aus Genua verjagt worden. Die italienischen Truppen in Albanien entwaffnet und die bereits gelandeten Truppen wieder verjagt worden.

Samstag, 25. 9.43

In einer amerikanischen Zeitung erscheint ein Artikel über Heß. ${ }^{7}$ Es wäre Heß durch Vermittlung gelungen, mit Minister Eden eine Unterredung zu führen. Heß' Rolle wäre eine „Ein-Mann-Mission“. Heß hätte Pläne unterbreitet, die mehr oder weniger vom Führer wären. Es handelt sich um eine Friedensschließung mit England. Deutschland erkennt das britische 
Imperium an. Deutschland erhält freie Hand in Europa, insbesondere im Osten. Ferner erhält es die vor dem Ersten Weltkrieg besessenen Kolonien zurück. Ferner müssen die Engländer aus dem Irak heraus. Der Führer würde es ablehnen, mit Winston Churchill zu verhandeln, da dieser bereits seit 1936 den Krieg vorbereitet hätte.

\section{Mittwoch, 13. 10. 43}

Heute habe ich seit meiner Gefangenschaft meinen ersten Arbeitstag. Ich erhalte für diese Leistung einen Tageslohn von 80 Cent, das ist z. Z. der Stundenlohn eines amerikanischen Arbeiters. Dieser Satz ist in der Genfer Konvention festgelegt. Seit unserer letzten Soldzahlung am 5. 10. 43 entfällt unser monatlicher Sold von 20 \$, den wir auf Grund unseres Dienstgrades erhalten hatten. Den eigentlichen Grund für den Wegfall konnte man noch nicht klar erfahren. Irrtümlich hatte man uns als untersten Offiziersdienstgrad eingestuft, wie wir später erfahren konnten. Somit erhalten wir in Zukunft nur noch $3 \$$ im Monat. Ich glaube mit diesem Betrag auskommen zu können. Da wir Mittwoch und Samstag schulfrei haben, ist die Möglichkeit vorhanden, an diesen Tagen zu arbeiten. Die bisherige Erfahrung zeigte, daß wir Dienstgrade als „Arbeitsaufsicht“ die schlechtesten Erfahrungen mit den Landsern machen mußten. Ich habe den Standpunkt vertreten, in dieser Hinsicht alles zu vermeiden, um in dieser kritischen Zeit die Nerven zu schonen. So bin ich heute mit einigen Kameraden hinausgegangen, um selbst die Arbeit draußen kennenzulernen. Wir sind 20 Mann, alles Dienstgrade aus unserem Schulbetrieb. Es sind nur drei Mannschaften dabei. Um 7.45 Uhr passieren wir das Tor, zwei amerikanische Soldaten als Bewachung schließen sich uns an. Wir marschieren in das große Truppenlager, das wir von unserem Lager sehen können. Auf der Arbeitsstelle angekommen, haben wir erst 20 Minuten Pause. Es kommt ein Unternehmer und ein Vorarbeiter, die uns in die Arbeit einweisen. Wir haben einen Fußsteig zu planieren und mit Steinplatten auszulegen. Aus der Stacheldrahtumzäunung kommen wir auch hier nicht heraus. Es sind tragbare Zäune, die uns umgeben. Schilder mit großer, weit sichtbarer Schrift machen hier jeden Vorbeikommenden darauf aufmerksam, daß hier Kriegsgefangene arbeiten und sich jeder hier fernzuhalten hat. Zu sehen gibt es nicht viel, lediglich exerzierende Soldaten. Der Fahrzeugverkehr ist sehr lebhaft. Was uns auffällt, daß hier sehr viele Frauen verkehren, sei es in eleganten Autos, natürlich in Begleitung von Offizieren, oder sie fahren in großen Omnibussen vorüber, dort sitzen überwiegend Mädchen des WAC (Women army corps). Die Landser machten es sich zur Aufgabe, die Anzahl der Frauen zu zählen, sie zu bestaunen und zu kritisieren, gehörte dazu. Nach 50 Minuten Arbeitszeit jeweils 10 Minuten Pause. Von 12.00 bis 13.00 Uhr Mittagspause. Es gibt drei belegte Weiß- 
brote und Kaffee. Satt sind wir geworden, und nun liegen wir in der Sonne und halten ein kleines Mittagschläfchen. Die Sonne scheint uns warm auf den „Pelz“. Das Arbeitstempo ist eines POW würdig. Es macht sich keiner kaputt. Der Vorarbeiter ist nicht mit großer Fachkenntnis bedacht. Die beiden Posten haben die angenehme Aufgabe, uns ständig zu bewachen. Ein Dolmetscher von uns führt die Unterhaltung mit dem Vorarbeiter. Ich selbst habe die Aufsicht über meine Arbeitsgruppe. Ich muß feststellen, daß es keinen Ärger mit meinen Kameraden gibt, es sind ja auch alles Dienstgrade. Um 15.00 Uhr kehren wir wieder heim, gegen 15.40 Uhr passieren wir das Lagertor, um zuvor einer körperlichen Untersuchung unterworfen zu werden.

\section{Sonntag, 17. 10.43}

Heute ist ein herrlicher Herbsttag, ein ganz verrückter Sonntagmorgen. Wir treten zum ersten Zählappell an, da erscheinen plötzlich weibliche Wesen im Glied, etliche hübsche Mädchen. Schaut man näher hin, so erkennt man bekannte Gesichter, Kameraden haben sich als „,bayerische Madln“ ausstaffiert. Heute ist ja das lang angekündigte ,Oktoberfest“ der 11. Kompanie. Nun, die Stimmung ist gut. Ein großes Hallo, als Feldwebel Häusler als Clown erscheint. Etliche Unentwegte haben sich bunte Blüten angesteckt und Papphüte aufgesetzt. Was wird unser KompanieChef sagen? Da kommt er schon. Oberfeldwebel Hausner macht Meldung. Er wußte schon Bescheid, schmunzelnd nimmt er die Meldung entgegen und schreitet die Front ab. Die Oktoberfestwiese ist inzwischen aufgebaut worden vor dem Platz der 11. Kompanie. Dort ist eine kleine Budenstadt entstanden. Es setzt ein toller Betrieb ein. Die Budenbesitzer machen ihrem Stand alle Ehre. Mit lauter Stimme werden hier und dort die Leckereien und dergleichen angeboten. Der Andrang ist toll, die Kameraden aus den Lagern I und II sind recht zahlreich erschienen. Da kann an einem Stand auf leckeren Eierstreuselkuchen gesetzt werden. „Otto der Radfahrer" hat auch einen Stand übernommen. Er hat genügend Kundschaft. Er steht mit Feldwebel Häusler, der eine Raritätenschau zeigt, in scharfer Konkurrenz, wer wohl die meisten Einnahmen hat. Da schlendern hübsche „Mädchen“ als Losverkäuferinnen über den Platz, sie haben natürlich einen Kavalier zu ihrer Begleitung, der sie vor allzu vielen „Belästigungen“ schützt. Auch ein gestrenger Gendarm darf bei diesem Betrieb nicht fehlen. Ein Mitglied der Theatergemeinde hat sich uneigennützig zur Verfügung gestellt. Da gibt es Bonbons, 5 Stück für 5 Cents, auch hier reißender Absatz. Begeisterte Fußballspieler können ihre Kunst beweisen, es gilt, eine Scheibe im Tor zu treffen. Ein anderer Stand verheißt einen 20-Cents-Gewinn bei nur 5 Cents Einsatz; eine Scheibe wird gedreht, es leuchten Mädchennamen auf. Der Name, der zuletzt aufleuchtet und das Rad stehenbleibt, hat gewonnen. Es herrscht eine recht fröhli- 
che Stimmung und ein buntes Treiben, wenn es auch hinter Stacheldraht geschieht; alles in allem ist die Stimmung noch immer ungebrochen. Für den Abend hat unser „Kleines Theater" ein Schauspiel angesagt: „Der Choral von Leuthen". Ein Stück aus Friedrichs großer Zeit. Die Kapelle umrahmt dieses Stück mit Märschen aus der Zeit Friedrichs des Großen. Das Spiel beginnt. Wir erleben den „Alten Fritz" in seiner Charakterstärke, seinen unbeugsamen Willen, den Feind anzugreifen und zu schlagen. Wir erleben die Anforderungen an seine Generale. Das zweite Bild zeigt uns das Hauptquartier der Österreicher. Der Angriffsbefehl der Kaiserin Maria Theresia wird überbracht. Das dritte Bild, eine Schloßwache vor dem Quartier des Alten Fritz. Wenn noch die Haltung der Soldaten zum Teil nicht fest genug erscheint, werden wir aber doch von der Haltung des Alten Fritz nachdrücklichst beeindruckt. - Das vierte Bild zeigt uns hohe Stabsoffiziere der Österreicher bei einem Festessen, wie sie schon ihren Sieg und ihre Beförderung feiern und trinken. Da erscheint plötzlich der Alte Fritz, alles ist überrascht, niemand weiß, wer nun eigentlich hier der Herr ist. Da rafft sich ein österreichischer Offizier auf und bittet den Alten Fritz um seinen Degen. Der schaut sie verwundert an, da ertönt von fern der Choral „Nun danket alle Gott“. Da geht ein jähes Entsetzen durch die Reihen der österreichischen Offiziere; sie haben begriffen. - Die Darstellung des Alten Fritz in Haltung, Gebärde und Ausdruck hinterläßt auf uns einen tiefen Eindruck. Die übrigen Spieler reihen sich einwandfrei in dieses geschlossene Bild. Die Kostüme können als ganz besonders gelungen bezeichnet werden.

Mittwoch, 20. 10. 43

Heute haben wir wieder schulfrei. Wir gehen heute zum Steinbruch zum Arbeitsdienst. Um 7.45 Uhr passieren wir das Tor, unsere Stärke beträgt 100 Mann. Der Weg führt durch ein Waldgelände. Vor uns marschiert ein gleich starkes Kommando, sie haben einen Schritt, als wenn man zum Begräbnis ginge. Ich bin ziemlich geladen. Beim Halten liegen die Landser auf der Straße, so wenig Haltung können sie bewahren. Nach einer dreiviertel Stunde erreichen wir den Steinbruch II. Es folgt eine Pause von zehn Minuten. Der Steinbruch liegt mitten im Wald auf einer Höhe. Die Vorarbeiter sind bereits da. Jeder schnappt sich ein Werkzeug. Ich habe mich mit mehreren Kameraden zu einer Arbeitsgemeinschaft zusammengeschlossen. Wir sind hier Neulinge. Die „Alten“ vom Steinbruch geben uns gute Tips für die Arbeit. Mit Brechstangen, Hämmern und Meißeln bewaffnet gehen wir auf die Steinplatten los. Alle 50 Minuten folgt eine Pause von 10 Minuten. Wir haben einen schlechten Platz erwischt, neben uns arbeitet ein Preßlufthammer mit mächtigem Getöse. Das Arbeiten macht uns insofern Spaß, als wir es als körperlichen Ausgleich betrachten. Es kommt hier nicht auf die Arbeitsleistung an, sondern etwas zu tun. Es 
sind u. a. Aufladekommandos eingeteilt, die die Lkws beladen. Eine Schottermaschine wird mit Material von den Schubkarren aus versorgt. Die heutige Arbeitsleistung wird vom Amerikaner als die bisher beste bezeichnet. Welch ein Zufall, daß heute ein großer Teil Dienstgrade mit hinausgegangen ist. Von 12.00 bis $13.00 \mathrm{Uhr}$ machen wir Mittag. Es gibt ein Paar Bockwürste, zwei Paar Butterbrote, ein Paar Marmeladenbrote und Milchkaffee. Um 15.00 Uhr formieren wir uns zum Abmarsch. Auf der Hauptstraße fädeln sich die anderen Kommandos von den anderen Steinbrüchen ein. Kamerad Stierschneider pflückt einen herrlichen Herbststrauß für unser Zimmer. Um 15.50 Uhr passieren wir das Tor und werden wieder untersucht.

Dienstag, 9.11. 43

Aus Anlaß des Gedenktages der „Gefallenen der Bewegung“8 tritt das Regiment um 17.30 Uhr zu einer Feierstunde im Lager III zusammen. Es ist heute ein klarer, sonniger Novembertag. Zur Feier des heutigen Tages haben wir unsere deutsche Uniform angelegt. Um 17.30 Uhr beginnt der Aufmarsch der einzelnen Kompanien auf dem Sportplatz unseres Lagers. Unsere 11. Kompanie erwischt leider einen schlechten Aufstellungsplatz. Wir stehen an der hintersten Front. Kurz vor 18.00 Uhr ist der Aufmarsch beendet. Die vereinigten Kapellen und Chöre des gesamten Lagers haben vorn auf einem Podium Aufstellung genommen. Um 18.00 Uhr wird dem Lagerführer (Lt.) Meldung gemacht. Die Feier wird durch eine ernste Musik eröffnet. Es setzt der Chor ein und singt das Lied „Deutschland hoch in Ehren".

Das Lied klingt aus. Es spricht der Lagerführer. Er kommt in kurzen Worten auf den 9. November 1923 zurück. Daß damals der Kampf um die innere Macht begann und nun zu einem der Nation geworden sei. Er erinnert an die Opfer dieses Krieges in den bisherigen Feldzügen, insbesondere an unsere Kameraden, die wir in der heißen Erde Afrikas gebettet haben. Aber nicht zu vergessen seien die Opfer der Heimat, das Opfer und Heldentum der vielen Frauen, Männer und Kinder. Sie seien für alle Verpflichtung, weiterzukämpfen bis der Sieg unser sei. Für uns Verpflichtung, Haltung zu bewahren, da $\beta$ wir uns einst nicht zu schämen brauchen, wenn wir in die Heimat zurückkehren werden. Er gedenkt des Führers, des deutschen Volkes und Vaterlandes. Wir bringen ein Sieg Heil auf Führer, Volk und Vaterland aus. Die Nationalhymnen beenden die Feier. Es war für uns eine erhebende Feierstunde, eine Stunde zur inneren Einkehr und mag manchen daran erinnert haben, ein Deutscher zu sein und innere Einkehr zu halten. Zu Beginn der Feierstunde konnten wir feststellen, daß die Wachtürme mit Posten verstärkt worden waren. Wir können darüber nur schmunzeln. Es waren immerhin ca. 3500 Mann aufmarschiert, das muß den Amis doch Respekt eingeflößt haben. Völlig durchfroren, aber heißen Herzens marschierten wir kompanieweise ab. 
Mittwoch, 10.11. 43

Heute an unserem schulfreien Tag bin ich wieder zur Arbeit hinausgegangen. Ich hatte ein Kommando von 1100 Mann zu führen. Wieder ein herrlicher Novembertag. Eine Stunde Weg haben wir zu marschieren. Wir sind für heute im Steinbruch I eingeteilt worden. Es hat sich wieder unsere alte "Clique" gefunden. Oberwachtmeister Behnke, Werkmeister Adam, Oberfeldwebel Jost, Wachtmeister Carstensen. Es macht uns Spaß, sich wieder einmal richtig auszuarbeiten und somit körperlich einen Ausgleich zu finden. Schnell ist der Vormittag verflogen. Von 12.00 bis $13.00 \mathrm{Uhr}$ Mittagspause. Es gibt drei Doppelbrote mit Marmelade, kaltem Braten und Käse. Um 15.00 Uhr geht es wieder heim. - Seit einiger Zeit dürfen wir keine Zeitung mehr in das Lager hereinbringen. Es war aber doch möglich, eine Zeitung hineinzuschmuggeln. So brachte unser Pressemann von der 12. Kompanie Nachrichten heraus. Ein amerikanischer Abgeordneter macht Mitteilungen über seine Reise nach London und brachte Einzelheiten über den Luftkrieg heraus. Er teilt mit, daß die Alliierten vorübergehend die Luftherrschaft verloren hätten. Deutschland hätte sich zur rechten Zeit auf Jägerproduktion umgestellt. Erwähnt wird der neue deutsche Jäger, der mit 4 bis 6 Raketen ausgerüstet wäre. Heimkehrende englische Jäger berichten mit Schrecken davon. Weiter wird ein deutscher Bomber ME 410 erwähnt, er soll $480 \mathrm{~km} /$ Std. fliegen. Weiter wird von deutschen Luftangriffen auf London berichtet. Ein überfülltes Tanzlokal, zwei Kinos usw. wären getroffen worden. Die Straßen eines Vorortes sähen wie ein Schlachtfeld aus. Weiter wird vom Kampf im Pazifik berichtet. Von einer Seeschlacht bei den Aleuten. Alliierte Streitkräfte hätten 56 Kriegsschiffe verloren, und 75 weitere Schiffe seien beschädigt, und das in der Zeit vom 31. 10. bis 5. 11. Deutsche Erfolge im Mittelmeer. 13 beladene Transporter und 2 Zerstörer wären versenkt worden. Dann wird die Führer-Rede vom 8.11.43 in kurzen Worten erwähnt. Der Führer sprach davon, gleich welche Opfer wir gebracht haben und noch bringen müssen, wir werden auf keinen Fall in der 11. Stunde aufgeben, sondern über die 12. Stunde hinaus den Sieg erringen. Wenn er von der kämpfenden Front das scheinbar Unmögliche verlange, zu kämpfen und zu siegen, so sei dies auf keinen Fall unmöglich, wie er unmöglich seine Nerven in diesem Kampf verlieren werde. Er erwähnte, daß die Alliierten eine zweite Front versuchen, aber das beweise, daß wir noch Reserven zur Verfügung hätten und durch nichts überrascht werden könnten. Leider wurde die Rede nur im Auszug wiedergegeben.

Mittwoch, 17. 11. 43

Was uns allen Kummer bereitet, das ist die Postfrage! Wenn in letzter Zeit Post eintraf, so war es nur wenige. Im Laufe der letzten Wochen konnte 
festgestellt werden, daß immer dieselben Kameraden, die bereits einmal Post bekommen hatten, Post aus der Heimat erhielten. Eine genaue Nachfrage durch den Kompanie-Führer ergab, daß 78\% von uns überhaupt noch keine Post erhalten hatten. Im Gegensatz, daß es bereits einige Kameraden gab, die etwa 8 bis 10 Briefe erhalten hatten. Der Inhalt dieser Briefe bringt nur familiäre Nachrichten und erwähnt mit keinem Wort die Kriegsereignisse. Es liegt die Vermutung nahe, daß die übrige Post diesbezügliche Nachrichten enthielt und unter Zensur gefallen sein könnte. Beschwerden von unserer Seite an die schweizerische Gesandtschaft haben bisher keinen Erfolg gebracht. Diese berichtete uns in einem Antwortschreiben, daß Nachfragen ergeben hätten, daß die amerikanischen $\mathrm{Be}$ hörden die ankommende Post innerhalb von 24 Stunden abfertigen würden! Die Schuld müsse wohl dann bei den deutschen Behörden liegen. Andererseits konnte von uns festgestellt werden, daß ein von hier abgegangener Brief, von der Zensurstelle wieder zurückgeschickt, nach Washington und zurück 10 Wochen gebraucht hatte. -

Seit einiger Zeit hat die Zeitungslieferung in die Kantine aufgehört. Von Zeit zu Zeit können Kameraden von ihren Arbeitsstellen Zeitungen in das Lager schmuggeln. So war es uns möglich, auch die auszugsweise Rede des Führers zu lesen. Gestern konnte ich selbst in der Kantine beobachten, daß die Tageszeitung an zwei Stellen zensiert war, d. h., zwei Stellen waren ausgeschnitten. Inzwischen konnten wir in Erfahrung bringen, daß Feldmarschall Rommel auf dem Balkan neun Partisanen-Divisionen zerschlagen hat, darunter drei vollmotorisierte Divisionen mit insgesamt 135000 Mann. Weiter hätten unsere Truppen in Italien Schlüsselstellungen zurückerobert, die für die Amis Voraussetzung waren, um auf Rom marschieren zu können. Eine heutige Zeitung von draußen besagt, daß die Krim eingeschlossen wäre, aber von den Deutschen noch besetzt sei. Die Russen Kiew besetzt hätten und an zwei Stellen den Dnepr überschritten. ${ }^{10}$ Gerüchte erwähnen, daß in Amerika ein Kohlenarbeiter-Streik ausgebrochen sei und sich auf eine Million Arbeiter beläuft.

\section{Dienstag, 30.11. 43}

Anschließend an das Abendessen haben wir Kompanie-Belehrung. Zur Sprache steht der Besuch des schweizerischen Gesandten, der unsere Interessen bei der amerikanischen Regierung vertritt. Er besichtigte unser Lager am Samstag, 27. 11. 43. Oberfeldwebel Hausner spricht die einzelnen Punkte durch, die ihm durch den Regimentssprecher Feldwebel Rudolf vorgetragen wurden, u. a. war er ehrlich überrascht, daß 70\%, ca. 2800 Mann, seit ihrer Gefangennahme noch keine Post erhalten haben. Er gibt nun selbst zu, daß die amerikanischen Zensurstellen dieser „Postflut“ machtlos gegenüber ständen. Er will wegen dieser Angelegenheit nach Washington fahren und bei der Regierung vorstellig werden. Weiter erfah- 
ren wir, daß die deutsche Regierung einen Hilfsfonds eingerichtet hätte. Es sollen für Mannschaften 6.- \$ und für Unteroffiziere 10.- \$ zur Verfügung stehen. $\mathrm{Da}$ aber jedem die Möglichkeit gegeben wäre, sich selbst Geld durch Arbeit zu verdienen, wurde dieser Fonds wieder aufgelöst. Die deutsche Regierung wünscht, daß ihre Soldaten während der Gefangenschaft einer Arbeit nachgehen, wenn sie nicht gegen die Genfer Bestimmung verstößt. Gerade dieser Punkt wurde von jedem so ausgelegt, wie er ihn brauchen konnte. Somit wurde jede Arbeitsverweigerung bzw. Drükkerei dahin ausgelegt, nicht für die Amerikaner arbeiten zu müssen. Wir Dienstgrade standen als "Aufsicht" zwischen zwei Feuern und hatten praktisch keine Handhabe gegen diese Einstellung. Es ist wohl ein Tiefstpunkt einer 10 jährigen Dienstzeit, sich von den eigenen Soldaten als ,Antreiber“ bezeichnen zu lassen. Nun ist diesen Elementen jede Auslegung nach ihrer Art genommen worden.

Die „Stacheldrahtpsychose“ treibt weiter ihre Blüten, wie Hausner mit trockenem Humor behauptet. Da gab es im Anfang die angeblich ,warmen Brüder“. Jetzt spukt die „Schwarze Hand“ im Lager umher. Vor etlichen Wochen wurde die Kommune mit 70 bis 80 Mann aussortiert und kam in ein anderes Lager für solche Leute. Jetzt sollen sie angeblich wieder nächtliche Versammlungen abhalten und sollen zu diesem Zweck im Lager II zusammenkommen. Man will in nächtlicher Stunde vermummte Gestalten durch den Zaun steigen gesehen haben. Prompt hat sich ein „Abwehrdienst" von sog. „150\%" gebildet. Dann hat man einen „Abhördienst" organisiert, der hinter Türen lauscht und so die Kommune entdekken will. Weiter hat man einen ,Wachdienst“" organisiert, der zu nächtlicher Stunde den Stacheldraht kontrolliert und die Leute aufschreibt, die durch den Zaun steigen. Leider wurden bisher nur Skatbrüder erwischt, die bei Kameraden einen Dauerskat gespielt und sich verspätet haben. Es hat nun etliche Aufregung gegeben, daß nun sogar von ,schwarzen Listen" gesprochen wird. Leider haben da einige Übereifrige die ganze Sache verkehrt angefaßt. Wie Hausner eingehend feststellt, daß diejenigen, die eine kommunistische Propaganda treiben, mit allen Mitteln unschädlich gemacht werden müßten, aber auf eine einwandfreie Art und Weise und nicht durch Spitzelwesen. Damit ist auch dieser leidige Punkt bereinigt worden.

Montag, 13. 12.43

Das war heute ein schwarzer Tag! Gegen 4.30 Uhr kommt der Sani, Unteroffizier Mattes, zu uns auf die Stube gestürzt und weckt Hausner, ein Toter in der Kompanie, war sein ,Weckruf". In kurzen Worten meldet er, daß auf der Baracke 02 der Obergefreite Hemler tot sei. Eine spätere Obduktion der Leiche ergab, daß ein Magengeschwür aufgebrochen und in die Bauchhöhle eingetreten war. 
Das „Spinat-Kommando“ verunglückte mit dem Lkw. Es gab einige Leichtverletzte. Bei der 3. Kompanie explodierte ein Wasser-Kessel. Vier Dienstgrade werden versetzt zu einer Neuaufstellung. Und zwar: Feldwebel Hamisch, Dannemann, Eichenreiner und Bruckmann.

\section{Donnerstag, 16. 12. 43}

Heute habe ich meinen 13. Arbeitstag hinter mir. Es war der sechste im Monat Dezember. Mit „Meister" Adam fuhr ich zur Sandgrube hinaus. Ein Kommando von 50 Mann war eingeteilt worden. Jetzt in den letzten Tagen hatten wir eine unverschämte Kälte. So wurden wir auch heute auf dem Lkw ganz schön ausgekühlt. Die Fahrt ging zwischen Bahn und dem Lager. Die Bahn wurde überquert, und es ging an einzeln gelegenen Siedlungen vorbei, wenn man von einer Siedlung überhaupt sprechen konnte. Es waren einzelne Häuser, vielmehr Bretterbuden armseligsten Ausmaßes. Es waren tatsächlich Bretterbuden, aus Kistenbrettern errichtet. Ich erinnere mich einzelner Häuser an der Hauptstraße, da fehlten sogar einige Fenster. Natürlich stand vor jeder Hütte ein alter ausgeschlachteter Ford. An anderer Stelle wieder war das Vieh im Freien, ein paar Pferde, Kühe und Maulesel, von einem Stall war nichts zu sehen. Die Landschaft zeigte den Charakter einer Prärie, wie in den Indianerbüchern so gut beschrieben. Zum Teil schien die Landschaft unberührt. Alles in allem erschienen mir die Holzhäuser und Dörfer in Rußland paradiesisch schöner. Unsere Fahrt dauerte etwa eine halbe Stunde. Gearbeitet wurde in einer Sandgrube. Es war ein Förderband aufgestellt, ein Kommando von 25 Mann mit je einem Schubkarren und je einem „Einlader“ (Befüllen des Schubkarrens) sorgte für die laufende Belastung des Transportbandes. Heute war es ein Rekordtag, 52 Lkws wurden beladen. Ich selbst habe wohl auch einen „Rekord“ aufgestellt, denn ich schob 58 Schubkarren. In einer „Betriebspause" wärmte uns ein Holzfeuer auf. Jedenfalls war es so kalt, daß wir nicht zum Schwitzen kamen. Der Vormann, ein alter Yankee, sorgte dafür, daß keiner unbeschäftigt blieb.

\section{Freitag, 17. 12. 43}

Heute ist der Tag der Beisetzung des Kameraden Hemler. Eine Ehrenkompanie mit drei Zügen ist von der 9. bis 12. Kompanie zusammengestellt worden. Um $10.40 \mathrm{Uhr}$ rückt die Ehrenkompanie zum Haupttor vor. Ich selbst werde die "Foto-Presse“ vertreten. Getarnt in einer nahen Baracke werde ich eine Aufnahme machen. Die Leiche ist vor der Hauptkantine aufgebahrt. Der Sarg ist mit der deutschen Reichskriegsflagge bedeckt. Seitwärts stehen die Kranzträger. Sie tragen einheitlich die schwarze Panzer-Uniform. Die Kränze sind mit wunderbaren Rosen und Chrysanthemen dekoriert. Der deutsche evangelische Pfarrer segnet die 
Leiche ein. Im Parademarsch defiliert die Ehrenkompanie an der Leiche vorbei. Der Pfarrer, die Kompanie-Führer des Regiments und der Chor schließen sich an. Wir verlassen im langsamen Marsch das Lager. Seitwärts der Straße stehen amerikanische Soldaten und grüßen. Zur Linken, längs des Stacheldrahtzaunes, aber stehen die Kameraden und grüßen, die Mütze in der linken Hand, die rechte zum Deutschen Gruß erhoben. Am Nordende des Lagers auf der Höhe ist der Platz bestimmt, wo deutsche Kriegsgefangene zur letzten Ruhe gebettet werden. Es ist der zweite Kamerad, den wir nun hier hinauftragen. Heute ist ein herrlicher Dezembertag, etwas kalt. Die Sonne scheint so klar. Dumpf dröhnt vorn an der Spitze die Trommel, nach deren Rhythmus wir marschieren. Die Posten auf den Wachtürmen stehen unter Gewehr und präsentieren. Wir haben das Grab erreicht und nehmen Aufstellung. Eine Gruppe amerikanischer Soldaten steht „Gewehr bei Fuß“ und soll den „Ehrensalut" schießen. Es spricht der deutsche Pfarrer. Er spricht vom Schicksal dieses Kameraden, der nun fern der Heimat, fern seiner Mutter, seine letzte Ruhe findet. So still, wie er unter den Kameraden lebte, so still ging er von uns. „Wer auf diese Fahne schwört, hat nichts, was ihm gehört", das waren die Worte an uns. Der Pfarrer hat gesprochen, der Sarg sinkt automatisch in die Gruft. Nach dem Ehrensalut singt der Chor das Lied vom „Guten Kameraden“" Als Abschluß aber ertönt aus weiter Ferne des "Soldaten letzter Gruß", geblasen auf dem Horn eines amerikanischen Soldaten. Es folgt die Kranzniederlegung unseres Kompanie-Führers Oberfeldwebel Hausner und einige kurze Gedenkworte sowie die der Kompanie-Sprecher. Die Feier ist beendet, wir formieren uns zum Abmarsch. „Fern bei Sedan“" und „Die blauen Dragoner" sind die Lieder unseres Marschgesanges.

Sonntag, 26. 12.43

Ich glaube, die Amis wollen uns mit überreicher Kost fertigmachen. Was wir in diesen Tagen zum Essen hatten, ist nicht zu beschreiben. Das einzigste, was uns wohl Freude hätte bereiten können, das wäre Post aus der Heimat gewesen, aber leider Fehlanzeige!

Donnerstag, 30.12.43

Einsam und verlassen, wo bleibt die starke innere Kameradschaft, die alles überwinden hilft?

Hier habe ich sie nicht und werde sie wohl nicht erleben. Da verkommen sie seelisch und körperlich. Bald werden sie in ihrer Koje verfaulen! Doch ich gehe meinen Weg allein, Kampf der Untätigkeit und Willenlosigkeit! - Gedanken des heutigen Tages. 
Freitag, 31. 12. 43

Das alte Jahr geht zu Ende. Wir feiern „,Silvester 1943“ als POW. - Einige Baracken haben einen „Silvesterrummel“ aufgezogen. Da wurde die eine Hälfte der Baracke ausgeräumt und eine „Bar" eingerichtet. Eine gedämpfte Beleuchtung, bunt in ihren Farben, gab den Augen einen etwas intimen Charakter. Eine ,Teufelsgeige" und ein Akkordeon gaben die Stimmungsmusik ab. Stimmung und Humor rissen uns über die jämmerliche Lage hinweg, in der wir uns eigentlich befanden. An der Bar gab es die beliebten ,C.C“-Getränke, reizende „,Damen“ unterhielten uns. Kurz vor $24.00 \mathrm{Uhr}$ wurde in einem ernsten Gedenken des Jahreswechsels gedacht. Wir hielten kurze Rückschau über unser Schicksal, da sich für uns die Tore der Freiheit geschlossen. Möge unser Wunsch in Erfüllung gehen, daß im kommenden Jahr die Tore der Freiheit sich endgültig öffnen mögen. Mit einem Prosit Neujahr heben wir das Jahr 1944 aus der Taufe. Was mag es uns bringen, fragen wir uns in Gedanken.

Am Anfang Deines Weges

Wirst Du nicht verstanden -

Das erreichte Ziel ist Dir Preis

Für alle Mühe!

31. 12.43

Dienstag, 4. 1.44

Seit Tagen berichtet die „Muskogeer“ Zeitung, daß die roten Truppen auf die polnische Grenze zu marschieren. Heute steht nun in dicker Überschrift, daß die Roten die ehemalige polnische Grenze erreicht hätten! Trotz dieser niederschmetternden Nachrichten glauben wir diesen „Schwindel“" nicht, es muß irgend etwas damit bezweckt werden. Dazu ist bemerkenswert, daß die Zeitung das amerikanische Volk darauf vorbereiten soll, daß es in Kürze mit Verlusten von etwa 500000 Mann rechnen müsse. „Die große Invasion", von der man sich soviel verspricht. Eine Spezial-Armee hätte Deutschland eigens als Abwehr aus Rußland nach dem Westen geworfen. Es fragt sich nur, wie sich das mit dem Vordringen der Russen verhält, daß trotz Vormarsch der Roten man eine Armee herausziehen und sie nach dem Westen werfen kann. Ich selbst gebe nicht viel auf diese Nachrichten, aber vielleicht doch wert, einmal der Wahrheit gegenüberstellen zu können. Vor zwei Tagen bekam ein Kamerad von der 10. Kompanie einen Brief aus der Heimat. Er muß wahrscheinlich die Zensur nicht passiert haben. Dieser Brief war vom 5. 7. 43. Darin wurde mitgeteilt, daß bis zu diesem Zeitpunkt ca. 10000 Panzer im Osten vernichtet worden wären. Weiter wurde mitgeteilt, daß ,die Rechnung von Stalin nicht aufginge“. Weiter hörte ich heute in der Pause unseres Unterrichts, daß im Lager II ein Kamerad einen Brief von seiner Frau erhalten hätte und diese ihm mitteilte, ,daß es schade für ihn wäre, in der Zeit der 
größten Siege nicht in der Heimat weilen zu können“. - Für uns ist es schwer, sich ein tatsächliches Bild von der wahren Lage auf den Kriegsschauplätzen zu machen. Man kann nur ein riesenhaftes Vertrauen besitzen zur eigenen Sache. Leider gibt es schon viele Schwarzseher.

\section{Sonntag, 30.1.44}

Wir begehen heute den Gedenktag des 30. Januar 1933, dem elften Jahrestag der „Machtübernahme“. - Die Kompanie ist um 9.20 Uhr zum Appell angetreten. Um 9.30 Uhr beginnt der Aufmarsch des Regiments auf dem Sportplatz des III. Bataillons. Die Feier wird um 10.00 Uhr durch das Präludium von Liszt eingeleitet. Es spricht der Regiments-Sprecher Wachtmeister Rudolfi. In kurzen Worten zeigt er uns den Weg nach der Machtübernahme. Die wenigen Friedensjahre, die den Weg in eine glückliche Zukunft aufzeigten, aber durch den Kampf um unser Bestehen als Volk unterbrochen wurden. Wir, die wir abseits stehen beim Schicksalskampf des deutschen Volkes, müßten weiterhin unser Deutschtum hochhalten. Die Rede wurde mit dem Sieg Heil auf Volk, Vaterland und Führer beendet. Mit dem Gesang der Hymnen war die Feier beendet. Die Kompanien marschierten mit Gesang wieder zu ihren Unterkünften.

Heute war nun der Tag gekommen, da unsere geheimnisvolle Schnapsbrennerei ihre Krönung fand. Der Erfolg: eine Gallone $=4 \frac{1}{2}$ Liter Eierlikör. So war es möglich, daß unsere Stubenbelegschaft im friedlichen Kreise zusammensaß, um diesen Augenblick zu genießen. Wie kamen wir zum Alkohol? Wir sammelten täglich unsere Pampelmuse, die wir als Nachtisch zum Mittagessen bekamen. Ein Mechaniker bastelte eine Kupferspirale, einen Wasserkessel, und mit einer Talgkerze wurde die Destille in Betrieb genommen. Zuvor wurde der Saft mit Zucker angesetzt, drei Tage im Gärprozeß gehalten und dann destilliert.

Für uns war auch der Tag gekommen, daß sich die Pforten des neuen Theaters des Lagers III öffneten. Das Kleine Theater brachte die Revue „Wie es Euch gefällt". In bunter Folge rollte ein nettes Programm mit Tanz, Gesang und Humor ab. Das Kleine Theater war ganz groß! Insbesondere gefiel uns die schmissige Musik der Orchesters. Auch das Bühnenensemble überraschte uns mit neuen Einfällen. Die Kostüme und Kulissen waren das Produkt einer fleißigen Arbeit. Groß war der Beifall für alle Mitwirkenden für den Erfolg ihrer Arbeit. Zwei Torten und ein Blumenstrauß waren das äußere Zeichen als Dank für ein begeistertes Publikum.

Sonntag, 6. 2. 44

Um 10.30 Uhr fand im Lager I ein Vortrag von Studienrat Trebesius statt über „H. v. Kleists deutsche Sendung“". Der Vortrag fand einen begeisterten Widerhall unter den Zuhörern. H. v. Kleist wurde vom Vortragenden 
als der erste politische Dichter herausgestellt, der in nationaler Not sein Volk aufrief und an die großen Männer der Geschichte erinnerte. Wir konnten viele Parallelen finden zwischen dem Ideal der damaligen Führergestalt, die einmal Deutschland zu Größe und Freiheit führen werde, und der heutigen Gegenwart. Viele wurden daran erinnert, daß der Kern unseres Kampfes erkannt werde. Es wurden die zwei uns feindlichen Welten herausgestellt, mit denen sich unser Vaterland im tödlichsten Kampfe befindet.

\section{Mittwoch, 9. 2. 44}

Der Frühappell ist vorüber. Sämtliche Unteroffiziere in den Speisesaal, hat es geheißen. Wir können es uns denken, um was es sich handelt: Versetzungen. Voller Erwartungen sitzen wir im Speisesaal, als Oberfeldwebel Hausner die Namen der Versetzten verliest, auch ich bin dabei. Von unserer Bude (12 Mann) bleiben Hausner, Oberschelp, Stierschneider und Jost, der ,,schwarze Schleicher“, zurück. Insgesamt bleiben 15 Unteroffiziere bei der Kompanie zurück. Um 13.00 Uhr müssen wir abmarschbereit stehen. Zur Zeit sind wir beim Packen und nehmen unsere letzte Mittagsmahlzeit hier ein. Um 15.15 Uhr stehen wir am Haupttor, von unserer Kompanie sind es 69 Unteroffiziere. Wir werden nicht durchsucht und marschieren zum Bahnhof. Gegen 17.15 Uhr fährt der Zug an. Wir sitzen wieder in der Polsterklasse. - Nicht zu vergessen die Abschiedsrede, die uns Oberfeldwebel Hausner um 14.00 Uhr bei Kaffee und Kuchen hielt. Dieser gute Mann hat bis zum heutigen Tag mit verdeckten Karten gespielt. „Es kommt ja alles von oben“, dieser gute Mann war ja mehr Amerikaner als Deutscher. Hoffentlich findet auch er einmal seinen Richter.

„Meister“ Adam, Zunke (aus Berlin von der LPG General Göring, 7. Hundertschaft, also ehemaliger Regiments-Kamerad von mir), Krakenberger (Steinmetz aus Saarbrücken), Otto Krämer und ich haben den Anschluß an unseren alten Haufen verloren.

\section{Donnerstag, 10. 2. 44}

Wir sind auf der Fahrt in das neue Camp. Um Mitternacht werde ich geweckt, meine Kameraden gratulieren mir zum 29. Geburtstag! Das kann ja ein netter Tag werden auf der Fahrt in ein neues Lager. Gegen 7.00 Uhr haben wir unser Ziel erreicht: Tonkava im Staat Oklahoma. Eine gottverlassene Gegend. Es vergehen noch zwei Stunden, ehe wir das Abteil verlassen. Unter starker Bewachung ziehen wir in das neue Lager ein. Wir empfangen am Lagertor unseren Seesack und werden anschließend untersucht. Wegen meiner Kamera habe ich ein schlechtes Gewissen. Ich bleibe erst einmal zurück und studiere die Lage, wie der „Hase läuft". Ich stelle fest, daß wir auf der rechten Seite der Lagerstraße Aufstellung nehmen müssen, in der Mitte der Straße untersucht werden und dann auf die linke 
Seite übertreten müssen. Wenn jeweils ein Posten frei ist, können wir vortreten und uns untersuchen lassen. Ich schultere meinen Seesack, gehe in die Gasse hinein, setze meinen Sack ab, gucke umher und schultere ihn wieder. Ich tat so, als ob ich gerade durchsucht worden wäre, und trete auf die andere Seite der Straße hinüber. Ich habe Glück gehabt, niemand hat diesen Trick bemerkt. Wieder einmal geschafft, denke ich bei mir. - Wir finden wieder Anschluß an unseren Haufen aus dem alten Camp Gruber. Der äußere Eindruck des Lagers ist für uns verheerend. Jetzt können wir mit Recht behaupten, daß wir aus einem Musterlager kommen. Es sieht wie nach einem Straflager aus. Hier sind nur Dienstgrade beisammen. Alle noch vorhandenen Mannschaften wurden ausgewechselt. Es kamen hier Unteroffiziere her, die in anderen Lagern die Arbeit verweigert hatten, was aber auf uns nicht zutraf. Denn wir gingen ja zeitweise einer Arbeit nach. Wir erfahren, daß hier vor einiger Zeit ein ,,Vaterlandsverräter“ von seinen Kameraden gesteinigt wurde. Es fand ein "Scherbengericht“ statt. Dieser Mann soll auf einen Zettel die Treibstoffanlagen im Hafen von Hamburg eingezeichnet haben. Dieser Zettel wurde aber vom Ami an den Spieß der betreffenden Einheit zurückgegeben, mit dem Vermerk: „Das wissen wir schon lange." Der Spieß gab diesen Fall beim Abendessen bekannt. Pfuirufe wurden laut, da verlor der bis dahin Unbekannte die Nerven und wollte hinauslaufen. Da warf irgend jemand eine Suppenschale, das war der Auftakt zu einem Scherbengericht. Er wurde gesteinigt. Der Ami wurde alarmiert, es wurde alles abgesperrt, und man suchte die heraus, die Blutspritzer an ihrer Kleidung aufzuweisen hatten. Diese Flecken genügten, sie der Tat zu überführen. Es wurde ein halbes Dutzend Leute verhaftet und ihnen der Prozeß gemacht. Darunter war auch der Spieß. Es sollen mindestens drei Mann zum Tode verurteilt worden sein. Und nach Beendigung des Krieges unter Roosevelt, der eine Begnadigung ablehnte, durch den Strang vollzogen werden.

Durch das Fehlen der Mannschaftsdienstgrade können wir nun den Küchen- und Latrinendienst selber machen. Das kann ja niedlich werden. Nichts ist hier von einer positiven Arbeit zu sehen, rein äußerlich gesehen. Was hatten wir doch ein schmuckes Lager im Camp Gruber! So vermissen wir unsere netten Baracken, mit Erdgasofen ausgestattet. Statt dessen stehen hier Steinkohleöfen aus der Pionierzeit in den Baracken, beheizt mit Steinkohlen. Hier werden wir die Arbeit vermissen, bei der wir uns einige Dollars dazuverdienen konnten. Jetzt am Abend haben wir alles verstaut und werden nun zu Bett gehen. Das war nun mein Geburtstag, Gott gebe, daß ich den nächsten in der Heimat verleben kann.

Freitag, 11. 2. 44

Bereits um 6.00 Uhr ist Wecken, um 6.30 Uhr Frühstück, das gemeinsam eingenommen wird. Während des Frühstücks und des Abendbrotes findet 
die Zählung am Tisch statt. Das stellt sich aber für den Ami scheinbar als recht schwierig heraus. Es vergeht jedesmal über eine Stunde, bis die Zählung von allen drei Teil-Lagern beim Hauptquartier gemeldet und für richtig befunden wurde. Wir sind überzeugt, daß das alles feine Nadelstiche für uns bedeuten sollen. Doch wir hoffen, daß unser Geist, der von über 600 Unteroffizieren getragen wird, auch hier in diesem Lager seine Verbreitung finden wird. Am Nachmittag findet durch die Feldwebel eine Neuwahl des Vertrauensmannes für unser Lager I statt. Es wird gewählt Stabsfeldwebel Mödel, ehemals Lager Camp Gruber - Lager II. Wir haben den Eindruck, daß die hiesigen Kameraden recht stark abgestumpft sind. Es fehlt hier scheinbar auch jede Unterstützung durch den Ami. Am Abend fand eine Besprechung der vorhandenen Lehrkräfte statt. Es soll der Unterricht wieder fortgesetzt werden. Der äußere Eindruck des Lagers, wie bereits schon erwähnt, ist sehr schlecht! Die Baracken machen einen düsteren Eindruck. Sie sind von außen mit schwarzer Dachpappe verkleidet. Das Innere ist jeweils in drei Räume unterteilt mit je 14 Mann. Das hinterlassene Bettzeug von den Herrn Landsern ist dreckig, man kann es nicht anders bezeichnen. Man muß sich schämen, daß hier deutsche Soldaten gehaust haben. Sie hatten ja ,soviel Arbeit", zwischen den Mahlzeiten wurde ja geschlafen. Die Bettbezüge waren einst weiß und sind sicher innerhalb von sechs Monaten nicht gewechselt worden. Meine erste Beschäftigung am Vormittag war, daß ich versuchte, meinen zwei Bettbezügen ihre ursprüngliche weiße Farbe zurückzugeben. Ich werde mehrere Versuche benötigen. Den Innendienst müssen wir Dienstgrade nun selbst ausführen. Ich selbst bin für morgen für den Küchendienst eingeteilt. Es sind täglich zehn Mann für die Küche und drei Mann für den Latrinendienst zu stellen. $\mathrm{Zu}$ verdienen gibt es hier nichts, wir erhalten ein Taschengeld von $3 \mathrm{~S}$ im Monat. Allerdings soll es in der Woche drei Flaschen Bier geben.

Samstag, 12. 2. 44

Heute war ich zum Küchendienst eingeteilt, zehn Dienstgrade waren wir, von 6.30 Uhr bis 20.00 Uhr hatten wir vollauf zu tun. Es war das Geschirr für 225 Mann zu spülen, ich machte den Spüler.

\section{Freitag, 25. 2. 44}

Heute sind es bereits 14 Tage, daß wir hier in diesem Lager leben. Wir haben uns an dieses traurige Milieu gewöhnen müssen. Leider hat unser Unterricht aus organisatorischen Gründen noch nicht beginnen können. Die ersten Tage haben wir benutzt, um die „kohlrabenschwarzen" Bettücher wieder in ihren Urzustand zu versetzen. Die Stimmung war in den ersten 
Tagen nicht die beste. Wir bekommen die Schikanen des Amis überall zu spüren. Es beginnt am Morgen damit, daß wir bei der Zählung eine Stunde im Speisesaal sitzen bleiben können, bis die gesamte Zählung im Lager beendet ist. Es beginnt dann das gemeinschaftliche Reinigen unserer Unterkunft. Anschließend wird bis zum Mittagessen gearbeitet. Wir beschäftigen uns selbständig. Leider haben wir auf unserer Bude zu viele Kameraden, die es nicht für nötig halten, sich irgendwie zu beschäftigen. So verbringen sie ihre Zeit damit, von morgens bis abends ihren ,,Dauerskat" zu spielen, dabei wird gestritten, geschimpft und geflucht. So treten sie uns stundenlang auf den Nerven herum. Nach dem Mittagessen wird bis 14.00 Uhr versucht zu schlafen. Um 17.00 Uhr Abendessen mit Zählung. Insofern ist es ja bequem, daß uns die Amis beim Essen zählen und wir nicht, wie im Camp Gruber, morgens und abends auf der Lagerstraße antreten mußten. Anschließend machen wir unseren Abendspaziergang. Es mögen wohl drei bis fünf Runden sein, die wir in unserem Teillager drehen, immer am Drahtzaun entlang. Dahinter nichts als eine weite Ebene, nichts zu sehen, was irgendwie das Auge erfreuen könnte. Wie lange werden wir hier unsere Runden drehen? „Alte Kameraden“" sind es, so ist es Walter Zunke, mein alter Regiments-Kamerad, ,Meister“ Adam, Appel und ich selbst, die die Runden drehen. Es wird über manches gesprochen, meistens sind es schöne vergangene Stunden, die Kraft des Erlebnisses bringt uns so über manche triste Stunde hinweg. - Das ist unser tägliches Einerlei. Wir denken mit Schrecken zurück, als wir am 10. 2. 44 hier das Lagertor passierten und die Landser sahen, die für uns zum Abmarsch bereitstanden, sturen Blickes standen sie am Stacheldraht. Es könnten auch Russen gewesen sein, gerade so sturen Blickes standen sie am Zaun. Mögen wir innere Kraft und Stärke finden, diese Zeit zu überwinden. Am Montag soll unsere Fachschule wieder beginnen. Ich selbst bin beim Lehrgang $A$ für Fortgeschrittene eingeteilt und habe mich für den Lehrgang zur Vorbereitung auf das Abitur gemeldet.

\section{Sonntag, 19. 3. 44}

In den Vormittagsstunden, um 9.00 Uhr, tritt das Bataillon zur Heldengedenkfeier an. Es spricht der Lagerführer Oberfeldwebel Fischer. In kurzen Worten würdigt er die Opfer der Gefallenen. Seine Worte klingen aus mit der Hoffnung und dem Glauben, daß all diese Opfer nicht vergeblich waren und wir uns dieser Opfer würdig erweisen. Der Chor singt das Lied vom ,Guten Kameraden“ während des stillen Gedenkens. Die Worte des Lagerführers klingen mit einem Sieg Heil auf Volk, Führer und Vaterland aus. Auf unserem täglichen Abendspaziergang kommen wir an der Kantine vorbei und sehen zu unserem Schrecken, daß zwei Posten vor der Kantine stehen. Wenig später erfahren wir, daß angeblich die 4. Kompanie vor der Zählung den Speisesaal verlassen hätte. Kurze Zeit später fährt 
ein Lkw vor. Wir sehen zu, wie sämtliche Kisten Bier und Coca-Cola-Kisten aufgeladen werden. Es hat sich allmählich herumgesprochen. Es bilden sich Gruppen und schauen zu. Eine halbe Stunde später ziehen Posten auf und schicken alle in die Baracken. Im weiteren Verlauf werden fünf Kameraden abgeführt, unter Begleitung vieler anwesender Kameraden werden sie zum Tor begleitet.

Das Ganze artet zu einem „Schauspiel“ aus. Eine Kompanie amerikanischer Soldaten marschiert auf. Leutnant Waldow, ein Jude, versucht vergeblich, die Anwesenden zu zerstreuen, großes Gelächter auf allen Seiten. Es erscheint der Bataillonssprecher und versucht zu vermitteln. Die Angelegenheit soll geklärt werden.

Montag, 20. 3. 44

Nach einer Untersuchung beim Oberst, dem Lagerkommandanten, wurden die betr. Unteroffiziere, ich glaube es waren vier, mit je sieben Tagen Arrest bestraft.

Wie mir Kameraden erzählten, unterließen es die anwesenden amerikanischen Offiziere bei der Feier zum Heldengedenktag, beim Absingen der deutschen Nationalhymne eine Ehrenbezeigung zu erweisen. Bei einer Nachfrage des Lagersprechers wurde ihm die Auskunft erteilt, daß ihnen die deutsche Nationalhymne nicht bekannt gewesen wäre. Diese Angelegenheit wird dem in Kürze zu erwartenden Vertreter der Schutzmacht übergeben werden.

\section{Donnerstag, 13. 4. 44}

Unsere morgendlichen Presseberichte, von Unteroffizier Scheidt vorgetragen, melden uns, daß die Ostfront im Süden weiter zurückgelegt wird. Heute hörten wir von der Aufgabe Odessas ${ }^{11}$, nachdem dort alles nachhaltig zerstört worden ist. Wir sind auf das tiefste davon betroffen. Nun steht der Russe an der polnischen Grenze, die Ölfelder von Ploesti liegen in der Reichweite seiner Kampfflugzeuge. Die Ortschaften Kowel und Sewastopol verteidigen sich immer noch! Auf der anderen Seite hoffen wir auf ein weiteres Vorgehen der Japaner im Fernen Osten. Die Invasion scheint vor der Tür zu stehen! Allerdings ist die Streikwelle in England in keiner Weise eingeschränkt. Es sind bereits über zwei Millionen Tonnen Kohle ausgefallen! Die Regierung droht mit der Einziehung der Streikenden.

\section{Montag, 1. 5. 44}

Nachrichten aus dem Osten melden von einem Aufruf Stalins. Er spricht von der Vorbereitung der Russen auf eine Offensive in Verbindung mit ei- 
ner großen gleichzeitigen Offensive im Westen. Bei einem Luftangriff auf Berlin wurden 126 Maschinen abgeschossen. Weitere Nachrichten von den Kriegsschauplätzen fehlen. In einer Notiz wird geschrieben, daß die deutschen Kriegsgefangenen etwas von ihrer Arroganz eingebüßt hätten, mit der sie nach Amerika gekommen wären. Wenn sie am Anfang verlangt hätten, mit dem Deutschen Gruß die amerikanischen Offiziere zu grüßen, so hätten sie sich daran gewöhnen müssen, amerikanisch zu grüßen. - Anmerkung: Was aber nicht stimmt, denn es wurde uns erst in letzter Zeit erlaubt, daß wir die amerikanischen Offiziere mit dem Deutschen Gruß grüBen dürfen! In einer Baracke wurde die Inschrift bemerkt: „,Wer gewinnt den Krieg? - Wir!" Und das, da die deutschen Kriegsgefangenen dieselbe Unterkunft, dieselbe Verpflegung (3200 Kalorien), dieselbe Menge Bier trinken wie die amerikanischen Soldaten. Dann wird von einem weiteren Fehltritt des General Patton berichtet. Damals hatte er einen amerikanischen Soldaten in einem sizilianischen Lazarett in das Gesicht geschlagen, weil er sich von der Front gedrückt hatte. Jetzt weilt er in England und ist dem Stab der Invasions-Armee zugeteilt. Jetzt meint er, daß die amerikanischen Soldaten nur recht viel von den englischen Ladies nach Amerika schreiben sollten, damit die amerikanischen Frauen eifersüchtig würden und von ihrer Seite dazu beitragen würden, daß der Krieg bald beendet wird.

Von Italien hört man, daß die Regierung Badoglio zurückgetreten sei, daß die Kommunisten in der neuen Regierung vertreten sind, Badoglio jedoch wieder Ministerpräsident. ${ }^{12}$ Diese Umbildung soll angeblich auf Druck von Stalin durchgeführt worden sein. Rußland will Sizilien als Stützpunkt erwerben.

\section{Montag, 8. 5.44}

Schlaglichter: Vor etwa einem Jahr wagten die Juden in Warschau, wie die alliierte Presse hervorhebt, einen Aufstand gegen die deutschen Besatzungstruppen der Stadt. ${ }^{13}$ Diesem Aufstand wurden durch eingesetzte deutsche Panzer und Flammenwerfer, die das Warschauer Ghetto ausräucherten, ein schnelles und gründliches Ende bereitet. Die Warschauer Ghetto-Juden jedoch werden jetzt in den alliierten Ländern als ,Helden von Warschau“ gefeiert. Gouverneur und Präsidentschafts-Kandidat Dewey verlas auf einer jüdischen Versammlung eine Ehrung für die jüdischen Helden. Die Welt wird niemals vergessen, wie heldenhaft die Juden von Warschau gegen die Nazis gekämpft haben.

Der US- und Armee-Kaplan Kapitän Lautenschlager, der sich bereits einmal ausgiebig mit den Nazis und POW in der Wochenzeitschrift „LIFE“ befaßt hatte, ließ wieder einmal von sich hören. In einer Versammlung von Kirchenfreunden im Fort Dix erklärte er: „Die gefangenen Nazis sind absolut unsere Feinde und zu allem fähig." Im Verlauf seiner 
Ausführungen warnte er vor irgendwelchen Sympathien für die POW. „Traut ihnen nicht, seid stets vorsichtig, sympathisierendes Verhalten ihnen gegenüber verstößt nicht nur gegen die Gesetze, sondern dient nur dazu, die Gefangenen sowie auch die Militärbehörden in Schwierigkeiten zu bringen. Seid nicht zu freundlich zu ihnen oder, noch besser, lehnt alle derartigen Freundschaften ab. Strenge und Disziplin, wie sie sie in der deutschen Armee gewöhnt waren, ist alles, was diese kennen." Der Kaplan wies ferner noch darauf hin, daß die größte Zahl der Gefangenen den Krieg seit seinem Beginn mitgemacht hätte und daß man keine große Einbildungskraft benötige, um den Gedankengang und die politische Überzeugung dieser Männer zu erraten.

Wehrmachtsbericht vom 3. 5. 44: $:^{14}$ Auf beiden Seiten des mittleren Siret begannen die Russen mit starken Kräften die erwartete Offensive. Der geplante Durchbruch wurde von deutschen und rumänischen Truppen abgeschlagen. Die Truppen gingen zu erfolgreichen Gegenangriffen über. 160 feindliche Panzer wurden vernichtet, davon 65 durch deutsche und rumänische Schlachtflieger.

\section{Donnerstag, 18. 5.44}

Seit einer Woche haben wir unter einer starken Hitze zu leiden. Über Nacht kam sie und hat uns erfaßt. Ist es in den Morgenstunden noch auszuhalten, so ist die Zeit von 12.00 bis $17.00 \mathrm{Uhr}$ wohl die unerträglichste. Noch führen wir unseren Unterricht bis um 12.00 Uhr durch. Doch es mehren sich die Stimmen, die nach Ferien schreien. Ganz träge Geister meinen, es sollten bis September Ferien gemacht werden. Man muß sich schon schwer zusammenreißen, um die Hausaufgaben zu verrichten, hätte es doch in den heimatlichen Breitengraden bei dieser Hitze schon längst „Hitzeferien“ gegeben, doch hier fängt die Hitze erst an. Die Gemüter sind gereizter und erregter geworden. Über Nacht gab es Streit, Zank und Zwistigkeiten. Waren die Dinge täglich nichts Neues, so treten sie jetzt häufiger in Erscheinung. Unser ,hysterischer Hausdrachen“ H., Herkunft München, provoziert uns, die „Schüler“", wo er steht und liegt. Flüche gebraucht er, man könnte ein Lexikon schreiben, geht aber jeden Sonntag zur Kirche. Bekam von seiner Schwester aus den USA einen Rosenkranz und einen echten amerikanischen Talisman geschickt, worüber er sehr stolz ist. Für ihn gibt es noch immer, selbst nach elf Jahren ,Machtübernahme“, eine „Mainlinie“ und ,ein katholisches Bayern“, und er sieht voll Verachtung auf uns ,,protestantische Preußen“ herab.

Staub überall, täglich geht etwa um 14.00 Uhr eine Windhose durch das Lager. Dann ertönt der Schreckensruf: Fenster zu! Doch überall dieser rötliche Staub in der Baracke. Es gibt nichts, was ihn zurückhalten könnte. Er ist unser täglicher Begleiter geworden. Besonders in den Nachmittagsstunden wehen die Passatwinde sehr stark. Staubfontänen von großer Dichte und Schnelligkeit ziehen durch das Lager. 
Jetzt in den letzten Tagen des Monats Mai liegt nun das erste Jahr unserer Kriegsgefangenschaft hinter uns. Für uns gab es Zeit und Muße, Rückschau zu halten. In diesem vergangenen Jahr haben wir die ersten bittersten Stunden der Gefangenschaft gekostet. Mußten erleben, wie eine militärische Moral zusammenbrach. Was einem zehn Jahre etwas bedeutete, unter dem man groß geworden, man stand urplötzlich vor Trümmern. Es waren die Zeiten der frühesten Jugendzeit, da man den Kommunismus erlebte und dann durch die ,Machtübernahme“ verschwinden sah, plötzlich stand dieses Schreckgespenst in den eigenen Reihen von deutschen Kriegsgefangenen. Soldaten der „Bewährungsbataillone“ waren es, politisch Vorbestrafte, denen man die Chance der Bewährung gegeben hatte, sie waren es, die uns wieder enttäuschten und unter deren Auswirkungen wir zu leiden hatten. Glaubten in den ersten Tagen Landser und Unteroffiziere jetzt ihre Zeit gekommen, gegen die Dienstgrade ihre Trumpfkarte auszuspielen, so war das anfangs eine Nebenerscheinung. Leider gab es genug Dienstgrade, die dazu genug Anlaß gegeben hatten, sog. „Stacheldraht-Dienstgrade", die hinter dem Draht auf manch unsaubere Art und Weise zu ihren Tressen und Sternen gekommen waren. Fiel in dieser Zeit jegliche Maske von jedermann, der innere Kern eines jeden lag nackt und häßlich vor einem. So hatte und mußte man sich an diese Zeiten gewöhnen, besonders schwer für solch einen, der eine saubere Kinderstube und reine Vergangenheit hinter sich gebracht hatte. Daher nicht verwunderlich, wenn Kameraden mit anständigem Charakter und gesunder soldatischer Ehrauffassung es unterließen, hier eine Änderung herbeizuführen. Waren in den Durchgangslagern die Bande zueinander nur sehr locker, so entstand im Stammlager ein gewisser Zusammenhalt. Jeder militärische Ton war strengstens verpönt, ja nicht an die Zeiten erinnern, da man noch Soldat war, jetzt war man doch POW im freien Amerika, dem Land der freien Meinungsäußerung. Na und das bekam man auch zu hören! Landser, die wohl früher nie das Maul aufgemacht hätten, hielten ihre Zeit für gekommen, einen Dienstgrad anzuschreien. Als Aufsicht beim Arbeitsdienst aber stand man zwischen zwei Feuern, dem Amerikaner und dem Landser, $z u$ dem sich in den meisten Fällen der Unteroffizier hinzugesellte. Er besaß nicht genug Größe, um seine Stellung als Unteroffizier dem Landser gegenüber zu behaupten. Unfruchtbare Debatten, wo man stand und schlief. $\mathrm{Zu}$ jeder Tages- und Nachtzeit, um selbst damit die Ruhe der Kameraden zu stören. Das ewig alte und junge Thema ,Nr. 1“ auch in der Kriegsgefangenschaft. Die Schuld am Zusammenbruch in Afrika, jetzt wußte man es ganz genau! Dann aber die großen Strategen, denen es ausgezeichnet gegangen war und die irgendwo in der Etappe einen guten Tag gelebt hatten. Die hätten nun alles besser gemacht. Sie sahen Fehler, wo es keine gab, und sahen nicht die Fehler, wo sie tatsächlich waren. Dann aber kam die Zeit, da an Türen gelauscht wurde, um zu denunzieren. - Es kam die Zeit, da es anfing zu weihnachten, auf einem 
Breitengrad, wo es keinen Schnee gab. Das deutscheste aller deutschen Feste aber vereinte uns unter dem brennenden Lichterbaum und ließ uns als Kameraden in der deutschen Uniform erscheinen. Dieses Erleben ließ alle Widrigkeiten vergessen, es verband uns mit der Heimat und ließ uns hoffen, das nächste Fest im Kreise unserer Lieben in der Heimat zu erleben. Die erfrischenden, kalten Tage gingen vorüber, und noch immer hatte man keine Post erhalten. Proteste auf Proteste. Am Tage meines Geburtstages die Versetzung in ein anderes Lager, Tonkawa im Staate Oklahoma, und damit wieder ein neues Umfeld. Jetzt wurde es uns klar, was wir aufgeben mußten, ein eigenes Spiegelbild einer deutschen Seele. Wir hatten ein Lager verlassen müssen, dem unsere Seele, unser eigenes Ich den Stempel aufgedrückt hatte. Hatten aus einer unkrautverwucherten Landschaft das dunkelste Grün hervorgezaubert. Hatten an der Lagerstraße, vor den Baracken, symbolhafte Denkmäler deutschen Kulturschaffens errichtet, damit zu beweisen, daß wir unsere Heimat und unser Heim nicht vergessen hatten. Unser Stolz eines jeden Teil-Lagers aber war unser Theater. In kürzester Zeit fertiggestellt. Es war die Stätte innerer Einkehr, Freude und Entspannung. Es war die Quelle zu neuem Hoffen. Das gezeigte Niveau aber stieg von Aufführung zu Aufführung. Die Perlen aber waren jeweils die Kapellen. Sie hatten es nach wochenlanger Arbeit und Üben zu einer bedeutenden Höhe gebracht. So war es die Musik, die in uns Erinnerungen erweckte, da wir glücklichste Stunden erleben durften. Dann tauchten Melodien auf, die uns gleichsam mit den süßen Worten einer Geliebten das Ohr berührten. Schemenhaft stieg deutsche Landschaft, deutsches Leben und Fröhlichsein in uns auf, und das alles mußten wir verlassen. Hier fanden wir nichts von dem! Grau und düster das Lager, verstockt und düster aber, was in den Baracken wohnte. Kein Wunder, wenn gleich zu Anfang es zu kleinen Zusammenstößen mit den , lieben“ Kameraden kam. Doch nun haben wir uns auch daran gewöhnen müssen. Für uns oder, besser gesagt, für einen kleinen Teil bedeutet unsere Schule bzw. Fortbildung alles. Sie erhält unser Wissen und bereichert uns mit neuem Stoff. Sie bereitet uns für die Zeit vor, da wir wieder in der Heimat sein und unsere Abschlußprüfungen ablegen werden. Sie gibt uns anregungsvolle Stunden. Sie bringt uns deutsches Wissen, Geist und Können nahe. Die Lehrbücher, nur in sehr geringer Zahl vorhanden, sind Sendboten unserer deutschen Heimat. Wir wissen dort das DRK, für das wir reichlich gespendet, da wir noch an den Fronten gestanden, jetzt von seinen segensreichen Einrichtungen selbst eine gewisse Kraft schöpfen können. Ich selbst befinde mich in einem kleinen Studienkreis, dem der Anwärter auf das Abitur. Möge diese Arbeit nicht vergebens sein, mögen wir einst die Lorbeeren in der Heimat ernten. Wenn wir auch zum Gespött der ,lieben“ Kameraden an unserer nicht leichten Aufgabe festhalten, an uns selbst glauben und nicht irre werden, dann kann der Erfolg nicht ausbleiben. Entspannung und Zerstreuung aber bringt uns unsere Bibliothek. Sie 
umfaßt die gesamte deutsche Literatur und ergänzt und vertieft unser Wissen. Sie bringt uns die deutsche Landschaft, die wir nirgends in der Welt wieder finden konnten, nach der wir uns so sehnen und hoffen, sie bald wieder zu erleben.

Seit Monaten beschäftigt sich die amerikanische Welt mit dem Beginn der Invasion. ${ }^{15}$ Schon längst haben sie es erkannt, daß ihr Ausgang die Kriegsentscheidung, vielleicht sogar das Kriegsende bringen kann, mindestens aber in Europa. So hoffen wir, daß die Macht des Schicksals der gerechten Sache den Sieg verleihen möge, und das mag wohl niemand bestreiten, daß es die unsere ist.

\section{Sonntag, 21. 5.44}

Das Teil-Lager II verläßt uns und wird in zwei Teile aufgeteilt. 45 Mann von der Kompanie sollen zurückbleiben. Wir sollen angeblich nach Camp Gruber kommen.

\section{Donnerstag, 25. 5.44}

Heute haben wir nun Reisetag. Gestern abend wurde schon alles gepackt. In den Vormittagsstunden verlassen wir das Lager. Am Tor müssen wir einzeln passieren, da wir mit unserem Steckbrief verglichen werden. Die Amis sind mißtrauisch geworden. Es beginnt nun der langwierige Untersuchungsakt. Die Amis sehen alles gründlich nach und packen auch alles an. Ich selbst will versuchen durchzurutschen, tatsächlich, es gelingt mir, auch ohne Filzung zu passieren. Wir liegen nun in der Mittagshitze und warten auf unseren Abmarsch zum Bahnhof. Unser Kamerad Otto Krämer ist aus unserem Kreis ausgeschieden. Er hatte einen guten Posten gefunden und blieb mit seinem neuen Freund Kurt Trummer zurück. Am Morgen verabschiedete er sich unter Tränen! Höre und schreibe! Aber die Tränen flossen bei ihm schon immer reichlich! Endlich gegen $14.00 \mathrm{Uhr}$ marschieren wir in Gruppen zu 50 Mann zum Bahnhof, doch erst um 17.00 Uhr setzt sich der Zug in Bewegung. Für uns ist die Fahrt eine schöne Abwechslung, und wir freuen uns am herrlichen Grün der Landschaft. Der Zug hält oft, die Stimmung ist gut.

\section{Freitag, 26. 5. 44}

Wir sind schon sehr früh wach. Jeder hat sein Nickerchen mehrmals unterbrechen müssen. Die Lage zum Schlafen war nicht die beste, um durchschlafen zu können. Die Landschaft ist inzwischen sehr hügelig geworden. Wir kennen uns nicht mehr aus. Wir zweifeln nun allen Ernstes, daß wir 
nach Camp Gruber kommen. Gegen 7.00 Uhr aber tauchen plötzlich die altbekannten Wachtürme auf. Mit einem Schlage kennen wir uns aus. Wir formieren uns in Marschordnung, gute 20 Minuten brauchen wir zum Lager. Wir, die alten "Camp-Gruber-Leute", sind sehr erfreut, in eine uns bekannte Gegend zu kommen. Hier ist uns nun fast jeder Weg und Steg bekannt, manche Erinnerung verbindet uns mit diesem Lager. Jetzt taucht für uns die große Frage auf, in welches Teil-Lager wir kommen werden. Da sehen wir auch schon die drei Kompanien zum Tor marschieren, also werden wir zum Teil-Lager III kommen. Und richtig, wir passieren das Tor, alles drängt sich an den Zaun. Viele alte Kameraden sehen wir beim Vorbeimarschieren. Es herrscht ein großes Hallo, freudige Begrüßungsszenen, man hatte uns also doch nicht vergessen. Die ,Filzung“ ist nur sehr flüchtig. Wir werden in den Bereich der 10. Kompanie eingeteilt. Leider konnten wir vier Kameraden, Zunke, Adam, Hammoser und ich, nicht zusammenbleiben, aber ich bin mit dem Kameraden Hammoser, meinem „Studienkollegen“, in der gleichen Kompanie. Mich wählte man zum „,Barackenältesten“.

Gegen Mittag treffen wir am Zaun des Teil-Lagers II alte Kameraden von der ehemaligen 10. Kompanie, die jetzt mit den Resten des Teil-Lagers III zur 1.Kompanie zusammengefaßt wurden. Ich treffe Hausner, Carstensen (ehemaliger Batterie-Kamerad) und Oberschelp (der „CelloSpieler").

Pfingstsonntag, 28. 5. 44

Am Abend fand die Wahl des Vertrauensmannes für das Lager III statt. Es standen zur Wahl: Wachtmeister Fricke von der 10. Kompanie, Wachtmeister Hohenberger von der 12. Kompanie und Oberfeldwebel Wilke von der 10. Kompanie. Als Hauptthema stand zur Debatte: Wird gearbeitet oder wird nicht gearbeitet. Nach einer Rundfrage hatten sich vom gesamten Lager sieben Mann gemeldet, die gegen Ableistung einer Unterschrift sich auf 30 bzw. 90 Tage verpflichtet hätten. Ein Zehntel, also etwa 100 Mann, hätten ohne Unterschrift sich verpflichtet zu arbeiten. Von den Hauptrednern wurde die These aufgestellt, daß man, nachdem man uns zu „Rebellen“ abgestempelt hat, es ablehnt, jegliche Arbeit zu leisten. Damit kam also nur ein Vertrauensmann in Frage, der dieselbe Einstellung vertrat. Gleichzeitig aber wurde verlangt, daß dieser Mann zugleich die Rolle eines Lagerführers einnimmt. Nach vielem Hin und Her wurde Oberfeldwebel Wilke gewählt, der sich als ,alter Nazi" bezeichnete und bereits auch eine „POW-Geschichte“ hinter sich hatte, wie er es so schön sagte. Es wurde dann einstimmig beschlossen, jegliche bezahlte Arbeit außerhalb des Lagers abzulehnen. 
Gegen 13.30 Uhr wurde das gesamte Lager III zusammengerufen. Der Kommandant des Lagers sprach zu uns. Einmalig in unserer POW-Geschichte. Wir waren auf dem Sportplatz angetreten. Man stellte eine Bank vor uns auf. In Begleitung einiger Offiziere stieg der Oberst auf diese Bank und sprach in englischer Sprache zu uns. Ein Dolmetscher aus unseren Reihen übersetzte den Text. Er führte aus, daß wir unser Leben hier im Lager selbst gestalten könnten und sie selbst bestrebt wären, die Genfer Konvention zu erfüllen. Dann kam er zum Hauptthema, das Arbeitsproblem. Es würden ca. 140 Mann für ein Farmkommando gebraucht werden. Die Unteroffiziere, die da arbeiten wollten, müßten sich für 30 oder 90 Tage verpflichten. Diese kämen dann in das Lager II oder I. Weiter führte er aus, daß die Regale der Kantine wohlgefüllt wären mit Waren. Doch sollten wir bedenken, wenn wir nicht arbeiten, müßten wir mit unseren drei Dollar auskommen. Es gäbe Bier und dergleichen mehr, das alles müßte dann beschränkt werden, wenn wir uns nicht verpflichten würden. Weiter führte er aus, daß unser Lager geschlossen bliebe und wir mit den anderen nicht in Berührung kämen. Wir müßten $20 \mathrm{Fuß}$ vom Zaun $\mathrm{Ab}$ stand halten. Sollten diese Befehle nicht ausgeführt werden, dann würde er es mit Disziplinarstrafen ahnden.

Nach dem Abendessen stellte sich der neugewählte Lagerführer des Teil-Lagers III, Oberfeldwebel Wilke, der 10.Kompanie im Speisesaal vor. Er führte aus, daß man sich bei der gestrigen Debatte der Barackenund Kompanie-Führer darüber einig geworden war, als Unteroffiziere jegliche Arbeit abzulehnen. Er selbst sei mit dieser seiner eigenen These als Vertrauensmann gewählt worden und werde diese rücksichtslos durchführen. Er sprach von denen, die da für den Amerikaner arbeiten wollen, in einer sehr abfälligen Form. Sie mag vom Standpunkt ausgehen, daß jegliche Arbeit für den Amerikaner eine Unterstützung wäre und damit ein Amerikaner für Europa frei würde. Wenn selbst ein Oberst zu uns spricht, daß wir uns zur Arbeit verpflichten sollten, dann ist das ein Beweis, daß Amerika auf die Arbeit jedes einzelnen Kriegsgefangenen angewiesen wäre. Daß man uns Uhren, Bier und dergleichen mehr in die Kantine schickt, das alles wären nur Lockmittel. Es ist daher mit der Ehre eines jeden deutschen Unteroffiziers unvereinbar, daß er sich zu einer Arbeit verpflichtet. Sollten doch etliche unter uns sein, die da arbeiten wollten, dann sollten sie es tun. Er würde für alle „Kameraden“ ein Ehrengeleit bis zum Tor stellen. Es würde ihnen nichts passieren. Die Anschauung der ,Gruber-Leute" geht zu dieser krassen Einstellung auseinander. Wir kennen hier diese Verhältnisse am besten, denn die Arbeit, die von uns im allgemeinen geleistet wurde, war nichts als eine „Arbeitsbeschäftigungs-Therapie". Aus dieser sturen Einstellung heraus müssen wir mit allerlei Repressalien rechnen. Es bleibt daher abzuwarten, wie sich das eine Zehntel der 
„Arbeitswilligen" verhalten wird und was der Amerikaner unternehmen wird.

Bei einer Rücksprache mit unserem ehemaligen Kompanie-Führer der 11. Kompanie, Oberfeldwebel Hausner, der jetzt die Tätigkeit des Regimentssprechers ausübt, erklärte uns dieser, daß unser neuer Lagersprecher einverstanden wäre, daß Unteroffiziere eine Arbeit, die ihrem Rang entspricht, annehmen könnten. Man sprach darüber, daß man eine Aufstellung vom Amerikaner verlange, in der diese Arbeiten genau festgelegt werden müßten. Von dieser Aussprache wurde jedoch in der programmatischen Rede des Oberfeldwebels Wilke nichts erwähnt. Wer wickelt wen ein? Das fragen wir uns, die Kameraden Zunke, „Meister“ Adam und ich. Wir hatten uns wohlweislich beim Hausner von dieser Aussprache unterrichtet, die der 0. a. Rede vorangegangen war.

Am Abend gab es den ersten Zwischenfall. Einige Leute waren am Zaun zwischen Lager III und II zu dicht herangetreten. Es hatte die Folge, daß ein Kommando von 40 Amis aufzog, um dem Befehl des Oberst, 20 Fuß Abstand zu halten, entsprechenden Nachdruck zu verschaffen.

\section{Dienstag, 20. 6. 44}

Seit den vergangenen 14 Tagen werden wir von den Ereignissen der Invasion beherrscht. Stehen drei oder vier Mann zusammen, über was wird wohl gesprochen? Doch nur über die Invasion. Unserem Nachrichtendienst war es weiterhin möglich, uns aus der „New York Times" Nachrichten zu übermitteln. Auch soll angeblich ein Rundfunkapparat im Lager sich befinden, der auf Kurzwelle umgebaut wurde und deutsche Nachrichten empfängt. Auf einer Karte, die sich im Unterhaltungsraum befindet, können wir die kriegerischen Ereignisse verfolgen. Kleine Fähnchen in den Nationalfarben zeigen uns den Frontverlauf. Der ursprüngliche Brückenkopf hat sich verkleinert, ungefähr westlich von Deauville bis in die Bucht von Cherbourg. Diese Hafenstadt soll abgeschnitten sein. Weiter hörten wir vom Absprung einer überschweren Fallschirmjäger-Division in der Nähe von Paris. In diesen Absprung aber sprang eine deutsche Fallschirmjäger-Division und vernichtete die feindliche Division, die $\mathbf{P a}-$ ris von den Deutschen befreien sollte. Weiter hören wir von den ungeheuren Verlusten der Alliierten am Kanal und Brückenkopf, hörten, daß die Franzosen sich weigerten, die Toten der Alliierten zu bestatten. Wir hören, da $B$ es den Deutschen nicht möglich sei, ihre Toten zu beerdigen, sondern könnten sie nur mit einer Chlorschicht bestreuen. Die ungeheuren Gefangenenmassen müßten an den französischen Städten vorbeigeführt werden, um sie vor der Wut der Einwohner zu schützen! Da aber kam für uns die große Überraschung, seit einer Woche ungefähr hämmern deutsche Raketengeschütze auf die englische Südküste als Vergeltung für die vielen Terrorangriffe auf deutsche Städte. Auch London soll von den Raketen er- 
reicht werden. ${ }^{16}$ Diese Nachricht wurde mit großem Jubel aufgenommen. Wir können uns in die Lage unserer Heimat versetzen, die im letzten Jahr unter den massierten Angriffen der Herrn Amerikaner und Engländer zu leiden hatte. Aber England wird die ganze Last des Krieges zu spüren bekommen, hatte der Führer in einer seiner letzten Reden ausgeführt. Nun hämmern deutsche Raketengeschütze pausenlos auf die Hauptstadt von England. - Mehr denn je sind unsere Gedanken und Wünsche bei Front und Heimat. Wir wissen, daß die Kameraden unser Schicksal entscheiden. Wir wissen, daß die Heimat uns bald heimholen wird. - Vom russischen Kriegsschauplatz hören wir von einer Offensive im Nordabschnitt, an der finnischen Südflanke. In Italien wurde Rom aufgegeben. ${ }^{17}$ Die deutschen Truppen zogen sich mit „Erfolg“ in weiter zurückgelegene Stellungen zurück. Ein Durchbruch der Alliierten gelang bisher nicht, trotz heftigster Versuche.

\section{Sonntag, 25. 6. 44}

Nach dem Essen teilt uns der Lagerführer den Inhalt seiner Unterredung mit dem Lagerkommandanten mit. Gestern wurde er zum Kommandanten gerufen wegen der Beschwerde, die über diesen beim Roten Kreuz geführt wurde. Diese Beschwerde hatte die Vorgänge zum Inhalt, die sich bei unserer Ankunft ergeben hatten. U.a. die Worte, die er bei seiner Ansprache zum Ausdruck brachte, wenn die „20-Fuß-Zone“ ab Zaun nicht eingehalten würde, der Posten vom MG Gebrauch machen würde. Dann die weitere Äußerung zum Lagerführer, daß die „Genfer Konvention“ für ihn Gummi wäre und sich ziehen und dehnen lasse. Jetzt fragt er, wie man zu dieser Beschwerde käme, denn das hätte er gar nicht gesagt. Der Dolmetscher habe falsch übersetzt und werde nun versetzt werden. Sollte die Beschwerde nicht zurückgenommen werden, werde er den Lagerführer versetzen und einige hundert Mann, es käme ihm nicht darauf an. Vor dieser Unterredung mit dem Kommandanten hatte der Lagersprecher eine Besprechung mit dem Dolmetscher, über deren Inhalt nichts bekannt wurde.

Seit einigen Tagen herrscht eine unverschämte Hitzewelle, es mögen wohl $49^{\circ} \mathrm{C}$ im Schatten sein. Von der Invasion hören wir, daß seit dem 15.6. 44 London und die Südküste ununterbrochen beschossen wird. Es wurde sogar von Flüchtlingen gesprochen, die an der Küste von Holland und Belgien gelandet wären. Bei den letzten Nachrichten hörten wir von einer Notiz aus einer amerikanischen Zeitschrift. Darin schlug ein deutscher Emigrant vor, um die Moral der deutschen Kriegsgefangenen und den Einfluß der Nazis zu brechen, müßte man die Deutschen aus den neugewonnenen Wohngebieten von denen des Altreiches trennen. Weiter befürchtet man, wenn man die deutschen Kriegsgefangenen zu sehr mit den demokratischen Idealen vertraut machen würde, dann müßte man mit Ge- 
genmaßnahmen der deutschen Regierung rechnen. Dann könnten die amerikanischen Kriegsgefangenen als überzeugte Nazis zurückkehren. Weiter gab man eine Meldung wieder, wonach die Russen sehr gute Erfolge mit ihren „Bekehrungen“ gehabt hätten, denn bereits $90 \%$ wären zum Kommunismus übergetreten.

\section{Donnerstag, 20. 7. 44}

In der vergangenen Nacht sind von der 9. bis 12. Kompanie je ein Mann und vom Lager I 22 Mann durch den Zaun gegangen. Wir haben bisher nichts von ihnen gehört. - In den Abendstunden hören wir von einem Attentat auf den Führer. Vier Offiziere aus seiner Begleitung sind verletzt bzw. tot, der Führer selbst soll Brandwunden davongetragen haben. Nähere Nachricht sollen wir morgen hören. Wir sind zutiefst erschüttert!

\section{Freitag, 21. 7. 44}

Nach dem Frühstück hören wir im Nachrichtendienst, daß auf den Führer ein Attentat verübt wurde. Eine Proklamation an das deutsche Volk wurde über den Rundfunk verbreitet. Wir sollen sie morgen hören. - Weiter hören wir, daß London seinen bisher schwersten Angriff erlebte. ${ }^{18}$ Die V-Geschosse sollen in solch einer Masse niedergegangen sein wie bei einem starken Artillerie-Feuer. Stärkste Angriffe der Alliierten am Brückenkopf. - Gegen 14.00 Uhr fand bei uns im Lager III eine plötzliche Untersuchung unseres Gepäcks statt. Ich kam ungeschoren durch.

\section{Samstag, 22. 7. 44}

Nach dem Frühstück hören wir die Proklamation des Führers. Er hatte selbst zum deutschen Volk gesprochen, um damit allen Gerüchten ein Ende zu bereiten. In kurzen Worten hören wir, daß durch die Aufopferung von vier Offizieren aus seiner Umgebung ihm das Leben gerettet wurde und er nur mit Brandwunden davonkam. Der Führer führte aus, daß er wisse, woher dieser Anschlag käme, und daß England nun die Folgen aus diesem Attentat zu spüren bekäme. Der Papst habe ein Glückwunschschreiben gesandt. Der Nachrichtendienst brachte erstmalig, daß London von der V1 salvenartig beschossen würde.

\section{Dienstag, 25. 7. 44}

Heute früh hören wir die Wiedergabe der Proklamation des Führers aus der „New York Times“. Es werden die Hintergründe des Attentats dem deutschen Volk aufgedeckt. Der Oberstleutnant von Stauffenberg vertrat 
eine Clique von davongejagten deutschen Generälen, die sich als unfähig erwiesen hatten. Diese wollten die Macht an sich reißen. Wir hören, daß Reichsführer SS Himmler das Ersatzheer übernommen habe, Guderian Generalstabs-Chef geworden ist. ${ }^{19}$ Es wird das deutsche Volk aufgefordert, dort, wo es Verräter gibt, sie sofort festzunehmen und wenn es sein muß zu töten. Wir sind beeindruckt, daß dieser Anschlag doch einen gewissen Kreis erfaßt hat.

Gestern kamen 27 Mann aus dem ,Nazi-Lager“ Alwa. Sie kamen in das Lager I. Es sollen sechs bis acht Mann unter ihnen sein, die arbeiten wollen. Wer weiß, ob die anderen nicht dort bleiben? - Heute abend erleben wir die erste Operette. „Madlon“ nach der Operette „Meine Schwester und Ich" in vier Bildern, frei gestaltet. Es war das Beste, was bisher aufgeführt wurde. Die Theatergemeinschaft hatte sich wahrhaft zusammengefunden und bescherte uns ein frohes Spiel mit Musik, Tanz und Charme. Dazwischen Balletteinlagen, ein Csárdás-Tanz mit einer reizenden Ungarin, die so echt wirkte in ihrem Aussehen, voll Feuer und Temperament, daß man vergaß, daß es ein junger Mann war. Es war wie in einem Märchen. Das erste Bild führt uns vor die Schranken eines Gerichtes. Hier klagt ein junger Kapellmeister auf Scheidung von seiner Frau, einer Prinzessin. Wie es zur Heirat kam, das zeigt uns das zweite Bild. Ein junger Kapellmeister ist bei einer Prinzessin als Bibliothekar angestellt, verdient ein fürstliches Geld, doch er hat Hemmungen. Im dritten Bild flieht er vor ihr in eine andere Stadt. Sie gibt ihm ein Päckchen mit für ihre Schwester, die als Schuhverkäuferin dort beschäftigt ist. Sie selbst spielt diese Rolle im dritten Bild. Sie verlieben sich auf den ersten Blick, es kommt zur Heirat. Das Rätsel löst sich. Im letzten Bild aber überzeugt das Hohe Gericht den Gemahl von der echten Liebe, und es kommt zur Aussöhnung.

\section{Samstag, 29. 7.44}

Vor zwei Tagen hörten wir durch den amerikanischen Pressedienst Auszüge aus der Rede von Dr. Goebbels, die er vor dem deutschen Volk über den Rundfunk hielt. Er sprach davon, daß nun der ,,totale Krieg ${ }^{* 20}$ in sein Endstadium getreten sei. Wir selbst würden in Kürze mit neuen Vergeltungswaffen aufwarten. Er selbst habe Gelegenheit gehabt, diese zu besichtigen. Für einen Augenblick drohte ihm das Herz stillzustehen, diese Waffen seien eine Wende in der Kriegsführung. Er sprach die Erwartung aus, daß die Heimat noch mehr ihre Pflicht tue und alles tue, um den Endsieg zu erringen. Es wurde weiter bekannt, daß Gen.-Oberst Beck und Höppner beim Putsch mit verwickelt wären. Beck hat durch Selbstmord seinem Leben ein Ende bereitet, gegen Höppner schwebe das Verfahren. Im Osten haben die Russen die Gouvernementsgrenze überschritten. Sie sind bereits über Lemberg nach Westen gestoßen, stehen weiter bei BrestLitowsk. ${ }^{21}$ Wann werden sie zum Stehen gebracht? Das fragen wir uns. 
Auf dem Brückenkopf herrschen laufend Offensiven, die aber jeweils zerschlagen werden. Die V 1-Waffe schießt im verstärkten Maße auf Südengland und London.

\section{Sonntag, 30.7. 44}

In der vergangenen Nacht wurde auf Oberfeldwebel Hausner, Wachtmeister Carstensen und Schmidt ein Anschlag von unbekannten Tätern in der Stärke von sechs Mann verübt. Oberschelp und Schmidt wurden in das Lazarett eingeliefert. Hausner hatte zuvor sein Bett gewechselt und hatte das wenigste abbekommen. Hausner wurde heute in der Frühe mit noch weiteren 15 Mann auf ein Außenarbeitskommando versetzt. Die 1. Kompanie hat eine ziemlich geschlossene Haltung für Hausner eingenommen. Die Folge war, daß die Spieler der 1.Kompanie am Btl.-Turnier des I. und III. Teil-Lagers nicht teilnahmen. Im Kleinen Theater fand um 21.30 Uhr eine Dichterlesung statt. Es wurde die Novelle von R. G. Binding „St. Georgs Stellvertreter“ gelesen.

\section{Montag, 31. 7. 44}

Nach dem Zählappell fand eine ärztliche Untersuchung des gesamten Teil-Lagers III statt. Es wurden Stich-, Hieb- und Kratzwunden gesucht. Anschließend hörten wir die Rede von Dr. Goebbels aus der „New York Times". Ihr Inhalt gab uns vieles und ließ uns wieder hoffnungsvoll in die nahe Zukunft schauen. Es wurden in dieser Rede die Hintergründe des Attentats vom 20. Juli 1944 aufgedeckt. Weiter der totale Einsatz der Heimatfront und Rüstung.

Ich hatte gehört, daß auch Wachtmeister Carstensen etwas abgekriegt hätte. Bei Anbruch der Dunkelheit gehe ich durch den Zaun zum Lager I, um mich über das Befinden von Hans C. zu erkundigen. Ihm selbst geht es gut. Er bekam im Schlaf eins über den Rücken. Er schildert mir ausführlich den Vorgang. Demnach drangen gegen 1.30 Uhr sechs Mann in den Schlafraum. Die Tür war verschlossen und mußte erst aufgebrochen werden. Die Überfallenen befanden sich im tiefsten Schlaf und wurden bereits im Bett mit Knüppeln überfallen, so daß an Widerstand nicht zu denken war. Das Ganze spielte sich in etwa zwei Minuten ab. Auf die Hilferufe der Überfallenen eilten Angehörige der 1. Kompanie zu Hilfe, kamen aber zu spät. Im Freien wurden starke Knüppel und ein langes feststehendes Küchenmesser gefunden. Schmidt und Oberschelp waren in Ohnmacht gefallen. Schmidt mußte in das Lazarett eingeliefert werden. Die Verbitterung ist bei der 1. Kompanie sehr groß. Durch Äußerungen des Feldwebel Kr. hat sich eine große Feindschaft zwischen 3. und 1. Kompanie entwickelt. Das Teil-Lager III soll mit drei Mann am Überfall beteiligt gewesen sein. Ich erfahre nähere Einzelheiten über die beiden deutschen 
Ärzte, die seit einigen Tagen sich im Lazarett hinter Draht befinden. Ihnen ist der Zugang zum Lager verboten worden. Durch den Putzer sind zwei Briefe mit verfänglichem Inhalt durch den Amerikaner abgefangen worden. Der Stabsarzt selbst hatte auf Führung des gesamten Lagers größten Wert gelegt. Dies hatte sich Hausner in seiner Eigenschaft als Lagersprecher höflichst verbeten. Das waren die Anfänge, die zum Sturz des Hausner führten. Der Ami hat angekündigt, bei weiteren Zwischenfällen mit MG-Feuer in das Lager zu schießen.

Sonntag, 6. 8. 44

Die Versetzung des Lagers III ist nun Wirklichkeit geworden. Die 10. und 11. Kompanie sollen nach Texas kommen, ca. 500 Meilen von hier entfernt. Es soll ein Waldlager sein und nur mit 500 Mann belegt werden. Morgen müssen um 13.00 Uhr die Seesäcke abgegeben werden.

\section{Mittwoch, 9. 8. 44}

Bereits um 5.00 Uhr war Wecken. Gegen 9.30 Uhr verlassen wir das Lager und marschieren zur Verladestelle. Das Küchenkommando fuhr mit dem Wagen voraus. Es werden zwei Küchenwagen mitgeführt, und wir erhalten warme Verpflegung während der Fahrt. Gegen 10.30 Uhr setzt sich der Zug in Bewegung. Unser Ziel heißt Brady.

Die Versorgung ist tadellos. Bis zum Nachmittag haben wir bereits viermal Eisgetränke erhalten. Zu Mittag gab es eine Gulaschsuppe mit einer Ananasscheibe. Die Hitze ist fast unerträglich. Nur gut, daß der Ventilator für Luftbewegung sorgt. Das Trinkwasser im Automaten wird laufend durch frisches Eis gekühlt. Die Posten sind erstmalig sehr großzügig, denn wir brauchen nicht mehr den Finger hochheben, wenn wir auf den Lokus wollen, wie es bisher so üblich war. Unsere Fahrt geht über die Orte Wagona - Claremore - Tulsa (13.15 Uhr) - Sherman (20.15 Uhr) - Dallas (23.30 Uhr). Das Abendbrot besteht aus einer Pellkartoffel, einer Scheibe Fleisch, roten Rüben, einer sauren Gurke, zwei Scheiben Weißbrot; als Getränk einen fabelhaften Bohnenkaffee mit Milch.

\section{Donnerstag, 10.8. 44}

Die Landschaft hat sich grundlegend geändert. Wir haben den Staat Texas erreicht. Ausgesprochene Buschlandschaft, endlose Steppengebiete, zwischendurch weite Maisfelder. Kakteen wuchern zwischen freiliegenden Felsplatten. Die Bevölkerung besteht zum Teil aus Indianern, Mestizen, Mulatten und Amerikanern. Wir sehen nur noch armselige Bretterbuden. Zwischendurch passieren wir einige größere Ortschaften. Unsere Gesich- 
ter werden immer länger, die Gegend immer trostloser. Gegen 11.30 Uhr haben wir unser Marschziel erreicht: Comanche (7.15 Uhr) - Brownwood (8.00 Uhr) - Brady (11.30 Uhr).

Wir sehen das Lager bereits von der Bahn aus. Es liegt in einer freien Ebene. Der Baumwuchs ist restlos zurückgeschlagen. Wir marschieren in Gruppen von 50 Mann zum Lager, ca. 15. Minuten Weg. Das Lager scheint ziemlich neu zu sein. Unser Handgepäck wird z.T. sehr eingehend durchsucht. Ich selbst habe Glück, denn ich werde nur flüchtig gefilzt. Zu unserer Überraschung werden unsere Seesäcke nicht durchsucht, und wir erhalten sie wenig später ausgehändigt. Wir beziehen die Baracken mit je 50 Mann. Sie sind bei weitem größer als die im Camp Gruber, aber enger belegt und luftiger. Wir werden es hier aushalten können, obgleich das Lager mit seiner Umgebung für das Auge keine Abwechslung bietet. Die Kakteen wachsen vor der Türe! Wir liegen im Lager II und befinden uns damit in der Mitte, damit ist uns die Aussicht nach außen versperrt. Der Buschwald tritt sehr weit zurück. Am Abend treffe ich den z.b.V. Hans Schlegel von unserer Einheit in Afrika. Er ging damals in Chancy (Algerien) „stiften“, wurde aber geschnappt. Er ging mit dem nächsten Transport nach England und von dort nach den USA. Er berichtet mir, daß das Lager I bei Wasser und Brot lebt, weil sie verweigert hätten, das Gras zwischen den Doppelzäunen zu mähen. Die Strafe besteht bereits seit zwei Tagen. Wir stehen am Abend noch lange am Zaun und erzählen uns unsere bisherigen Erlebnisse. Mit Einbruch der Dunkelheit geht manches Brot durch den Zaun.

Sonntag, 13.8. 44

Es mag gegen 9.00 Uhr gehen. Wir haben einen herrlichen Sonntagmorgen. Es weht eine frische Brise, die den ganzen Tag anhält. Ich sitze an der SW-Ecke des Mittellagers und habe hier einen weiten Blick in das Land hinein. Nicht weit entfernt, etwa $3 \mathrm{~km}$, liegt die Ortschaft Brady. In weitem Umkreis ist das Land mit Buschwald bewachsen. An der äußersten Ecke des Lagers in Richtung Brady steht der unvermeidliche Wachturm, nicht zu vergessen die Bogenlampen, die jeweils in $50 \mathrm{~m}$ Abstand stehen. Neben dem Lager I wird gerade Handball gespielt. Lebhafte Zwischenrufe schallen herüber. Kameraden ziehen vorbei, sie drehen ihre Runden. Die Luft ist frisch und klar. Das Zirpen der Grillen kommt an die Lautstärke derer von Camp Gruber nicht heran.

Freitag, 18. 8. 44

Die amerikanische Lagerführung trat an unsere Lagerführung mit dem Ersuchen heran, ca. 35 Mann zur Arbeitsleistung zu stellen. Es sind Arbeitsposten für die wirtschaftliche Führung des gesamten Lagers. Es wurden 
alle Stellen abgelehnt. Darauf verlangt der Kommandant, daß die Kompanie-Führer die Kompanie selbst befragen, dies geschieht in Gegenwart von amerikanischen Dolmetschern. Wir sind lediglich dafür, daß wir unsere eigene Müllabfuhr durch drei Mann stellen. Die neu hierher verlegte 5. Kompanie muß es sich erst einen Tag überlegen, wie sich der Kompanie-Führer ausdrückt. Er könnte ja keinen Mann dazu bestimmen, sonst würde man ihm das Kreuz einschlagen, das sagte er in Gegenwart der amerikanischen Dolmetscher.

\section{Freitag, 25. 8. 44}

Die amerikanische Lagerführung tritt an uns heran, daß wir Arbeitskommandos stellen. Nach ihrer Aussage wären Unteroffiziere mit anonymen Schreiben an sie herangetreten, bezahlte Arbeit zu erhalten. Beim Mittagessen tritt der Kompanie-Führer an die Kompanie heran, dieses Anliegen wird von der Gesamtheit abgelehnt.

\section{Samstag, 26. 8. 44}

Beim Frühstück teilt uns der Kompanie-Führer mit, daß der Oberst befohlen habe, bis um 8.00 Uhr zehn Mann Arbeitsdienst vom gesamten Lager zu stellen, um für uns bestimmte Verpflegung aus den Waggons auszuladen und auf die Fahrzeuge zu verladen. Sollte dieses Kommando nicht gestellt werden, wird ab 8.00 Uhr die Verpflegung gesperrt, und es kommt nur Brot in das Lager. Diese Anordnung wird vom Oberst damit begründet, daß die MP sich weigert, weiter für uns die Verpflegung aus den Waggons auszuladen und nach dem Dienst extra Posten für den großen Sportplatz abzustellen. Gestern wurde nach vielen Verhandlungen der große Sportplatz für das Lager II geöffnet. Der Befehl, ein Arbeitskommando zu stellen, wird von der gesamten Kompanie abgelehnt. - Auf unserer Baracke entsteht ein großer Disput über das Für und Wider. Wir sind uns alle klar darüber, daß wir nach drei Tagen Hunger diesen Befehl doch ausführen müssen. Denn über die Tätigkeit der Schweizer Vertreter sind wir uns klar darüber, daß sie im Sinne des Ami entscheiden. Die drei Lagerführer haben sich um 8.00 Uhr beim Oberst zur Aussprache angemeldet. Vom Kameraden Gondesen erfahre ich, daß sich um $8.00 \mathrm{Uhr}$ zehn Mann zum Arbeitsdienst freiwillig gemeldet haben, und zwar vom Lager III sind es vier Mann und den anderen je drei Mann. Der Lagerführer hat der amerikanischen Führung zum Ausdruck gebracht, für die Sicherheit dieser Leute nicht garantieren zu können.

\section{Freitag, 1. 9. 44}

Am Abend um 20.00 Uhr fanden wir uns von der Kompanie im Speisesaal der 7.Kompanie zu einer Feierstunde anläßlich des 5.Jahrestages des 
Kriegsbeginns zusammen. Wir erschienen alle in unserer Afrika-Uniform. Eine große Stille liegt über dem Raum. Am Kopfende sind die Nationalflaggen aufgespannt, dazu ein übergroßer Adler mit dem Spruch „Unser Glaube heißt Deutschland“. Das Streichquartett hat Platz genommen, die Lichter verlöschen, es ertönt das "Largo" von Händel. Wir finden Zeit genug, um uns innerlich zu sammeln. Die ernsten und feierlichen Töne sind verklungen. Es spricht der Kamerad Rosnow zu „Die Schlacht bei Salamis". Wir hören von dieser ersten Seeschlacht der Weltgeschichte. Hier wurde der Ansturm der Perser gebrochen und die abendländische Kultur vor dem Untergang gerettet. Wie die Griechen am Sund von Salamis angesichts ihrer Frauen und Kinder in den Kampf gingen und wissen, daß sie alles verlieren oder auch gewinnen können. Daß nicht die Zahl der Feinde ausschlaggebend war. Die schwerfälligen Schiffe der Perser werden vernichtend geschlagen, und Xerxes zieht ab. - Es spricht der Kamerad Speitel anläßlich des 5.Jahrestages des Kriegsbeginns. Er läßt die Geschehnisse an unserem geistigen Auge vorüberziehen und kam auf die jüngsten Ereignisse zu sprechen, daß wir auch wieder in die Offensive gehen können. Wir hörten von den Erfolgen unserer Truppen bei Dorpat, wo in mehreren Tagen über 700 Geschütze und über 500 Panzer vernichtet wurden. Wir hören vom Rückzugsbefehl der Truppen auf den Westwall, weil dort erst die neue Geheimwaffe infolge ihrer furchtbaren Wirkung zum Einsatz kommen könne. Wir hören von der Feststellung im englischen Unterhaus, daß die Raketengeschütze nicht in Calais stehen, sondern in der Eifel. Hören weiter, daß in Schottland das Hauptmunitionslager und sechs weitere in die Luft geflogen sind. Man nimmt Fernzündung an. In einer kurzen Stille gedenken wir der Opfer, die an der Front und in der Heimat gebracht wurden, währenddessen das Quartett das Lied vom „Guten Kameraden" spielt. Unterdrücktes Schluchzen hinter mir. Es wird einige Kameraden, die es besonders hart getroffen hat, doch sehr gepackt haben. - Der Kamerad schließt seine Ausführungen mit einem Sieg Heil auf Führer, Volk und Vaterland. Die Lieder der Nation beschließen die Feierstunde.

Montag, 11. 9. 44

Wir haben erfahren, daß heute die ersten „Brückenkopf-Gefangenen“ eintreffen werden. Im Laufe des Vormittags marschieren ca. 250 Mann ein. Für uns etwas Neues, jetzt auch das „Feldgrau“ zu sehen. Sie sehen im Vergleich zu uns sehr blaß aus. Sie machen sonst in ihrem Anzug einen guten Eindruck. $Z u$ uns kommen sechs Mann zum Frühstück. Es sind alles Unteroffiziere. Ich habe heute zufällig Küchendienst und bin Zeuge ihrer ersten Berichte. Sie machen große Augen, als ihnen kalter Braten, Koteletts, Weißbrot in reicher Auswahl serviert wird. Im Grunde genommen können sie nur persönliche Erlebnisse wiedergeben und waren alle vom 
„Bombenteppich“ mitgenommen worden. „Ja, wenn der nicht gewesen wäre !“ Am Nachmittag hängt alles am Zaun, denn sie kamen in das Lager III. Das Bild rundet sich ab. Auch an der Front hat sich der Verrat am Führer ausgewirkt. Es soll vorgekommen sein, daß Offiziere während der Angriffe übergelaufen sind. Man hört über den Fall von Cherbourg sehr Unrühmliches. Man hört, daß drei Tage vor der Invasion die gesamte Munition in Brest gesprengt werden sollte, es aber nicht ausgeführt wurde. Jetzt kämpft diese Festung heute noch. Wenn man hören muß, daß Urlauber in die kämpfende Linie geleitet wurden, und sie waren der Meinung, sich auf einem Rastplatz zu befinden. Am anderen Tag kamen die Amis und weckten die Kameraden zum Marsch in die Gefangenschaft! Ein groBer Teil wurde erst im Monat August gefangengenommen. Alle sagen aus, daß die Franzosen Verrat größten Ausmaßes getrieben hätten, wie sie auch im Terror ihren Mann gestanden hätten. Wir erfahren, daß die meisten Kameraden seit Jahren in Frankreich gestanden hätten. Mein persönlicher Eindruck und auch meine eigene Erfahrung von 13 Monaten Frankreich-Aufenthalt, daß die gesamte Truppe vom jüngsten Landser bis hinauf zum General demoralisiert war. Frankreich hat mit seinen Huren eine Schlacht gewonnen. Ich erinnere mich der Aussage eines deutschen Truppenarztes, daß von der gesamten Truppe in Frankreich sich ständig ca. 150000 in ärztlicher Behandlung (wegen Ansteckung) befanden. - Übereinstimmend wurde ausgesagt, daß die ,HJ-Divisionen“ sich überragend geschlagen hätten! - Am Spätnachmittag rückten zu unserer Überraschung alte Kameraden vom Afrika-Korps ein. Wir wollten es nicht glauben, sie kamen aus Afrika. Sie waren 15 Monate in französischer Gefangenschaft. Viele von uns trafen alte Kameraden von ihren Einheiten wieder. Sie waren seinerzeit in Tunesien mit uns zur gleichen Zeit in Gefangenschaft geraten. Sie hatten aber das große Unglück gehabt, zu den Franzosen zu kommen. Was sie uns erzählten, war ein 15 monatiges Martyrium gewesen. Sie waren in Französisch-Marokko, am Rande der Sahara, zum Bau der Wüsten-Bahn eingesetzt worden. Auf 1000 Mann starben 83 Mann an Unterernährung. Mit größter Schikane, grausamster Behandlung und schlechtester Kost wurden sie schlechter als Tiere gehalten. Wir waren erschüttert zu hören, wie man deutsche Soldaten zur letzten Ruhe getragen hatte. In einem Lumpen von Decke eingewickelt, wurden sie von Kameraden zum Friedhof getragen und unter präsentiertem Gewehr zur letzten Ruhe gebettet. Dabei zog man ihnen noch die Decke weg. Es war übrigens die erste Arbeit, rückten Kameraden in ein neues Lager ein, daß sie einen Friedhof anlegen mußten. Franzosen, die auf Grund eines Führer-Erlasses „Dieppe“ aus deutscher Kriegsgefangenschaft entlassen wurden, schikanierten deutsche Kameraden in Afrika bei $70^{\circ} \mathrm{C}$ (?) Hitze im Schatten. Hatten Kameraden das Pech, bestraft zu werden, trugen sie täglich sechs Stunden einen Sandsack von 30 Pfund im Nacken und mußten so ihre Runden drehen. Die Reitpeitsche, von Elsässern geschwungen, 
half von Zeit zu Zeit nach, wenn der Schritt etwas langsamer wurde. Sendungen vom DRK wurden ihnen auch zugeteilt, aber wie. Die einen bekamen das Brot, die anderen die Butter, andere bekamen den Tabak, andere die Blättchen zum Drehen der Zigaretten, aber ohne Tabak. - Die Kameraden waren vom Essen überwältigt, das ihnen hier zum ersten Male aufgetischt wurde. Kameraden von $1,80 \mathrm{~m}$ hatten nur noch 94 Pfund am Körper. Wir alle haben nur einen Wunsch, einmal nach Hause zu kommen und die Herren Franzosen anzutreffen. Es wird da manche Rechnung noch beglichen werden müssen. Ein Schrei der Vergeltung wird sich Luft machen. Das können diese Bestien nie wieder gutmachen. Die jüngsten Ereignisse haben bewiesen, wie weit es mit unserer Gutmütigkeit gekommen ist. Der deutsche Michel lernt nie aus!

Von den „Brückenkopf-Leuten“" konnten wir aus England interessante Angelegenheiten erfahren. Dort teilte man die Gefangenen nach ihrer Landsmannschaft ein, so die „Ostmärker“, Sudetendeutsche, Schlesier usw. Man nahm Abstimmungen vor, ob sie für den Führer, gegen ihn oder neutral wären, doch damit hatten sie eine große Pleite erlebt. Es gab auch Schattenseiten, vorgelegte Verpflichtungsscheine zum Arbeiten wurden von einer großen Zahl unterschrieben. Scheinbar standen sie noch zu sehr unter dem Eindruck ihrer Gefangennahme. SS-Leuten drohte man mit Rußland, diese jedoch waren stark und ließen sich nicht einschüchtern. Es gab auch einige, die nach drei Tagen versuchten, einen Soldatenrat aufzustellen, diesen wurde aber ,heimgeleuchtet". Dasselbe, wie es zum Teil auch bei uns vorgekommen ist. Kameraden, die durch London gefahren wurden, wurden entweder die Augen verbunden, oder es wurden die Vorhänge in den Zügen vorgezogen. Einige konnten die Vl fliegen sehen und das damit verbundene Geräusch hören. Das Verhältnis zwischen den Amis und Tommys ist dort sehr gespannt.

Samstag, 16. 9.44

Gestern abend beim Schlafengehen kamen wir, mein Kamerad Erich G. und Speitel, noch ins Gespräch über die augenblickliche Lage. Speitel konnte uns aus vertraulichen Meldungen berichten, daß der Ami bei Aachen und bei Trier stände. ${ }^{22}$ Aachen wäre bereits evakuiert, 309 Meilen wären sie noch von Berlin entfernt, wie der amerikanische Nachrichtendienst durchgab. 5000 deutsche Offiziere sollen erschossen worden sein, 350000 deutsche Gefangene in Frankreich gemacht, Feldmarschall Kluge soll Selbstmord verübt haben. Der Kommentarsprecher Fritzsche soll im Rundfunk gesprochen haben, daß, wenn es schiefginge, das deutsche Volk keine Schuld träfe, lediglich dann die deutsche Wehrmacht. Die neuen deutschen Geheimwaffen wären bald da. Sie müßten aber erst in der Serienherstellung erzeugt werden. Das sind Nachrichten, die einem das Herz 
fast abdrücken können. Was mag die West-Armee nur für eine Truppe sein? Was sagt die Heimat dazu? Das Ende wäre nicht auszudenken! Man muß sich die Opfer der Heimat vor Augen halten, im täglichen Bombenhagel eine Arbeit von 12 Stunden vollbracht zu haben. Demgegenüber soll es deutsche Soldaten im Westen gegeben haben, die vier Jahre dort in Saus und Braus gelebt hätten. Jetzt den Glauben noch zu behalten, ist ein schwierig Ding! Es können jetzt nur noch Wunder wirken, aber das ist ein billiger Trost.

\section{Donnerstag, 29. 9. 44}

Wir sind Zeuge der Ferntrauung des Kameraden Oberfeldwebel Siedemann. Das Theater ist durch die 6. Kompanie gefüllt. Es ist $9.00 \mathrm{Uhr}$, als Kamerad Siedemann mit dem Lagerführer und dem Kompanie-Führer den Raum betreten. Im Hintergrund der Bühne leuchten die Fahnen der Nation. Die Mitglieder des Orchesters haben Platz genommen. Vor ihnen steht ein kleiner Tisch, darauf steht das Porträtbild der Gattin, von Blumen geschmückt. Alle drei Kameraden nehmen vor dem Bild Platz. Der Musikleiter erhebt den Taktstock, ernste Musik ertönt. Kamerad Rosnow spricht Worte von Claudius über die Ehe. Weiter spricht Kamerad Speitel Worte des Führers. In kurzen Worten spricht Kamerad Oberwachtmeister Sickmann über die Bedeutung dieser Stunde, insbesondere für unseren Kameraden. Denn vor wenigen Stunden wurde in der Heimat die Ehe geschlossen, wie hier dieses Augenblickes gedacht wird. Nach weiteren Musikstücken spricht der Lagerführer die Glückwünsche des Lagers aus. Die Feier ist damit beendet.

Samstag, 14. 10. 44

Seit einigen Tagen gärt es wieder einmal im Lager. Unsaubere Elemente haben sich wieder entpuppt. Da erzählt man sich, daß ein Schiffskoch sich als Lump erwiesen hat. Dieser Mann hatte mit dem Ami Beziehungen aufgenommen und ließ sich am Morgen unter Bewachung abholen, nachdem er am Abend zuvor in einer Kompanie-Veranstaltung über nationalsozialistische Haltung gesprochen hatte! Ein anderer, ebenfalls aus dem Lager III, hatte dem Ami berichtet, daß die gesamte Lagerführung einen Druck ausüben würde auf die, die da arbeiten wollten. Ferner, daß deutsche Nachrichten in das Lager kämen. - Eben habe ich meinen Morgenspaziergang beendet, heute ist ja schulfrei, sehe ich zwei POW, ihren Seesack auf dem Rücken, mit einem Ami in Richtung auf das anliegende Arbeitslager gehen. Ganz empört wurde ich von Kameraden aus dem Nachbarlager III gefragt, von welcher Kompanie die Kameraden wären. Ich war ganz er- 
staunt zu hören, daß sie aus unserem Lager kämen. Ich traf die Kompanie- und Lagerführer, diese stellten fest, daß die fraglichen POW aus der 5. Kompanie kämen. Es ist beschämend festzustellen, daß in dieser Notzeit sich die unsauberen Elemente von uns lösen. Mögen sie einst in der Heimat ihren Richter finden. Heute beim Frühstück wurde uns ein politischer Bericht aus der Heimat verlesen, der in einem Päckchen den Weg zu uns gefunden hatte. Er war vom April 1944 und zeigte uns die Kriegsziele auf, die Absichten der Feinde und ihre Vorbereitung. Er gab uns die Gewißheit, daß in der Heimat alles getan werde, um diesen Verteidigungskrieg siegreich zu beenden.

Amerikanische Abendmeldungen brachten gestern, daß laut Berlin die Russen die ostpreußische Grenze überschritten hätten. Tilsit wird von russischer Artillerie beschossen, Aachen soll bis zur Hälfte von den Amis besetzt worden sein. ${ }^{23}$ Weiter tobt eine heftige Schlacht bei Metz. Wir können nur hoffen, daß wir diesen Winter gut überstehen.

Dienstag, 24. 10. 44

Es ist ein sonniger Oktobertag. Ich sitze vor der Baracke und lese gerade das Buch „Der Gefangene des Padscha“. - Hornsignale ertönen, es ist das Zeichen der bevorstehenden täglichen Flaggenparade, die hier die Amis feierlich vornehmen. Es ist 16.50 Uhr, als nach dem Hornsignal eine Walzermelodie erklingt, ich traue meinen Ohren nicht, es ist nicht zu glauben, eine Großlautsprecheranlage überträgt den ,Kaiserwalzer" von Johann Strauß. Diese unsterblichen Klänge sollen nun beim Heraustreten der Wachmannschaften die Zeit bis zur Flaggenparade um 17.00 Uhr verkürzen. Ich stehe am Tor und bin wohl ungefähr $250 \mathrm{~m}$ von dieser Zeremonie entfernt. Mit den letzten Klängen des Walzers haben die Mannschaften Aufstellung genommen. Es tritt eine kurze Pause ein. Drei Mann haben am Flaggenmast Aufstellung genommen, zwei Offiziere stehen vor der Front der angetretenen Abteilung. Ein kurzes Hornsignal, Kommandos ertönen, die Offiziere und Mannschaften ohne Gewehr grüßen durch Handanlegen an die Kopfbedeckung. Jetzt ertönt durch den Lautsprecher eine feierliche Melodie, und die Flagge wird langsam eingeholt, das erstreckt sich auf einen Zeitraum von ca. drei Minuten, und das alles wurde durch einen deutschen Walzer eingeleitet. Als wenn alles auf diesen Augenblick gewartet hätte, strömen nun die weiblichen Angestellten aus dem Hauptquartier. Mädchen in heller Kleidung, einen leichten Mantel über dem Arm. Links von den Wirtschaftsräumen oder Schuppen kommen deutsche Soldaten. Für uns sind es die „Überläufer", die sich unter dem Schutz der Amis in das Arbeitslager begeben haben. Sie haben ihre tägliche Arbeit beendet und rücken in ihre Unterkünfte ein, nachdem sie sich einer körperlichen Untersuchung an der Wache unterzogen haben. Ich 
zähle 16 Mann. Sie haben es vorgezogen, ,ehe es zu spät ist, zum Ami überzuwechseln". Täglich rauchen sie ihre dicken Zigarren oder Zigaretten ohne Einschränkung und haben ihr tägliches Bier (eine Flasche). Für uns bedeutet das nur Köder unter Ausnutzung der menschlichen Schwächen. Wir verzichten auf diese materiellen Genüsse und bleiben uns und unserem Vaterland treu, wenn auch alles zur Zeit dagegen spricht.

\section{Donnerstag, 9. 11.44}

Zum heutigen Gedenktag wurde die vorgesehene Feierstunde vom Lagerkommandanten verboten und zum Arbeitstag erklärt. Der Lagerführer hat einen Aufruf erlassen, auf Grund des heutigen Tages im Gedenken an die Heimat eine namhafte Spende zu opfern. Auf den Schreibstuben liegen Einzeichnungslisten aus, die das DRK beauftragen sollen, die gezeichneten Beträge dem $\mathrm{WHW}^{24}$ zu überweisen. Am Vormittag trage ich meinen Betrag von 200,- RM ein. Die bisherigen Beträge belaufen sich im Durchschnitt alle über 100,- RM. Höchstbeträge waren 1000,- und 5000,- RM. Die Feierstunde soll am 12.11. 44 getarnt durchgeführt werden. Im Lager III wurde über die Lagerstraße hinweg an einem Leitungsdraht eine Hakenkreuzflagge befestigt. Wenig später wurde sie vom Ami heruntergeholt. Kurz vor Mittag fuhren vier Lkw mit Bewachung in das Lager III vor die Küchen und holten sämtliche Verpflegung heraus. Das gesamte Lager wurde auf Wasser und Brot gesetzt, weil sie es abgelehnt hatten, heute zu arbeiten, und das Werkzeug nicht abgeholt hatten. Wir arbeiteten zwar auch nicht, hatten aber das Werkzeug geholt und taten so, als ob wir arbeiten würden.

Sonntag, 12. 11.44

Um 10.00 Uhr haben wir uns zu einer Feierstunde im Theater zusammengefunden. Der Sprecher Kamerad Speitel gedenkt in wenigen Worten des 9. November. Wir gedenken der Gefallenen der Bewegung und der des Krieges. Die Kapelle spielt das „Lied vom guten Kameraden“. Nachträglich erfahren wir, daß im Reich ebenfalls die Feier für die Gefallenen des 9. November am heutigen Tage durchgeführt wurde und der Volkssturm von insgesamt einer Million vereidigt wurde. Es wurde eine Proklamation des Führers vom Reichsführer Himmler verlesen. Hierin kam zum Ausdruck, daß das deutsche Volk zu jedem Opfer bereit sein müßte. Er, der Führer, werde das deutsche Volk zum Endsieg führen. Das Schweigen des Führers hatte einen großen Verleumdungs-Feldzug der feindlichen Presse zur Folge, unter dessen Wirkung wir auch zu leiden hatten. Der Nachrich- 
tendienst gab durch, daß der Führer schwer erkrankt sei, einige Sender meldeten, er sei gelähmt, einige andere, er wäre wahnsinnig geworden.

\section{Montag, 22. 1.45}

Gestern abend, bereits nach dem Zapfenstreich, kamen weitere Nachrichten von der Ostfront durch den Rundfunk. Es waren wahre Hiobsbotschaften! Es mag wohl 22.30 Uhr gewesen sein, als mir gegenüber Kamerad Speitel und Hein sich im Flüsterton unterhielten, doch laut genug, um es zu verstehen. So sollen die Russen 33 Meilen SW vor Königsberg stehen, nach Insterburg die Artillerie hineinschießen, Tannenberg genommen und die Russen vor Allenstein stehen. Bei Oppeln die schlesische Grenze in einer Front von 50 Meilen überschritten worden sein. Tilsit von uns aufgegeben sein. Ich glaubte, mir sollte das Herz stehenbleiben, so ungeheuerlich war das, was ich vernehmen mußte! Unfaßbar, und doch muß es stimmen. Ich kann es nicht glauben, nie, daß wir den Krieg verlieren, nie, daß unsere Fronten zusammenbrechen, es wäre ein Schrecken ohne Ende! Das alles mag mir wohl durch den Kopf gegangen sein, an Schlaf war nicht zu denken, Stunden vergingen, und ich wälzte mich von einer Seite auf die andere. Warum muß ich diesen schrecklichen Weg durch die Gefangenschaft gehen, das habe ich mich wohl schon oft gefragt. Es ist eine nervenaufreibende Zeit, daß man kein Ende absehen kann. Doch was nützt das alles, sich darüber den Kopf zu zerbrechen, wo der Verstand aufhört, fängt der Glaube an.

Freitag, 20. 4. 45

Vor dem Frühstück wird ein Appell des Lagerführers verlesen. Er gedenkt in packenden Worten des Geburtstages des Führers, gedenkt des tapferen Kampfes unseres Volkes und ruft die Schwachen auf, sich an ihnen ein Vorbild zu nehmen. Die Starken aber weiter fest im Glauben an das eigene Volk zu bleiben, in der festen Gewißheit, daß das deutsche Volk am Ende doch siegen werde. Der Aufruf schloß mit einem „Sieg Heil" auf den Führer.

In den Mittagsnachrichten hören wir, daß in den beiden ersten Tagen der russischen Offensive fast 800 Panzer abgeschossen wurden. Erstmalig wird ein Vorstoß der Amis auf Dessau gemeldet. - Gegen 21.30 Uhr geht im gesamten Lager plötzlich das Licht aus. Schlagartig war in jede Baracke ein Posten gegangen und drehte die Sicherung aus. Es wurden sämtliche Kameraden, die sich auf der Lagerstraße befanden, in die Baracken geschickt. Mit Scheinwerfern, Holzknüppeln und Maschinenpistolen traten die Posten in Erscheinung. Bei uns auf der Baracke waren zwei Talglichter angesteckt worden. Da kamen auch schon mehrere Posten unter Führung eines deutschsprechenden Soldaten in unsere Baracke. „Gehen Sie sofort ins Bett!" ertönte es in akzentfreiem Deutsch. 
Freitag, 27. 4. 45

Am heutigen Tage wurde vom amerikanischen Kommandanten Saxone befohlen, daß ab sofort der ,Nazi-Gruß“ verboten sei. Es ist ab sofort nur noch der militärische Gruß anzuwenden, das gilt auch beim Grüßen untereinander. Bei der Morgenzählung wurde dieser Befehl durch den deutschen Lagerführer verlesen, und es wurde von ihm gefragt, wer sich gegen diesen Befehl stellen will. Es trat niemand vor. Das Teillager II hatte entgegen der Empfehlung der Lagerführer diesen Befehl verweigert. Es wurde daraufhin die gesamte Verpflegung aus den Küchen abgeholt und das gesamte Lager auf „,Wasser und Brot“ gesetzt. Die gesamte Lagerführung einschließlich Dolmetscher und Kompanie-Führer wurden in Untersuchungshaft gesetzt. Man spricht davon, daß sie vor das Kriegsgericht kommen sollen, wahrscheinlich wegen Anstiftung zur Meuterei.

\section{Donnerstag, 3. 5.45}

In einer Ortszeitung aus Texas konnte ich heute lesen, daß der Führer den „Soldatentod" gefunden habe im Kampf gegen den Bolschewismus. Es heißt weiter, daß Großadmiral Dönitz am 30.4. 45 vom Führer zu seinem Nachfolger bestimmt wurde. ${ }^{25}$ Der deutsche Rundfunk meldete am 2. 5.45 über den Sender Hamburg wörtlich: Aus dem Führerhauptquartier wird gemeldet, daß gestern nachmittag der Führer im Kampf um die Reichskanzlei den Tod gefunden habe. Diese Worte kündete ein Trommelwirbel an, Musik von Wagner beschloß diese Meldung. - Kurze Zeit darauf sprach Großadmiral Dönitz zum deutschen Volk, u. a. daß er das deutsche Volk führe und der Kampf gegen den Bolschewismus weitergehe. Er fordert die deutschen Soldaten auf, weiter ihre Pflicht zu tun. Die Nationalhymnen beschlossen diese Ansprache. Es heißt weiter, daß der russische Rundfunk meldet, daß dies ein großer Trick der Nazis sei. Der Führer sei geflohen und leite den Untergrundkrieg. - Wir alle sind in ernster und gefaßter Stimmung. Wir glauben nun, daß wir eines Tages mit den Amerikanern und den Engländern gegen den Russen kämpfen werden.

\section{Montag, 7. 5.45}

Worte vermögen es nicht zu sagen, was wir empfinden zu wissen, daß unser Vaterland diesen Zweiten Weltkrieg verloren hat. $\mathrm{Zu}$ wissen, daß man als Einzelschicksal vor einem Nichts steht! - Meine Gedanken sind mehr denn je zu Haus, was mögen meine Eltern, was mögen die Schwestern machen? Wie werden sie alles überstanden haben? Ich selbst befürchte das Schlimmste. 
Dienstag, 8. 5.45

Der Kommandant gibt in einer Proklamation bekannt, daß es keine deutsche Wehrmacht und keine nationalsozialistische Regierung mehr gibt. ${ }^{26}$ Wir sind allen Verpflichtungen entbunden. Bis um 16.30 Uhr verlangte der Kommandant eine Meldung, wieviel Prozent bereit sind, eine Arbeitsverpflichtung einzugehen. In einem diesbezüglichen Befehl erkennt er unsere Haltung an, bisher von unserem Recht Gebrauch gemacht zu haben. Jetzt, da wir nun allen Verpflichtungen entbunden sind, gibt es für uns nur noch die Wahl, hier zu arbeiten und damit für unsere Heimat, für die Amerika Verpflegung und Bekleidung liefern müsse! Von 325 Mann verweigerten 15 Mann eine Arbeitsverpflichtung.

Mittwoch, 9. 5.45

Ich habe mich entschlossen, mich mit dem Kameraden Greif als Kraftfahrer zu melden, und wir wollen versuchen, zur Handelsmarine zu kommen.

Freitag, 11. 5. 45

Die Verpflegung ist in den letzten Tagen äußerst knapp geworden. Zum Abendbrot gab es Kartoffelsalat und fünf Scheiben Brot, eine Apfelsine und Kaffee. Der Kommandant hat auf eine Anfrage erklärt, daß auch die Amerikaner gekürzt worden sind, da z. Z. Transportschwierigkeiten herrschen. Von z. Z. herrschenden Streikbewegungen spricht man nicht.

Sonntag, 13. 5.45

Heute habe ich eine Arbeitsverpflichtung auf 90 Tage unterschrieben, und zwar zur Handelsmarine und als Kraftfahrer.

Samstag, 19. 5.45

Nach zweimaliger Rücksprache des Lagerführers beim Kommandanten wegen der z. Z. sehr schlechten Verpflegung wurde diesem erklärt, daß er keinen Einfluß auf die Zusammensetzung habe. Das sei „,von oben“ festgesetzt. Er werde aber bei passender Gelegenheit darüber vorstellig werden. - Solange wie wir jetzt in den USA sind, haben wir noch nie so viel Hunger gelitten wie jetzt.

Freitag, 25. 5. 45

Am Vormittag erhielten wir Formulare mit der Aufforderung, daß wir uns zu einer Versetzung in jedes Lager und zu jeder Arbeit zu denselben Be- 
dingungen wie für Mannschaften verpflichten. Frist war 12.30 Uhr. Bis zu dieser Zeit hatten etwa die Hälfte aller unterschrieben. Daraufhin kam vom Oberst die Genehmigung, daß die übrigen das Formular nach ihren Wünschen abändern können. Fritz Greif und ich entschlossen uns gegen 17.00 Uhr, davon Gebrauch zu machen, und verpflichteten uns zu einer 90tägigen Arbeit. Am Montag soll ein Transport von ca. 750 Mann erfolgen. Man spricht von Arizona, Bewässerungsarbeiten.

Auf jeder Baracke wurden fünf Hefte mit Aufnahmen von der amerikanischen und britischen Armee aus deutschen Konzentrationslagern und von den vorgefundenen Tatsachen aufgelegt. Wir wurden stark beeindruckt.

\section{Sonntag, 27. 5. 45}

Am Vormittag kam unsere Versetzung heraus. Wir werden nach dem Camp Florence [Arizona] am Montag in Marsch gesetzt. Unser beider Hoffnung ging nicht in Erfüllung. Fritz Greif bleibt hier, ich bin dabei. Leider sind so unsere Pläne nicht in Erfüllung gegangen.

\section{Montag, 28. 5.45}

Der Zeitpunkt ist gekommen, da es heißt, Abschied zu nehmen. Den Vormittag habe ich noch mit Fritz Greif verplaudert. Leider ist unser Wunsch, zusammen versetzt zu werden, nicht in Erfüllung gegangen. In den $37 \mathrm{Ta}$ gen, da wir zusammen waren, haben wir uns in tiefer Freundschaft gefunden. - Jeden Abend saßen wir noch nach dem ,Zapfenstreich“ auf unserem Hocker hinter der Waschbaracke. Vor uns schimmerten in weiter Ferne die Lichter von Brady. Direkt vor uns aber zogen die Kameraden zu nächtlicher Stunde ihre Runden. In dieser Stunde von 22.00 bis $23.00 \mathrm{Uhr}$ aber gingen unsere Gedanken zurück in die Heimat. So rollten unsere verlebten Jahre vor unserem geistigen Auge ab. Dann konnten wir wohl für diese Zeit vergessen, daß wir hinter Stacheldraht saßen. - Wir mußten annehmen, daß Fritz Greif wegen seiner Arbeitsunfähigkeit, auf Grund seiner schweren Verwundung nicht mitkam. So habe ich einen guten Freund und Landsmann aus meiner Heimat verloren. Wie Fritz Greif mir versicherte, will er nun versuchen, ausgetauscht zu werden. Einen Tag zuvor bekam er von seinem Mädel, Erika Lange, der Tochter von Lehrer Lange, seinen ersten Brief. Ich konnte mich überzeugen, daß die Zeilen von einem fabelhaften Charakter geschrieben worden waren. Wir haben gegenseitig Bilder ausgetauscht, und sie sollen für uns Erinnerung bleiben an den Tag, da der Zufall uns zusammenführte und wieder auseinanderriß. Wir stehen abmarschbereit. Wir haben uns verabschiedet, viel haben wir uns nicht zu sagen. Wir wünschen uns gegenseitig alles Gute. Wann werden wir uns wiedersehen? Unser Abmarsch zum Bahnhof verzögert sich, 
da jeder einzelne mit seiner Kennkarte von einem Offizier verglichen wird.

Wir nehmen Abschied von liebgewordenen Kameraden wie: Heinz Peters (Dipl.-Ing.), Karl Huber, Herbert Wallmeier, J. Paulsmeier, Herbert Ollendorf und Udo Geßner.

Wie immer müssen wir unseren Seesack vor das Lagertor tragen, von dort soll er mit Lkw zum Bahnhof transportiert werden. Bisher konnte ich meine heißumkämpfte Kamera heil durchbringen, um sie vor der Beschlagnahme zu retten. Bange Minuten hatte ich vor mir. Keine Seele wußte, ob wir wieder gefilzt werden. Mit meiner bisher erfolgreichen Taktik ging ich wieder als einer der letzten zum Tor hinaus. Am Ende der „Filzung" wurden die Amis ruhiger und langsam müder bei einer Temperatur von über $30^{\circ} \mathrm{C}$ im Schatten. - Als ich das Lagertor passierte, sehe ich rechter Hand einen großen Haufen Seesäcke liegen. Kurz entschlossen werfe ich meinen Sack hinzu und schließe mich den anderen Kameraden an. Doch da werde ich von einigen Kameraden angemosert, mich vor der „Filzung“ nicht zu drücken. Wenn die um mein Geheimnis wüßten. Jetzt erst werde ich gewahr, daß auf dem Rundweg die Kameraden in einzelnen Abständen ihren Seesack ausleeren mußten. Weiter bemerkte ich blitzschnell, daß die gefilzten Kameraden mit ihrem Seesack in einem FünferBlock antreten mußten und einzeln abgehakt wurden. Ich handelte wieder sehr schnell und stellte mich in die Fünfer-Gruppe. Ich erwischte einige Kameraden von meiner Baracke, die von meinem Geheimnis wußten. Ich machte meinem Kameraden Udo Geßner durch Zeichen klar, daß mein Seesack bereits auf dem Haufen liege. In der Marschgruppe wurden wir, mit unserem Sack vor uns aufgestellt, einzeln von einem Offizier auf einer Namensliste abgehakt. Udo Geßner schaltete schnell. Auf mein Zeichen, als sein Namen abgehakt wurde, rückte er im Zeitlupentempo einen Schritt nach links und ließ dabei seinen Sack stehen. Als der Offizier meinen Namen in der Liste suchte, machte ich einen Schritt nach links und stand so vor seinem Sack. Alles O.K., sagte der Offizier. Unsere FünferRotte machte links um und marschierte in der Reihe zum Abwurfplatz. Vier Mann mit Sack, ich in der Mitte der Reihe „ohne“, ob ich wohl auffallen werde? Doch niemand merkte etwas. Erhöhter Pulsschlag. Ich hatte es wieder einmal geschafft!

Gegen 19.00 Uhr erreichten wir nach einer halben Stunde Marsch das Abstellgleis für unseren Sonderzug. Die Presse von Brady hatte berichtet, daß 750 Unteroffiziere sich zur Arbeit verpflichtet hätten. Zu unserem Erstaunen finden sich etwa zwanzig Autos ein, in der Mehrzahl mit weiblichen Personen besetzt. Wir bestiegen unsere Abteile. Doch wir können noch lange warten, denn erst um 21.15 Uhr fuhr der Zug an.

Mittwoch, 30.5.45

Um 6.40 Uhr haben wir in Tucson einen längeren Aufenthalt. Es ist die 
bisher größte Stadt, die wir passiert haben. Auf einem Nebengleis hält ein Zug. In der Mehrzahl von Soldaten besetzt. Links neben uns auf einem Nebengleis steht ebenfalls ein Zug. Wir können genau in das Abteil eines Speisewagens hineinschauen. Zivilisten und Soldaten sitzen bei ihrem Morgenfrühstück, das aus einem Setzei und geröstetem Brot besteht. Weiß gekleidete Neger bedienen die Gäste. Auch die lieben Amis müssen beim Zahlen ihre Marken überreichen. Uns würdigt man keines Blickes. Wir sind ja deutsche Kriegsgefangene. Gegen 9.00 Uhr erreichen wir unser Ziel, das Lager Cortaro (Arizona), es ist ein Nebenlager von Florence. Mit gemischten Gefühlen standen wir auf einem Nebengleis und warteten, bis unsere Seesäcke ausgeladen waren. Wie wird unser Lager aussehen, werden wir hier zur Arbeit eingesetzt und was für welche? Es waren viele Fragen, die ihrer Erfüllung warteten. - Wir haben uns zum Abmarsch formiert und marschieren auf einem Landweg. Unsere Neugier sollte bald befriedigt werden. Von weitem sehen wir die Spitzen von einer Zeltstadt aufleuchten. Wir sind restlos bedient. Zu beiden Seiten der Straße sehen wir weite Baumwollfelder, das wird wohl unsere künftige Arbeit sein, sind unsere Gedanken. Nach einem dreiviertelstündigen Marsch erreichen wir das Lager. Der Lagerführer, ein Oberfähnrich, empfängt uns und läßt uns in der bisherigen Kompanie-Einteilung weiter bestehen. Er gibt uns bekannt, daß wir nach 7 bis 10 Tagen in Kompanie-Stärke zur endgültigen Arbeitsstelle versetzt werden. - Schnell haben wir unser Zelt bezogen, ein Hauszelt mit acht Mann belegt. Jetzt warten wir, was wir zum Mittag auf den Teller bekommen werden.

Unser Lager befindet sich auf einer Hochfläche von ungefähr $1200 \mathrm{Me}-$ ter. Rings um uns herum ziehen sich die Berge entlang. Sie mögen eine Höhe von ca. 2500 Meter haben. Die Hitze ist hier ziemlich stark. In den Zelten kann man es nur für eine kurze Zeit aushalten, oder man sucht sich ein schattiges Plätzchen hinter dem Wachgebäude. Doch das haben auch schon andere entdeckt, und so muß man anstehen. Doch bereits gegen 18.00 Uhr wird es erträglich, dann scheinen die Grate und Höhen in klarer Sicht. Im Westen jedoch scheinen die Berge als dunkle Silhouette gegen den hellen Himmel, wenn die Sonne hinter den Bergen verschwunden ist. - Tagsüber erdröhnt die Luft von Motorengeräusch. Unzählige Flugzeuge befinden sich in der Luft. Im NW befindet sich ein Militärflugplatz. Des Nachmittags aber schlägt der Wind um und kommt aus Westen, das bedeutet nichts als Sandstürme. Auch daran haben wir uns gewöhnt. Es ist ganz so, wie wir es in Afrika erlebt hatten. Das Wichtigste aber, die Wasserfrage und das Essen, ist zu unserer Zufriedenheit gelöst. Mittags gibt es einen Salat, eine Milchsuppe, ein halbes Weißbrot und einen Apfel. Zum Abendbrot gibt es entweder Bohnensuppe, Haferbrei oder Pellkartoffeln mit einem Hering, dazu jeweils Kaffee. Des Morgens wieder Haferbrei und ein Viertel Brot und Erdnußbutter für eine Scheibe Brot. Es reicht aus, um satt zu werden. 
Freitag, 1.6. 45

Am Vormittag kamen Amis von Florence und prüften unsere politische Gesinnung. Zuvor unterschrieben wir wieder einmal eine Verpflichtung auf 90 Tage zur Arbeit, mit Wirkung vom 1. 6. 45. Anschließend wurden wir an einzelne Tische gerufen und kurz verhört. Nach harmlosen Fragen über die Zugehörigkeit zu welchem Truppenteil bzw. Wehrmachtteil (Heer, Marine und Luftwaffe) erfolgte die Frage von einem Sergeant in Frankfurter Dialekt, wie meine politische Einstellung sei. Ich sagte, daß ich ein anständiger deutscher Soldat sei mit einer deutschen Gesinnung. Auf die Frage, wie es mir in Deutschland gegangen sei, antwortete ich: „Nicht schlecht." O.K. war die Antwort. Mit einem schnellen Blick konnte ich feststellen, wie der Ami auf seinem Formblatt von drei Wahlmöglichkeiten - Demokrat/Nazi/Weder noch - das Wort „Nazi“ unterstrich. Somit wurde ich, obwohl ich keiner Organisation angehörte, außer der ,,Deutschen Arbeitsfront“"27 während meiner Ausbildungszeit bei der Sparkasse, zum ,Nazi“" abgestempelt!

Freitag, 8. 6. 45

Am Abend breitete es sich mit Windeseile aus, daß morgen Versetzungen stattfinden sollen. Wir sind neugierig, ob wir auch dabei sind. In den Abendstunden kommt die Versetzungsliste heraus. Wir stellen fest, daß es alle Kameraden sind, die bei der „,Gewissensprüfung“ zum ,Nazi“ abgestempelt worden waren. Von unserem Zelt sind dabei: Karl Hauger, Walter Ohlendorf und ich selbst. Es geht nach dem Staat Idaho, an der Grenze von Kanada. Jetzt sind wir uns im klaren, daß wir nach dem Norden kommen und eine interessante Fahrt vor uns haben werden.

Samstag, 16. 6. 45

Gegen 13.30 Uhr treffen wir im Fort Shaw (Montana) ein. Es liegt etwa 25 Meilen von Great Falls entfernt. Wir fahren mit acht Lkw durch die Stadt. Sie macht einen sauberen Eindruck. Die Straßen sind mit parkenden Autos angefüllt. Fort Shaw ist eine kleine Siedlung. Es stehen hier etwa zehn Häuser, zum Teil verfallen. Wir sollen hier auf den umliegenden Farmen zum Zuckerrübenziehen eingesetzt werden. Untergebracht werden wir in einem Schulgebäude, im Turnsaal, und in acht Zelten mit je sechs Mann belegt. Wir liegen in einer herrlichen Lage. Rings von Hochflächen umgeben. Im Westen zieht sich das Felsengebirge hin, dessen Spitzen noch mit Schnee bedeckt sind. Hohe Pappeln, dichter Rasen, Vogelgezwitscher lassen uns den niedrigen Stacheldrahtzaun übersehen. Ein Captain, ein Oberleutnant und 40 Mann Bewachung sind für uns 234 Mann aufgebo- 
ten. Am kommenden Montag soll es mit der Arbeit losgehen. Es sollen Gruppen von 15 bis 20 Mann gebildet werden.

Sonntag, 17.6. 45

Es muß sich herumgesprochen haben, daß sich hier im Fort Shaw deutsche Kriegsgefangene, deutsche Soldaten des Afrika-Korps, befinden. Den ganzen Tag fahren Autos vor, bis auf den letzten Platz besetzt. Es war ein herrlicher Tag. Am Vormittag waren wir mit unserer Wäsche beschäftigt. Am Nachmittag standen wir vor dem Schulgebäude und sahen uns das Auffahren der Fahrzeuge mit an. Für uns wie auch für die Besucher etwas Neues. Man kam sich vor wie an einem Sonntag im Zoo. Dort kommen die Zuschauer auch mit Kind und Kegel, um sich die wilden Tiere anzusehen, so kamen wir uns auch vor. Die ,Ladies" natürlich durchwegs kräftig geschminkt. - Morgen beginnt unser erster Arbeitstag!

\section{Montag, 18.6. 45}

Wir haben uns in einer Arbeitsgruppe von 20 Mann zusammengefunden und haben nun den ersten Arbeitstag hinter uns gebracht. Zuckerrüben verziehen war unsere Tätigkeit. Um 7.00 Uhr wurden wir von den Farmern abgeholt, denen wir zugeteilt waren. Nach einer zwanzigminütigen Fahrt erreichten wir unsere Arbeitsstelle. Das Grundstück selbst bestand nur aus einem Sommerhaus und zwei schäbigen Schuppen. Sonst alles in einem sehr verwahrlosten Zustand. Jeder von uns bewaffnete sich mit einer Rübenhacke am kurzen Stiel. Er hatte die Länge von $30 \mathrm{~cm}$, das entsprach dem Maß für den Pflanzenabstand. Die Arbeit bestand darin, mit einem Schlag alle Pflanzen wegzuschlagen, so daß immer nur eine Pflanze im Abstand von $30 \mathrm{~cm}$ von der anderen stehenblieb. Oft mußte man mit der linken Hand eine oder zwei Pflanzen ",nachziehen", daher spricht man auch vom „Rübenverziehen“. - Nach einer achtstündigen Arbeitszeit hatten wir etwa $3 \frac{1}{2}$ acre verzogen. Gegen $17.15 \mathrm{Uhr}$ erreichten wir unsere Unterkunft. Jeder von uns klagte über Kreuzschmerzen.

\section{Dienstag, 19. 6. 45}

Nichts als Kreuzschmerzen! Das eigentliche Arbeitspensum soll sich nach den ersten zwei Tagen auf 10 acre pro Gruppe erhöhen, das soll die Hälfte sein, was die Zivilisten arbeiten. Schon jetzt kann man sagen, das kann von uns nie erreicht werden. Im Akkord wird für den Tag 12 \$ gezahlt und dabei ein acre verzogen. - Wir haben heute ein „Arschloch“ von Posten erwischt. Den ganzen Tag blieb er beim letzten Mann der Gruppe. In der siebten Stunde, als wir uns mühsam durch die Reihen schlugen oder schleppten, trieb er uns mit einem kräftigen Fluch an. - Beim Einschlafen 
sah ich nur Reihen von Zuckerrüben vor mir und gab mir Mühe, mit jedem Schlag nur eine Pflanze stehen zu lassen.

Freitag, 22. 6. 45

Heute hat uns der Farmer John Walt, der Schweizer, angenehm überrascht. Zum Mittag bekamen wir eine Weißbrotschnitte mit Butter und zwei Scheiben Leberwurst sowie ein Stück Nudeltopfen. Er ist mit unserer Arbeit sehr zufrieden. Inzwischen hat es sich herausgestellt, daß die vielgerühmten Mexikaner auch nicht mehr arbeiten als wir und nicht solch eine gute Arbeit liefern. - Interessantes erfahren wir aus der Presse, demnach kostet ein Pferd nur 10 bis 15 \$, ein Dutzend Eier nur 0,30 \$!

Samstag, 21.7. 45

6.00 Uhr Idaho Falls - 11.00 Uhr Minidoka. Wir sehen nur Steppe! Höhe: 4280 feet. Gegen $13.30 \mathrm{Uhr}$ erreichen wir das Lager Fort Rupert, das nach halbstündiger Fahrt von der Stadt in einer weiten Grassteppe liegt. Als wir aussteigen, hören wir wildes Hundegebell. Die Posten haben zwei Schäferhunde mitgebracht. Ein uns fremder Captain benimmt sich äußerst gemein. Beim Zählen springt er mehrmals in die Rotten und versetzt Kameraden Faustschläge. Beim Marsch in das Lager müssen wir im Gleichschritt marschieren. Die Filzung findet in einer Baracke statt. Es werden uns die deutschen Uniformstücke abgenommen. Sie werden mit Namen versehen, und wir sollen sie beim Verlassen des Lagers wieder erhalten. Als wir in der „Filzbaracke“ in einer Linie vor unseren Seesäcken stehen, fing ein besonders eiliger Ami bei mir an. Er mußte aber abbrechen, da der später eintretende Sergeant befahl, daß an der Gegenseite mit dem „Filzen" zu beginnen ist. Diesen Wirrwarr nutzte ich mit dem Bluff aus, daß ich am Ausgang erklärte, daß ich bereits ,gefilzt“ worden sei. So bekam ich wieder einmal meine geliebte Kamera durch. - Ein fragwürdiger Dolmetscher übersetzt eine Anordnung des Lagerführers. Wir erfahren, daß wir uns in einem Straflager befinden. Warum weiß kein Mensch. Der deutsche Führungsstab ist vom Ami eingesetzt worden. Bis Kriegsende war es erwünscht, daß das Führungspersonal von uns gewählt wurde. Von dortigen Kameraden werden wir gewarnt, keinem über den Weg zu trauen. Es herrscht eine gedrückte Stimmung. Der „deutsche“ KompanieFührer stellt sich vor, ohne seinen Namen zu nennen. Bei Verstößen droht er uns mit Arrest. Ich glaube, daß es ein Pole ist. Er soll angeblich ein Russe sein, der sich 18 Monate lang in deutscher Gefangenschaft befunden haben soll. 
Montag, 23. 7.45

Seit heute werden wir alle an einem täglichen Pflichtunterricht in Englisch teilnehmen. Seit heute ist es bei Strafe verboten, irgendein deutsches Uniformstück im persönlichen Besitz zu haben. Selbst Achselstücke sind eingeschlossen. - Die Gesamtheit der Kompanie ist im täglichen Arbeitsdienst eingeteilt. Es wird die stumpfsinnigste Arbeit verrichtet, die man sich vorstellen kann. Man sieht Bilder, bei denen man annehmen könnte, daß man sich in einem Irrenhaus befinden würde. Da sieht man zwei Mann, jeder mit einem Besen bewaffnet, stundenlang die Straße auf und ab marschieren, indem sie den Besen hinter sich herziehen, um so die Straße zu fegen. Ich selbst bin mit einem Kameraden zum Fensterputzen eingeteilt. Ich sitze rittlings auf der Fensterbank und putze einen halben Tag lang eine Fensterscheibe im Speisesaal. Anderntags müssen wir die letzten Kieselsteine suchen, um Entwässerungsgräben damit auszulegen.

Freitag, 27. 7. 45

Urplötzliche Verlegung. So stimmen wohl doch die Gerüchte, daß man uns aus Versehen hier ausgeladen hat.

Gegen 13.30 Uhr befinden wir uns auf der Durchfahrt (mit der Bahn) in Minidoka - gegen 14.30 Uhr durchfahren wir Shoshone. Im Zug herrscht eine unheimliche Hitze. - Wir durchfahren eine endlose Buschsteppe. 16.40 Uhr Montains Home - 18.15 Uhr Nampa. Die Nacht hindurch fahren wir durch ein Gebirge.

\section{Samstag, 28. 7. 45}

7.15 Uhr The Dalles. Seit den frühen Morgenstunden fahren wir durch eine interessante Flußlandschaft. - 9.30 Uhr Portland - 10.45 Uhr Vancouver - 13.00 Uhr Contralia, hier sehen wir große Sägewerke. Seit den Morgenstunden sind wir durch ausgedehnte Tannenwälder gefahren. Gegen 13.30 Uhr befinden wir uns an einem großen See. - 15.00 Uhr erreichen wir Seattle. Fahrzeuge erwarten uns bereits am Bahnhof. Wir befinden uns in einer Millionenstadt. Es herrscht ein starker Fahrzeugverkehr in der Stadt. Ein Kradmelder fährt voraus und gibt ein Sirenengeräusch von sich. Nach kurzer Fahrt erreichen wir ein großes Truppenlager, das unmittelbar an der Meeresbucht (Pouget Sound) auf einer Höhe liegt. Die Stadt selbst erstreckt sich zu beiden Seiten der umliegenden Höhen. Die Hoffnung, daß wir in guten Baracken Unterkunft finden würden, hat sich als Trugschluß erwiesen. Mit je vier Mann beziehen wir ein amerikanisches „Hauszelt". Von innen durch ein Holzgerüst versteift. Die Seitenwände in halber Höhe ebenfalls durch eine Bretterwand ,,winterfest" gemacht. Wir befinden uns in einem Arbeitslager mit 750 Mann Belegungsstärke. Wir sind die einzigen ,Afrika“-Gefangenen, alle anderen sind ,West"-Gefangene aus jüngster Zeit. Die Politik scheint hier keine Rolle zu spielen. Hier 
gibt es keine sog. „Überläufer" wie im Camp Rupert. - Die Stadt selbst besitzt einen großen Hafen, der eine große Rolle für den Pazifik-Einsatz spielt. Die hier vorhandenen Kameraden sind am Bahnhof und im Hafen mit dem Verladen von Kraftfahrzeugen beschäftigt. Unser Zelt befindet sich in der letzten Reihe und ist zugleich Eckzelt. Wir haben von hier einen schönen Blick auf die Stadt und Bucht, bedingt durch unsere Höhenlage. Die Steilufer sind mit Tannen (Pitchpine-Kiefer) bewachsen. Im Westen sehen wir einen hohen Gebirgszug (Olympia-Gebirge). Nach aller Wahrscheinlichkeit sollen wir geschlossen, unsere 80 Mann, die hierher verlegt wurden, in einer amerikanischen Truppenküche eingesetzt werden. Man spricht allerdings von 14 Arbeitsstunden. Das Beste bei dieser Arbeit ist, daß wir an der amerikanischen Truppenverpflegung teilnehmen sollen.

Montag, 30. 7. 45

Mit dem heutigen Tage arbeiten wir als geschlossenes Kommando in der Ami-Küche IV. Wir sind mit 70 Mann zum Küchendienst eingeteilt. Unser Dienst beginnt bereits um 4.45 Uhr und endet um 19.00 Uhr. Die Arbeit ist nicht allzu schwer, nur fällt einem das Stehen schwer. Unsere Verpflegung ist ausgezeichnet! Offiziell dürfen wir kein Kotelett, keine Butter und keinen Kuchen essen. Trotzdem ist das Fleisch mehr als ausreichend, das wir als „Ersatz" bekommen, und Kuchen bekommen wir auch, nach dem Grundsatz, man soll dem Ochsen, der da drischt, nicht das Maul verbinden. Essen können wir, soviel wir wollen. Am heutigen Abendessen (warm) hatte ich mir zuviel auf das Tablett gelegt. Es gab „Hamburgers“, darauf in Fett gedämpfte Zwiebeln, Pommes frites, Salat mit Mayonnaise, zuvor eine Gemüsesuppe. Als Nachtisch Apfelkuchen und Bohnenkaffee. Zuvor hatte ich im Laufe des Tages eine nette Geste meines „Chef-Kochs“ Bill erlebt, dem ich als Anlernling zugeteilt wurde. Er fragte mich: „Do you like pineapples?" Ich antwortete: „Yes". Er gab mir ein Zeichen, faßte in eine große Konservendose und zog mit seinem Zeigefinger etliche Ringe pineapples heraus und drückte sie mir in die Hand. Ich drehte mich um, damit der Staff-Sergeant nichts sah, und drückte sie herunter. War das ein Genuß, waren meine Gedanken. Ja, zu nächtlicher Stunde wälzte ich mich in meinem amerikanischen Feldbett hin und her. Aber es blieb mir nichts übrig, ich mußte zur Toilette und steckte den Finger in den Mund. Ich erbrach mein schönes Abendessen. Ich hatte die Zwiebeln, die vor Fett getrieft hatten, nicht vertragen. Wir waren ja seit der Kapitulation auf Magerkost gesetzt worden und hatten alle an Gewicht verloren.

Montag, 10.12. 45

Bei der Abendzählung wurde bekanntgegeben, daß die seinerzeit angege- 
benen Weihnachtswünsche ins Wasser fallen. Der Ami will uns entgegenkommen. Wir dürfen für $1,30 \$$ Zigaretten oder Schokolade bestellen. Hier zeigt sich wieder einmal das wahre Gesicht, erst Versprechungen, und dann kann man sie nicht erfüllen, obwohl es im voraus feststand, daß es nichts gibt. Weiter darf auf den Zelten kein Grünschmuck angebracht werden. Es dürfte ohnehin kein Bedürfnis vorliegen, sich eine Weihnachtsstimmung vorzuzaubern. - Es gehen wieder Gerüchte im Lager um, $\mathrm{da} ß$ bis Ende April nächsten Jahres alle deutschen Kriegsgefangenen in der Heimat sein sollen. Ich glaube an diesen Schwindel nicht. - Wie sehr die Spannung zwischen uns wächst, beweist ein kleines Beispiel bei uns in der Küche. Durch das Streichen der Küche bedingt, sollte die Küche ursprünglich am Sonntag durch das Kochpersonal gereinigt werden. Daraus ist aber nichts geworden, sondern wir hatten freibekommen. Ein anderes Kommando mußte die Arbeit verrichten. Das übrige Kommando wurde auf die übrigen Arbeiten verteilt. Das war aber ohne unseren Einfluß geschehen, sondern vom Ami befohlen. Es war Anlaß gegeben, gegen uns beim Ami etwas zu unternehmen. Schon lange war ja angekündigt worden, daß man etwas gegen die Köche unternehmen würde. Viele hatte es geärgert, daß die Köche zuviel aktive Zigaretten rauchen würden. Wir hätten uns auch dafür interessiert, wenn an der Ausgabe für die Spüler Zigaretten abgegeben würden. Es wurden sogar Verdächtigungen ausgesprochen, daß die Köche Verpflegung verschieben würden. Hier sind leider einige Kameraden vom Kochpersonal beteiligt, aber es dürfte sich nur auf einen Kameraden beziehen. Die Ursache zu dieser feindseligen Haltung dürfte daran liegen, daß wir in Schicht arbeiten und der übrige Teil nur an vier Tagen der Woche in Schicht arbeitet, während sie an drei Tagen voll arbeiten müßten, d. h. zwölf Stunden. Man hat nun beim „Alten“ erreicht, daß die Köche die Küchenmaschinen und Wurstschneidemaschinen reinigen müssen, jedoch nur, wenn es ihre Zeit erlaubt. Soweit ich die Lage überblicken kann, kam dieses Ersuchen nicht vom Küchenreinigungsdienst, sondern von solchen, die mit dieser Arbeit nichts zu tun haben. Bei uns herrscht eine äußerst miese Stimmung und wird morgen wahrscheinlich ihr Nachspiel haben. Jedenfalls hat man uns angegriffen, und wir werden Kontra geben. So lächerlich sich diese Sache anhört, so bezeichnend ist sie für uns Deutsche im allgemeinen. So wie hier bei uns in der Gefangenschaft, mag es auch in der Heimat sein, daß einer den anderen verkauft, wenn es einem etwas besser geht. Für den einzelnen, das heißt für den Angegriffenen, sein eigenes Ich in jeder Weise durchzusetzen. Wo ist die Gemeinschaft geblieben, die uns zwei Jahre geschlossen dem Ami zeigte und vieles durchzusetzen vermochte?! Ich will zu unseren Gunsten annehmen, daß es ein Zustand einer längeren Gefangenschaft sein mag und eine Ausgeburt überreizter Nerven, verursacht durch einen verlorenen Krieg. - In letzter Zeit verfalle ich immer mehr in Grübeleien, was immer eine schlaflose Nacht zur Folge hat. Es ist eine Kritik meiner eigenen 
Vergangenheit. Eine weitere Erkenntnis, dem Leben zu wenig abgewonnen zu haben. Vorwürfe, zu anständig gelebt zu haben und das Leben zu wenig genossen zu haben. So sehe ich all meine verflossenen Mädchen vor Augen. Wie oft ich sie wohl enttäuscht haben mag. War das alles im Anfang eine stolze Erkenntnis, da ja ein guter Ausgang des Krieges das alles gerechtfertigt hätte.

So erfolgte mit militärischem Zusammenbruch auch ein moralischer Zusammenbruch, denn nun war alles umsonst gewesen. Diese Erkenntnis hatte ich oft in Rußland, wenn der Gevatter Tod mehr als einmal anklopfte. Dann kam in langen besinnlichen „Bunkerstunden“ in einem das Gefühl auf, im Leben zu wenig genommen zu haben, das Leben zu wenig genossen zu haben. Wäre es nach einem guten Ausgang des Krieges möglich gewesen, sich eine materielle Grundlage $\mathrm{zu}$ einem Lebensglück $\mathrm{zu}$ schaffen, so ist heute alles verloren. Kommen wir eines Tages in die Heimat zurück, dann beginnt der Kampf um das nackte Leben, und dann dürfte wohl kaum Zeit vorhanden sein, "leichten Abenteuern" nachzugehen. Wir sind Überlebende aus einer kurzen, aber ,großen Zeit". Manchmal beneidet man die Kameraden, die in Rußland blieben und im Glauben an den deutschen Sieg ihr Blut dahingaben. Sie wissen nichts von der Vernichtung des deutschen Volkstums, sie wissen nichts vom Hungertod des deutschen Volkes, der gleichfalls den Tod einer europäischen Zivilisation bedeutet. Wie oft steigen mir Bilder der Erinnerung auf in diesen schlaflosen Stunden. Wie oft bin ich in Gedanken zu Haus. Wie oft sehe ich das Abschiedsbild vor meinen Augen, wie du, liebe Mama, mit der kleinen Ingrid auf dem Arm mir nachschaust, als ich euch in den ersten Tagen des Januar 1943 verließ. Wie du, kleine Ingrid, mir eine Kußhand nachwarfst. Ich ahnte so etwas, daß ich euch so bald nicht wiedersehen sollte. Wie nahm ich dieses Bild in meinem Gedächtnis auf. Nie werde ich es vergessen, sollte ich euch nicht wiedersehen können. Nichts weiß ich von eurem Schicksal. Rechne ich mit dem Schlimmsten, dann mag ich vielleicht der einzigste Überlebende einer Familie sein, so wie es bei vielen sein mag. Du Menschenherz, wie magst du das alles überstehen? Wir müssen unseren Weg zu Ende gehen und weiter der Hoffnung leben. Möge einst der Tag kommen: „Immer daran denken, aber nicht davon sprechen." - Verachtung und $\mathrm{Haß}$ wurde in meinem Herzen geboren, als ich den Weg in die Gefangenschaft antrat, und so ist es auch heute geblieben. Lumpen, die sich Kameraden nennen, zu verachten und den Feind zu hassen, der sich mit dem Teufel verband, um das große deutsche Volk zu vernichten.

Samstag, 29. 12.45

Heute abend um 19.30 Uhr mußten wir uns den Film „Deutschland erwache" ansehen. Er schildert uns die Zustände in den KZ-Lagern Buchen- 
wald und Belsen beim Zusammenbruch, wie sie durch die Amerikaner angetroffen wurden. Die Sprache war deutsch. Es war ein Haßgesang auf alles Deutsche, auf das „Dritte Reich“" insbesondere. Kurze Ausschnitte aus der „Bewegung“ zeigten die Ziele auf, für die unser Vaterland gekämpft hatte.

\section{Mittwoch, 2. 1. 1946}

Heute abend um 20.00 Uhr hatten wir im Speisesaal unserer Lagerküche die schriftliche Prüfung abzulegen nach Abschluß des Unterrichts über „Amerikanische Geschichte“. Auf einem vorgedruckten Formular wurden uns 50 Fragen vorgelegt. Bei der Prüfung sollte ursprünglich der ,,Intelligence Officer" zugegen sein, hatte aber abgesagt. Somit nahm unser Kamerad Lorenz, der den Unterricht geleitet hatte, die Prüfung ab. Die 49. Frage lautete: ,Warum scheiterte der Völkerbund?“

\section{Dienstag, 8. 1. 1946}

Um 20.30 Uhr wurde uns durch den Lagersprecher (über Lautsprecher) eine Meldung aus der Presse durchgegeben. Das Kriegsdepartement teilt mit, daß alle Kriegsgefangenen, die sich zur Zeit in den USA befinden, bis zum 30. 4. 46 in ihre Heimatländer überführt werden sollen. Im Augenblick stehen 80000 Deutsche zur Abfahrt bereit. Weiter wurde bekanntgegeben, daß laut „,Genfer Konvention“ Amerika nicht verpflichtet wäre, vor Abschluß eines Friedensvertrages die Kriegsgefangenen heimzuschikken. Wegen der besonderen Arbeitslosigkeit wünscht das Kriegsdepartement eine frühere Heimschickung. Die 5000 japanischen Kriegsgefangenen werden auf den Hawaii-Inseln angesiedelt, da diese in ihrer Heimat als tot gelten.

\section{Donnerstag, 9. 5. 46}

Heute vor drei Jahren traten wir den Weg in die Gefangenschaft an. Heute vor einem Jahr unterschrieben wir im Camp Brady unseren Arbeitsvertrag auf 90 Tage. Nun habe ich bereits 265 Arbeitstage hinter mir. Rückblikkend auf die drei Jahre waren es harte und lichte Tage, hoffnungsvolle und schmerzvolle. Die ersten zwei Jahre wurden durch den Glauben an den Sieg Deutschlands mit einer gewissen Leichtigkeit ertragen. Dann aber kamen die Tage eines März, April und Mai vor einem Jahr. Ich denke an die Nächte von Brady, da der Rundfunk die Meilenzahlen angab, als der Russe unaufhaltsam auf Berlin marschierte. Das Herz wollte einen schier erdrücken. Was ist aus den Eltern geworden, den lieben Schwestern, das frage ich mich schon ein ganzes Jahr. Seit über einem 
Jahr keine Nachricht mehr von zu Haus. Man darf sich nicht selbst verlieren! Das Herz hat sich mit einer Eiskruste umgeben. Was wird nun werden!? Eine oft wiederholte Frage. Das Leben will gemeistert werden, doch zuvor die Gefangenschaft. Unsere Tage sind gezählt, daß wir abgelöst werden, man spricht vom 19. Mai. Wann werden wir die Fahrt in die Heimat antreten?

Mittwoch, 19. 6. 46

Am Montag wurde bei der Nachmittags-Zählung durch den Lagersprecher bekanntgegeben, daß am Donnerstag die Marschgruppe I (Zone 1 bis 4 und 6) das Lager verläßt. Gestern abend um $20.00 \mathrm{Uhr}$ erschienen der Lagerkommandant vom Fort, der Führer des Kaplan. Corps, unser Lagerkommandant, die Lageroffiziere, der Lagerführer und als Zivilist Prof. Böhmer. Sie alle erschienen, um über den Lagerpfarrer Worte des Dankes und des Abschieds zu sagen. Am meisten beeindruckt waren wir von der Rede des Obersten, der uns sagte, daß er uns lange beobachtet habe, daß er unsere Arbeit gesehen habe und uns alles Gute wünscht, ein frohes Wiedersehen in der Heimat. Prof. Böhmer sprach darüber, was ihn am meisten in den USA beeindruckt hat als naturalisierter Deutscher, wenn er nun auch Amerika verlassen würde und einen Rückblick halten würde. Er sprach von der Gleichheit der Person, der persönlichen Freiheit, der Gewalt des Staatsbürgers durch seine Stimme. Er sprach weiter von der Hilfsbereitschaft des einzelnen, vom amerikanischen Tempo. Der Amerikaner müsse immer beschäftigt sein, und das können wir am besten beurteilen, er habe aber von uns das Gegenteil festgestellt. Er führte weiter aus, daß er sehr gern zu uns gekommen sei, denn wir wären für ihn die Brücke zwischen der alten und der neuen Heimat. Er berichtete, daß er seine Mutter in Kürze aus Deutschland erwarte, die nun im hohen Alter ihre Heimat verläßt. Seine Nachbarn wüßten, daß sie wenig Kleider habe, und so wurden ihm bereits welche angeboten. Kurz gesagt, es war eine Propagandarede für die Demokratie von Amerika. Auch er gab uns wie die übrigen Herren schöne Abschiedsworte mit auf den Weg und hoffe auf Nachricht aus unserer Heimat. Der Pfarrer, der wohl den besten Eindruck bei uns allen hinterlassen hat, ließ seine Adresse zurück. Zum Abschluß sprach der Lagersprecher und gab den Herren unseren Dank zum Ausdruck für ihr Erscheinen und ihr entgegengebrachtes Interesse. Im Laufe des Vormittags wurden die Seesäcke durchsucht. Es wurde insbesondere die Seife, Zigaretten auf die vorgeschriebene Menge überprüft (vier Stangen Zigaretten, acht Stück Seife). Es wurde festgestellt, daß in den vier zugelassenen Stangen Zigaretten jeweils zwei Päckchen mehr enthalten waren, wer erwischt wurde, hatte sie einmal gehabt. Ich selbst hatte Glück und bekam alles durch. In mein Bücherpaket hatte ich bei der Zensur einen Teil meiner schwarzen Zigaretten hineingeschmuggelt. Bei der Waage hatten wir 
auch Glück, es waren 65 Pfund eingestellt, einschl. 10 Pfund Bücher, und so kam ich mit 3 Pfund Übergewicht durch. Es gab natürlich auch etwas zum Lachen, ein Kamerad hatte den Befehl, alles aus den Behältern zu entleeren, nicht durchgeführt. Die Folge war, daß der Posten alles aus dem Karton auskippte und nicht wenig erstaunt war, daß es im Karton noch immer klapperte. Es waren Zigaretten, lose im doppelten Boden verpackt! Handschuhe, Seife und Zigaretten wurden von den Posten als willkommene Beute vereinnahmt.

\section{Donnerstag, 20.6. 46}

Seit 6.30 Uhr stehen wir am Tor. Gegen 8.00 Uhr verlassen wir das Lager. Völlig durchschwitzt haben wir den Abmarschplatz erreicht. Ich trage am Körper eine Sommergarnitur Unterwäsche, eine Wintergarnitur, eine Khakihose, eine Tuchhose, einen Winterpullover, einen Uniformrock, unter dem Wintermantel den Brotbeutel getarnt, angefüllt mit Seife, zwei Paar Strümpfe und ein Paar Schnürschuhe (Alaska-Stiefel). Die Presse ist erschienen, Aufnahmen werden gemacht. Fahrzeuge fahren vor. Neger fahren uns, die freuen sich mit uns, daß wir heimkehren sollen. Gegen 10.00 Uhr verläßt der Zug den Verladebahnhof des Lagers. Zonenweise haben wir die Wagen bestiegen. Linker Hand grüßt uns das Olympiagebirge, weiße Schneefelder bedecken die Spitzen. Unendlich lang erstreckt sich die Bucht. Abgestellte Kriegsschiffe, Transporter. Bald durchfahren wir das Felsengebirge. Es ist eine großartige Gebirgslandschaft. Schneebedeckte Gipfel, enge Schluchten, vorbei an reißenden Gebirgsbächen, dicht bewachsene Berghänge mit hohen Tannenwäldern. Das Tal breitet sich aus, wir sind im Wenadscheetal, berühmt wegen seiner Obstplantagen. Auf den windgeschützten Berghängen erstrecken sich die großen Obstplantagen. In der Mehrzahl Äpfel und Birnen. Gebirgswasser wird zur Bewässerung abgeleitet. Von 15.00 bis $17.00 \mathrm{Uhr}$ haben wir Aufenthalt. Bis zum Einbruch der Abenddämmerung durchfahren wir ein weites Steppengelände. In den Abendstunden durchfahren wir wieder bebautes Land. Gegen 22.00 Uhr erreichen wir Spokane und bleiben auf einer Straßenbrücke stehen. Wir sehen auf eine hellerleuchtete Straße. Lichtreklamen blinken uns entgegen. Liebespärchen wandeln eng umschlungen daher. Die Fahrzeuge reißen nicht $a b$. In der Nacht durchfahren wir den Staat Idaho.

\section{Sonntag, 23. 6.46}

Gegen 8.00 Uhr erreichen wir die Vorstädte von Chicago im Staate Illinois. Zeitweilig können wir die Umrisse der Wolkenkratzer von Chicago sehen. Wir durchfahren das Industrieviertel. Fabrik an Fabrik. Selbst an einem großen Schlachtviehhof geht die Fahrt vorbei. Hier herrscht ein un- 
heimlicher Gestank, doch bekommen wir einen Eindruck von dieser Anlage. Zwei tote Schweine von etwa 4 bis 5 Zentner liegen auf einer Rampe. Wahrscheinlich sind sie kurz vor Feierabend kaputtgegangen. Wir laufen nun in einen Überholungsbahnhof ein. Hier werden die Züge nachgesehen und versorgt. Neger beiderlei Geschlechts reinigen die D-Züge. Um 13.30 Uhr verlassen wir Chicago. Die Fahrt geht südlich des Michigansees durch den Staat Indiana. 17.30 Uhr Battle Creek. Den Staat Michigan erreichen wir um 14.00 Uhr. Wieder geht es an herrlichen Seen entlang. Autos parken irgendwo am Strand. Schöne Motorboote, Paddelboote, Segelboote. Alt und jung badet im See. Dichte Laubwälder und Hecken durchziehen das Land. Weizenfelder von unermeßlich großer Ausdehnung. Farmen, von dichtem Laubholz umgeben, den grauen hohen Silos, rot gestrichene und weiß abgesetzte Farmhäuser. Hier herrscht jetzt in erster Linie Viehzucht. Die Weideflächen werden von dichtem Laubwald unterbrochen, Weißdornhecken grenzen die Weideflächen voneinander ab. Schöne aufgelockerte Landstädte. Jedes Haus ist von dichten Laubbäumen umgeben. Schöne gepflegte Rasenflächen umgeben das Haus. Plattenbelegte Wege führen vom Haus zur Straße. Kein Zaun stört das Bild! Jedes Haus steht im gleichen Abstand vom nächsten. In der Nacht durchfahren wir kanadisches Gebiet, nördlich am Eriesee entlang. Passieren Buffalo im Staat New York.

\section{Montag, 24. 6. 46}

Gegen 7.00 Uhr passieren wir die Stadt Syracuse. Noch immer dicht bewaldetes Gebiet, Erlen und Weiden. Schwarzweiß und buntgeflecktes Rindvieh auf den Weiden. Es herrscht teilweise Bergland vor. Das landwirtschaftliche Gebiet wechselt nun in Industriegebiet über. Seit $11.00 \mathrm{Uhr}$ fahren wir am Hudson-Fluß entlang. Der Strom erreicht die Breite der Donau bei Wien. Die Flußlandschaft hat den Charakter der Wachau, nur daß die Burg-Ruinen fehlen, statt dessen stehen Villen auf den Höhen. Gegen 16.00 Uhr erreichen wir das Verschiffungslager Shanks. Lautsprecher orientieren unsere Posten. Fahrzeuge fahren für unser Gepäck vor. Bald marschieren wir zum Lager. Es herrscht hier eine unheimliche Hitze. Uns läuft der Schweiß, wenn man bedenkt, daß wir einen Pullover und Wintermantel tragen. Große Massen stehen am Lagereingang. Etwa 9000 POW sollen hier im Lager sein. Täglich gehen etwa $3000 \mathrm{ab}$. Wir treffen viele Bekannte aus früheren Lagern. Etwa zwei Tage sollen wir hier bleiben.

Mittwoch, 26. 6. 46

Schon gestern war es uns bekannt, daß heute der Tag unserer Verschiffung sei. Bereits um 11.15 Uhr mußten wir abmarschbereit antreten. Es hatte viel Schweiß gekostet, bis wir um 12.15 Uhr die Fahrzeuge bestiegen 
hatten. Die Negerfahrer fuhren uns wie die Feuerwehr. Etwa acht Meilen ging die Fahrt auf einer herrlichen Waldstraße entlang. Mittels eines Fährschiffes wurden wir auf einen Truppentransporter der Viktoria-Klasse gebracht. Gegen 13.00 Uhr verließen wir amerikanischen Boden. Ich schätze, daß etwa 1000 Mann das Schiff betreten haben. In drei Etagen sind wir untergebracht. Unter Deck sind an Haltestangen je acht Hängematten aufgehängt. Es gibt einen Speisesaal sowie Toilettenräume an Bord. Gebläse sorgen für frische Luft. Gegen 16.30 Uhr werden die Anker gelichtet. Wir durften zu unserer Freude an Deck bleiben. Der Hudsonfluß wird immer breiter. Zu beiden Seiten bewaldete Hänge. Zur linken Seite erstrecken sich die ersten Häusermassen von New York. Unmittelbar am Uferrand zieht sich eine Autohochbahn entlang. Eine nicht abreißende Autoschlange nach beiden Fahrtrichtungen. Auf der rechten Seite verkehren D- und Güterzüge nach beiden Richtungen. Wir passieren eine ungeheure Hängebrücke, getragen von gewaltigen hohen Betontürmen. Die Häusermassen werden dichter, die ersten Hochhäuser sind zu sehen. Gegen 17.00 Uhr passieren wir die ersten Wolkenkratzer. Gewaltig ragen diese grauen Stahlbetonklötze in den Himmel hinein. Wir nähern uns der berühmten Halbinsel Manhattan, hier sind die Wolkenkratzer auf engem Raum massiert. Das höchste Bauwerk der Welt, das Empire State Building, und das Chrysler-Gebäude als zweithöchstes zeigen sich uns in einmaliger Höhe. Nun fahren wir zur linken Seite an den Anlegestellen der Passagierdampfer und zur rechten an den Frachtern vorbei. Dort wo sich der Hudson zur Bucht ausweitet, der äußersten Spitze der Halbinsel gegenüber, erhebt sich die Freiheitsstatue, den Ankommenden zum Gruß, den Scheidenden zum Abschied. Auf einer Insel ragt diese Figur, auf einen Sockel gestellt, in den Himmel. Das Haupt nach Osten gedreht, von einem Strahlenkranz umgeben, die rechte Hand erhoben, umfaßt eine Fackel, die Fackel der amerikanischen Freiheit. Was man darunter zu verstehen hat, dafür muß man drei Jahre als POW in diesem Lande gelebt haben. Noch einmal werfen wir einen Blick nach rückwärts und sehen das berühmte Panorama des Wolkenkratzerviertels von See her, wie es sich als eine gewaltige Masse gegen den blauen Himmel abhebt. Mit zunehmender Entfernung jedoch - verschwinden die Wolkenkratzer immer mehr im Dunst dieser großen Stadt. Nicht zu zählende Schiffe, hauptsächlich Transporter, liegen in der Bucht. In Höhe des Feuerschiffes wird der Lotse von einem Motorboot an Bord genommen, wir beobachten dieses interessante Manöver. Das Festland tritt immer mehr zurück, wir befinden uns nun auf freier See. Es ist Zeit zum Essen geworden. In einzelnen Buchstabengruppen werden wir in den Speisesaal gerufen. Masse Mensch, wo man hinschaut, wann werden wir daraus erlöst werden? Es ist 21.00 Uhr geworden. Ich liege in der vierten Etage, im vierten Bett hoch und schreibe diese Zeilen. Aus der Lautsprecheranlage ertönt amerikanische Musik. 
Freitag, 5. 7. 46

Wetter: leicht bewölkt, Sonnenschein. Frühstück: Haschee, Reisbrei, zwei Scheiben Brot, Kaffee. Gegen Mitternacht hatten wir die südliche Enge der Irischen See durchquert. Gegen 7.00 Uhr sehen wir rechter Hand Land, es ist die englische Küste! Schwärme von Möven begleiten uns. Um 12.30 Uhr fallen die Anker im Hafen von Liverpool. Seit 19.00 Uhr stehen wir an Deck, um erst gegen 23.30 Uhr den bereitstehenden Zug zu betreten. Gegen 0.15 Uhr verlassen wir den Bahnhof. Das Ziel ist unbekannt.

Sonnabend, 6. 7.46

Gegen 5.30 Uhr erreichen wir den Bahnhof Nottingham. Unser Gepäck wird verladen. Wir marschieren in etwa 15 Minuten zum Lager. Es ist im Wollaton-Park gelegen. Bis zur Mittagszeit liegen wir auf der Filzwiese.

Die Filzung geht schnell vonstatten. Die Tommies sehen nach Zivilklamotten. Wir werden in Baracken mit je 50 Mann untergebracht. Es ist ein Durchgangslager, das in einem schönen Eichen- und Buchenpark eingerichtet wurde. Am Rande, auf einer Höhe jenseits des Stacheldrahts liegt ein Schloß. - Am Abend sehen wir im Lagerkino einen Vorfilm: ,Singendes Deutschland“ und als Hauptfilm den deutschen Film: ,Glück unterwegs“.

Sonntag, 7. 7.46

Gestern abend kamen weitere 1000 Mann aus Übersee, vom Camp Shanks bei New York. Einen Tag haben wir gebraucht, um uns von dem Schock zu erholen, daß wir nicht in die Heimat geschickt, sondern in der Landwirtschaft eingesetzt werden sollen. Der Menschenhandel geht weiter. Am Abend Konzert im Freien. Die Kapelle überraschte uns mit guter $\mathbf{M u}$ sik, ein Chor und Tenor gaben Einlagen. Auf der Höhe am Schloß hatte sich eine Menschenmenge eingefunden. Darunter viele Mädchen und Frauen! - Am Nachmittag wurden wir neu aufgenommen, d. h., wir erhielten auch eine neue Gefangenen-Nummer.

Dienstag, 9. 7.46

Am Vormittag mußte jede Gruppe zur großen Aufnahme und einen Fragebogen mit sechs Fragen ausfüllen. 
Die 1. Frage lautete: „War die nationalsozialistische Idee eine gute Idee?"

Die 2. Frage: „War die nazistische Idee nur schlecht ausgeführt worden?"“

Die 3. Frage: ,Würde ein nationalsozialistischer Sieg das menschliche Dasein der übrigen Völker Europas verbessert haben?"*

Die 4. Frage: „Waren Sie Mitglied der Partei?"“

Die 5. Frage: „Ist das deutsche Volk am Krieg schuldig?"

Die 6. Frage: ,Wird der ProzeB in Nürnberg ${ }^{28}$ zur Aburteilung der führenden Nazis zu Recht geführt?“

Der Inhalt der Fragen war uns schon zuvor bekannt geworden. Die Ratschläge des Stammpersonals besagten, daß die ersten fünf Fragen mit "nein" zu beantworten wären und die letzte Frage mit ,ja“. Im großen und ganzen ist in diesem Sinne der Fragebogen beantwortet worden. „Wir sind nur noch Maske", war die allgemeine Stimmung. Es hat kein Mensch Interesse, sich irgendwie die „Finger zu verbrennen“. Gestern gab der Rundfunk bekannt, da $B$ in New York die letzten 8000 deutschen POW auf ihren Abtransport nach Übersee warten, aber wohin, das wurde nicht bekanntgegeben. Wir selbst haben es ja am eigenen Körper erlebt, wohin die Reise ging! - Am Abend wurde uns von den Kameraden ,,von drüben“ die Operette „Zauber der Liebe“ gegeben. Geschrieben in vier Akten und komponiert von Kurt H. Heinrich. Sie hatte ,die große Sehnsucht nach Liebe" zum Thema und war vielleicht ein Spiegel unseres eigenen Ichs. Es gab nette Schlager, die gewiß einmal ihren Weg in der Heimat machen werden. Natürlich war das weibliche Geschlecht auch vertreten. Alles in allem waren wir überrascht von dem Dargebotenen und klatschten begeistert Beifall.

\section{Mittwoch, 24. 7. 46}

Wir haben unseren ersten Arbeitstag bei einem Bauern hinter uns. Mit 13 Mann fanden wir uns um 7.30 Uhr am Tor ein. Hier stand ein Lkw einer Farmgenossenschaft. Fünf weitere POW aus einem benachbarten Lager waren uns zugeteilt. Es hieß, daß wir Rüben verziehen sollten, und das gab uns einen leichten Schock (in Erinnerung an das Rübenziehen in den USA). Die Fahrt ging quer durch die Stadt Nottingham. Was uns überraschte, waren die vielen Frauen, die wir zur Arbeitsstelle eilen sahen. Die Bürgersteige waren dicht begangen, an den Haltestellen drängten sie sich. Nur wenige Männer konnten wir entdecken. Was uns an den Frauen auffiel, daß sie im Durchschnitt sehr klein waren. Alle sehr schlank, blaß und leicht geschminkt. Weiter fiel uns auf, daß sie keine Strümpfe trugen. Viele lächelten uns zu, alle nahmen zumindest Notiz von uns. Kinder winkten uns zu. Nach vierzig Minuten Fahrtzeit erreichten wir eine kleine Bergarbeitersiedlung nahe einer Kohlenzeche. Kumpels, ihren Schutzhelm 
noch auf dem Kopf, kamen von der Arbeit heim. Schwarz im Gesicht, wie sie aus dem Stollen kamen, gingen sie nach Haus. Für uns brachte das ein Erstaunen zum Ausdruck, denn uns war bekannt, daß unsere Kumpels gewaschen die Zeche verließen. - Vom Bauernhof fuhren wir zum nahen Feld. Der Bauer selbst nahm von uns keine Notiz. Unser Lkw-Fahrer, zugleich Vorarbeiter, regelte den Arbeitsablauf mit ihm. Wir hatten Kartoffeln zu lesen. Je neun Mann auf eine Reihe eingeteilt, fuhr der Bauer mit seinem Traktor und angehängter Kartoffelbuddelmaschine Runde für Runde. Jeder von uns hatte etwa ein Strecke von $50 \mathrm{~m}$ zu sammeln. Es waren Frühkartoffeln und im Durchschnitt sehr klein. Bald hatten wir es heraus, daß es sich zu zweit besser sammelte. Der Geizkragen von Bauer hielt an, wenn er auf der Strecke noch eine kleine Kartoffel liegen sah. - Von 12.00 bis $13.00 \mathrm{Uhr}$ gab es Mittagspause, und wir verzehrten unser halbes Brot, dazu etwas Margarine, etwa $20 \mathrm{~g}$, etwas Fleisch, ca. $30 \mathrm{~g}$. Der Bauer hatte uns einen Wasserkakao zur Verfügung gestellt. Das „Stimmungsbarometer" war nicht das beste. Es wurde über den geizigen Bauern geschimpft, 38 Milchkühe auf der Weide und keinen Tropfen Milch im Kakao. - Von 13.00 bis $17.00 \mathrm{Uhr}$ ging es im alten Tempo weiter. Bis zum Freitag soll hier unsere Arbeit dauern. Wir hoffen, dann ein kleines Kommando mit vier Mann zu bekommen. In der Mittagspause erzählten uns die Kameraden vom 262. Lager Episoden aus ihrer Zeit in Belgien. Zum Teil wurden sie an der Elbe gefangengenommen und nach Belgien transportiert. Es wurde ihnen alles abgenommen, selbst das Taschentuch. Den Winter verbrachten sie im 228. Lager. Untergebracht in Zelten auf nacktem Kalkboden. Sie erhielten fünf Decken pro Nase. Öfen mußten sie sich aus Konservendosen herstellen. Pro Tag gab es ein Pfund Kohle. Geheizt werden durfte erst ab 17.00 Uhr. Schikaniert wurden sie auf das schwerste. Sie mußten stundenlang bei der Zählung im Schlamm stehen. An den Wintertagen mußten die Zeltwände aufgerollt werden. Geschlagen und auf Hungerrationen gesetzt. Ein jeder erklärte ihnen, daß aus diesem Lager ein belgisches Belsen ${ }^{29}$ gemacht würde. Von 25000 Mann starben 5000 Mann an der Ruhr. Am Anfang wurden sie von der belgischen Bevölkerung beschimpft und bedroht. Später, als die Bevölkerung die englische Besatzungszeit verspürte, verwandelte sich der $\mathrm{Haß}$ in Sympathie, und man dachte an die deutsche Besatzungszeit zurück.

Die KPD hatte durch eine Untergrundbewegung Fluchtversuche organisiert. Die Gebühr bestand in einer goldenen Uhr oder Wertsachen von ansehnlichem Wert. Die Flüchtlinge wurden bis zur deutschen Grenze gebracht und erhielten ordnungsgemäße Entlassungspapiere. In erster Linie wurden sie in die russische Zone überführt. Die drei Kameraden im Alter von 19 bis 21 Jahren und ein älterer Kamerad von etwa 35 Jahren erklären uns, „wir können es nicht mit Worten schildern, was wir mitgemacht haben". - Im Monat März kamen die ersten Kameraden aus den Staaten, denen hatte man auch erzählt, daß sie nach Hause kämen. Sie mußten 
freiwillig ihren Tabaksbestand abgeben und durften nur zwei Päckchen Zigaretten und vier Päckchen Tabak behalten. Die dortigen Kameraden erhielten jedoch nur einen geringen Prozentsatz an Rauchwaren, alles andere verschwand.

\section{Mittwoch, 14. 8. 46}

Überraschend schnell hat unsere Zeit im Wollaton-Park ein Ende gefunden. Was es uns bedeutete, empfinden wir jetzt in einer trostlosen Einsamkeit auf einem ehemaligen Fliegerhorst der RAF. Gegen 9.00 Uhr verlieBen wir 47 Mann, meistens ,Amerikaner“, wie wir von Übersee genannt wurden, die man schnell loswerden wollte, das Lager. Im Fahrzeug wurden wir zum Hauptbahnhof von Nottingham gebracht. Mit einem fahrplanmäßigen Zug verließen wir um 11.00 Uhr die Stadt und fuhren über Lincoln. Gegen 14.30 Uhr erreichten wir in der Nähe von Boston das Lager Revesby. So liegen wir nun mit 150 Mann in einer Wellblechbaracke (Nissen-System) und sollen hier etwa drei Monate lang in der Landwirtschaft eingesetzt werden. Unsere Stimmung ist trostlos! Noch dazu, wenn man hinterher erfährt, daß eigentlich diese 47 Mann vom Stammpersonal versetzt werden sollten. Der Lagerführer hatte es verstanden, uns dafür abzuschieben. Das ist eine Folge der überaus großzügigen Selbstverwaltung der POW, deren Opfer wir nun geworden sind. Wir befinden uns in einem Seitenlager des Lagers 79.

\section{Montag, 19.8. 46}

Am Abend sprach der „Intelligence“-Sergeant zu uns. Er kam auf unsere Arbeit in der Landwirtschaft zu sprechen, daß die Ernährungslage in der Welt kritisch sei, so auch in Deutschland. England müsse größere Mengen Lebensmittel in die britische Zone einführen, und sie hätten selbst nichts im Überfluß. Von unserer Arbeit sei es abhängig, daß die englische Ernte restlos eingebracht werde und somit einen Beitrag an der Ernährung Deutschlands liefere. Von unserer Arbeit wird es abhängen, in welcher Reihenfolge wir heimkehren werden. Wann allerdings, darüber kann er auch keine Angaben machen. Ab September sollen allerdings von Nordengland monatlich 500 POW nach Deutschland kommen. Es ist wohl anzunehmen, daß die Zahl in Kürze erhöht werden wird. Auf unsere Einwände, daß uns schon so oft eine baldige Heimkehr versprochen wurde, kam er auf unsere Kriegsschuld zu sprechen. Wir hätten friedliebende Völker überfallen. Wir sollten nur an das russische Volk denken, und nun müßten wir auch die Folgen zu tragen wissen. In einer anschließenden Debatte wurde eingewandt, daß bereits viele Nazis nach Hause gekommen wären, und die eigentlichen Anti-Nazis wären immer noch hier, das wäre wohl keine Gerechtigkeit. Er mußte diesen Einwänden beipflichten 
und bemerkte hierzu, daß es sich eben um Leute handelt, denen man in der Heimat nichts nachsagen konnte. Er sprach ein fließendes Deutsch ohne Akzent. Ich habe später erfahren, daß er tschechischer Jude war.

\section{Samstag, 7. 9. 46}

Wieder Weizen eingefahren. Um 12.30 Uhr Feierabend. Nach Rücksprache mit dem Bauern, daß er uns etwas besseres Essen geben sollte, konnte er nicht stattgeben. Er erklärte uns, daß es für ihn verboten sei und er wöchentlich eine schriftliche Belehrung bekäme. Er müßte POW melden, die mit einem solchen Ansinnen an ihn herantreten.

Die Presse hatte inzwischen laufend berichtet, daß es die Ernte wahrscheinlich verregnen würde. Man müßte mit der schlechtesten Ernte seit achtzig Jahren rechnen. Man hatte die letzte Chance dem Wochenende gegeben, aber auch das verregnete es gründlich. So muß man wohl diese Ernte aufgeben. Noch nie in meinem Leben hatte ich ausgewachsenes Getreide gesehen. Die aufgestellten Mandeln hatten alle einen grünen Schimmer. Die Körner hatten in der Ähre grün ausgetrieben.

Ein besonderes Ereignis brachte die vergangene Woche. Eine Rede des Außenministers Byrnes (USA) in Stuttgart zum deutschen Volk. „Hoffnung für Deutschland" brachten die Zeitungen als Überschriften. Byrnes brachte zum Ausdruck, daß das amerikanische Volk für die Freiheit der Völker gekämpft habe und Amerika nun entschlossen sei, sich weiter an der europäischen Politik zu beteiligen. In absehbarer Zeit soll das deutsche Volk eine demokratische Regierung erhalten. Es werde eine bundesstaatliche Verfassung gefordert. Wenn auch der Krieg schon ein Jahr vorüber sei, so müsse bald ein Friedensvertrag dem deutschen Volk vorgelegt werden. Amerika entspricht dem Antrag Frankreichs, das Saargebiet abzutreten. Im Osten sollten Grenzbereinigungen zugunsten Polens vorgenommen und eine endgültige Grenze festgelegt werden. Amerika ist bereit, Deutschland zu helfen. Es müsse aber Jahre harter Arbeit hinter sich bringen, um wieder den Lebensstandard europäischer Völker zu erreichen. „Es liegt nicht im Interesse des deutschen Volkes und des unseren, $\mathrm{da} ß$ es in einem Kampfe zwischen Ost und West eine Rolle spielen wird“, war ein deutlicher Hinweis auf die augenblickliche Lage.

Ich konnte mit eigenen Ohren hören, wie der Rundfunk die Worte brachte: „Amerika habe einen weiteren Beitrag geleistet und sämtliche Kriegsgefangenen in die Heimat entlassen." Wir selbst spüren die Unwahrheit eines Staatsmannes am eigenen Körper. Er führte weiter aus, daß „,Deutschland wieder einen Platz an der Sonne erhalte“.

Donnerstag, 28. 11. 46

Gestern fuhren wir mit Werner Anders und Fritz Neumann nach einer 
Woche Arbeitsruhe wieder hinaus zur Arbeit. Wir waren zu dritt bei einem Bauern eingeteilt und waren neugierig, was es für Arbeit geben würde. Wir hatten über eine Stunde zu fahren. Es war die Strecke über Northkyme. Als wir den kleinen Hof betraten, sahen wir, daß Vorbereitungen zum Dreschen getroffen wurden. Es dauerte bis etwa gegen 10.00 Uhr, da der Bauer seinen Traktor nur schwer aufstellen konnte. Ich selbst stand auf der Miete und reichte einem Mädchen, der Nichte vom Bauern, die Garben zu. Sie stand auf der Dreschmaschine und schnitt die Garben mit einem Messer auf und ließ das Getreide in den Kasten rutschen. Es war ein windiger und regnerischer Tag. Gegen 11.00 Uhr machten wir Pause und kamen nicht mehr zur Arbeit, da der bisher feine Regen nun immer stärker geworden war. Unser englischer Zivilfahrer, wegen seiner schlechten Fahreigenschaften übel verleumdet, war schon beim Einfahren in den Hof in den größten Dreck gefahren, als er im Hof nicht mehr kehrtmachen konnte und auf die Wiese fuhr.

Gegen 12.00 Uhr verließen wir das Gehöft, um die anderen Kommandos abzuholen. Etwa um 13.00 Uhr fuhr unser Lkw auf regennaßer Straße in eine rechtwinklige Kurve mit einer Geschwindigkeit von ca. 30 Meilen. Der Fahrer bremste in der Kurve scharf $a b$, es gab einen scharfen Ruck, und der Lkw mit ca. 35 Mann kippte um, alle vier Räder nach oben. Ich fühlte einen starken Schlag gegen meine rechte Kopfhälfte. Mein rechter Arm war mir zurückgerissen worden und war so zusammengedrückt, daß ich mich nicht rühren konnte. Wir alle saßen auf aufgestellten Bänken, die nicht auf dem Boden befestigt waren. Ich saß auf der letzten Bank mit dem Rücken zum Fahrerhaus. Uns war klargeworden, es hatte einen Unfall gegeben. Es gab sofort einige Kameraden, die zur Ruhe mahnten. Wir machten uns etwas Luft und riefen den anderen $\mathrm{zu}$, daß sie sich beeilen sollten, aus dem Lkw herauszukommen. Nur schwer bekam ich meinen Arm in eine normale Lage und war der letzte, der aus dem Wagen herauskroch. Ich sah noch vor mir das gerissene Maschendrahtgitter, das als Auflage für die Plane diente. Meine Mütze lag vor mir, innen mit Blut befleckt. Werner Anders rief mir zu, ich sollte nach hinten aussteigen bzw. kriechen. Meine erste Frage war, als ich draußen war, ob mein Kopf ganz war. Er klärte mich auf, daß ich einen Riß über dem rechten Auge hätte. Ich solle nicht hinfassen. Im nachhinein konnte ich mich erinnern, daß vom gesprungenen Drahtgeflecht ein Stück senkrecht stand, scharf wie eine Messerspitze, hatte es meine Kopthaut dicht über dem rechten Auge aufgeschnitten. Ich wurde in ein nahes Farmerhaus gebracht, dort befanden sich schon die anderen Verletzten. Ich sah zwei aufgeregte Frauen hin und her laufen, wie sie ihren Teppich zusammenrollten und die Stühle zusammenschoben. Einige Kameraden hatte man auf den Boden gelegt. Ich mußte mich auf einen Stuhl setzen. Ich spürte starke Schmerzen im Kopf. Wenig später kam ein ziviler Arzt, der uns die Erste Hilfe zukommen ließ. Ich wurde in ein anderes Haus geführt, in der Küche lagen andere Ver- 
letzte. Auch hier war ein Arzt an der Arbeit. Bald waren alle verbunden und unsere Namen aufgeschrieben. Ein „Bobby“ war auch anwesend und ließ sich unsere Namen geben. Der Kraftfahrer, der nach dem Unfall querfeldein geflüchtet war, inzwischen zurückgekehrt, verteilte Zigaretten, die Hausfrau schenkte uns einen Tee ein. Gegen 15.30 Uhr erschienen zwei Fahrzeuge, die den Lkw abschleppten und die Unverletzten mitnahmen. Wir anderen mußten bis 18.00 Uhr warten, bis uns ein Pkw zum Hauptlager Morby brachte. Nach einer Stunde Fahrt erreichten wir das Lager. Im dortigen Krankenrevier wurde ich von einem deutschen Unterarzt, im Rang eines Oberfähnrichs, ärztlich behandelt. Ich erhielt eine örtliche Betäubung, die Schnittwunde wurde mit mehreren Fäden genäht, anschließend wurde ich zu Bett gebracht. Die weitere Diagnose lautete: mittelschwere Gehirnerschütterung. Meine rechte Kopfhälfte war verschwollen.

\section{Donnerstag, 5. 12. 46}

Am heutigen Vormittag wurden wir zu dritt nach Lincoln in das englische Lazarett transportiert zwecks Röntgenuntersuchung. Von mir wurde je eine Aufnahme vom Kopf und von meiner Schulter gemacht. Die Aufnahmen zeigten keine inneren Verletzungen. Zwei Kameraden waren bereits gestern eingeliefert, einer mit einem Schädelbruch, der andere mit einem Oberarmbruch. Die Fahrt war für mich sehr anstrengend. Ich leide noch immer an sehr starken Kopfschmerzen. Die ersten sieben Tage war ich in einem Einzelzimmer untergebracht worden, da ich unbedingte Ruhe benötigte. Seit heute liege ich wieder in einem Krankensaal mit 18 Betten. Die Nähte wurden entfernt, und ich trage nur noch ein Kopfpflaster.

\section{Mittwoch, 25. 12. 46}

Gestern wurde uns die Verfügung des Kriegsministeriums bekanntgegeben, daß es den Kriegsgefangenen gestattet sei, im Umkreis von fünf Meilen das Lager zu verlassen, Einladungen von englischen Familien anzunehmen und Gespräche mit den Zivilisten zu führen. Es ist verboten, öffentliche Verkehrsmittel zu benutzen sowie öffentliche Häuser zu betreten, wie Kinos, Tanzstätten, Gastwirtschaften.

Auf allgemeinen Wunsch des Lagers wurde auf eine Weihnachtsfeier verzichtet. So verlief der gestrige Tag wie jeder andere. Für heute und den nächsten Tag ist arbeitsfrei. Heute morgen gab es zum Frühstück einen Stollen, zwei Pfefferkuchen und eine Handvoll Pfeffernüsse. Ein Weihnachtsbaum steht im Speisesaal, ein äußeres Zeichen, daß wir Weihnachten haben. Allgemein kann festgestellt werden, daß jeder bemüht ist, die Gefühle einer weihnachtlichen Stimmung zu unterdrücken. Wer hatte wohl vergangene Weihnachten nicht gehofft, doch bestimmt diese Weih- 
nachten bei den Angehörigen zu verbringen? Die Enttäuschung ist zu groß, um sich dem Zauber dieses deutschesten aller deutschen Feste hinzugeben. Ein bedeckter Himmel spiegelt unsere Stimmung wider. Ein starker Wind zerfetzte die Regenwolken. Am Vormittag wie am Nachmittag machte ich einen Spaziergang in die nähere Umgebung.

Zu Mittag gab es eine Flasche Bier, das Stück Fleisch war dieses Mal in einem Stück zu sehen, und die Soße fiel etwas fetter aus als sonst.

Einige Kameraden hatten Einladungen erhalten und dürfen bis um 22.00 Uhr ausbleiben. Bei der Nachmittagszählung um 16.30 Uhr fehlten bereits 18 Mann. Die Folge, daß bei der Zählung die Fehlenden aufgeschrieben wurden. Leider gab es zu den Feiertagen keine Post. Die Theatergemeinschaft wartet an den Feiertagen mit einem Varietéprogramm auf.

\section{Sonntag, 26. 1.47}

Gestern berichtete „,Daily Mail‘“, daß es den deutschen Kriegsgefangenen in Frankreich freigestellt wird, entweder nach Hause zu fahren oder sich als freie Arbeiter zu verpflichten. Es handelt sich um $476000 .^{30}$

Seit Freitag bin ich wieder in Arbeit mit einem Kommando von zehn Mann beim Grabenreinigen. Wir haben eine Fahrt von einer Stunde. Man hat uns Gummistiefel zur Verfügung gestellt. Es ist eine schwere Arbeit, den Morast aus den Gräben zu entfernen.

\section{Mittwoch, 29. 1. 47}

Die heutige Presse bringt die Nachricht, daß auf Grund einer Anfrage im Unterhaus sich zur Zeit 355000 deutsche Kriegsgefangene im Land befinden. Seit September 1945 bis Ende des Jahres 1946 wurden 466000 Deutsche heimbefördert.

\section{Samstag, 1. 2. 47}

Abschrift des Fragebogens über die politische Einstellung: „Hitler ist in einer verzweifelten Lage des deutschen Volkes zur Macht gekommen und verstand es, durch - Brot und Spiele - von verantwortungsvoller Mitarbeit abzuhalten. Diejenigen, die da warnten, wurden als - Meckerer - in den KZ kaltgestellt. Durch geschickte Propaganda wurde seine Stellung als Despot - dem Volk verschleiert. Er führte das Volk in einen Krieg, den es nie gewollt, auf einen Weg, den es selbst in der Masse nicht zurück konnte. Hätten sich Männer gefunden, ihn zur rechten Zeit zu vernichten, dann wäre es vielleicht nicht zu spät geworden. Durch Nichtachtung des Lebens einzelner wie fremder Nationen, durch Verletzung abgeschlosse- 
ner Verträge, hat er das Vertrauen der Welt Deutschland gegenüber auf das empfindlichste Maß mißbraucht und die deutsche Ehre beschmutzt. Beim Scheitern seiner Pläne sich der Verantwortung entzog und sie plötzlich dem deutschen Volk zuschob, somit das Volk in den Abgrund einer völligen Vernichtung stoßen wollte. Aus dem Nichts emporgestiegen, in das Nichts hinabgestiegen, sich selbst und seiner Idee den Tod gegeben."

Gegen 18.40 Uhr erfolgte meine Vernehmung durch einen Major. Als ich den Schulraum betrat, sah ich den Offizier hinter einem Schreibtisch sitzen, und er schrieb. Es dauerte einige Sekunden, bis er aufblickte und meinen Namen nannte. Er hatte meinen ausgefüllten Fragebogen vor sich liegen, den ich seinerzeit in Amerika ausgefüllt hatte. Ich überreichte meinen hier ausgefüllten Fragebogen. Er las meine Angaben, drehte das Blatt und las meine Stellungnahme über Hitler.

„Wofür haben Sie das EK II bekommen?“ war seine erste Frage. Ich gab zur Antwort, daß ich es in Rußland erhalten hätte, bei der Abwehr eines Angriffs auf den Troß durch die Russen. „Seit wann sind Sie in der Wehrmacht, sind Sie vorher bei der Polizei gewesen?" war die zweite Frage. Ich erklärte, daß ich 1933 bei der Polizei eingetreten wäre und im Oktober 1935 zur Luftwaffe übernommen wurde. ,Sehen Sie, das war auch solch eine Sache, die übertreten wurde“, war seine Antwort. Ich erklärte ihm, daß ich auf Grund wirtschaftlicher Nöte einen Beruf meinen Neigungen entsprechend nicht ergreifen konnte. Ich wurde durch meinen Vater beeinflußt - Junge, werde Beamter -, mich zur Polizei zu melden. „Ja, und warum hat Deutschland den Krieg verloren?" war die dritte Frage. Ich antwortete, daß der Krieg schon zu Unrecht begonnen wurde und damit schon verloren war. kung.

„Nicht durch den Verrat Ihrer Offiziere?“ war seine Zwischenbemer-

„Dieser Verrat hatte keinen Einfluß mehr auf den Ausgang des Krieges", gab ich zur Antwort.

„Ja, was dachten Sie sich, als das Regime 1933 zur Macht kam?“ war seine vierte Frage.

„Daß es nichts Gutes bedeuten konnte, wenn das durchgeführt wird, was programmiert wurde“", antwortete ich.

Damit war das Verhör beendet, und ich war nach sechs Minuten entlassen.

Freitag, 30. 5. 47

Seit Mittwoch, 28. 5. 47, arbeiten wir an der Ausfallstraße WoodhallKirkby, in der Nähe des Polenlagers. Wir wären ja gern noch eine Zeitlang an der alten Baustelle geblieben, in der Nähe von Conningsby. Unsere Arbeitsbude stand einem einzelstehenden Haus gegenüber, hier wohnt ein ehemaliger Förster. Unser Kaffeekoch, Hermann, hatte ,Was- 
serbeziehungen" aufgenommen, mit dem Erfolg, daß wir jeden Tag eine Flasche Milch und sechs Eier bekamen, also jeder Mann von uns ein Ei zu Mittag erhielt.

Am letzten Mittwoch hatte ich in Vertretung die Gelegenheit, die alte Dame zu sprechen, und war erfreut, wirklich eine nette Frau kennenzulernen, die voll Hochachtung von uns Deutschen sprach. Ihr Gatte war vor dem Frieden in der Nähe von Köln und hatte den denkbar besten Eindruck von Deutschland. Sie sprach ein ausgezeichnetes Englisch, daß es eine Freude war, sich mit ihr zu unterhalten. Ja, erklärte ich ihr, das wäre das erste Mal gewesen, daß wir Eier geschenkt bekommen hätten, und die nicht von einem Bauern, sondern von einem Rentier.

Jetzt arbeiten wir in der Nähe des Polen-Camps und können so etwas Einblick bekommen. Wir konnten nur feststellen, daß sich diese Soldaten der englischen Armee den ganzen Tag sonnten und dafür vom englischen Staat bezahlt wurden. Unsere englischen Arbeiter, mit denen wir zusammen arbeiten, sind gar nicht gut auf die Polen zu sprechen. Sie werden als Arbeitswillige von ihnen abgelehnt. Die Polen haben zum Teil Quartiere mit ihren Frauen. Das Lager besteht aus ,Nissen-Hütten“ und ist von schattigen Bäumen umgeben. Nur eine Viertelstunde Fußweg von Woodhall-Spa entfernt. - Die Gerüchte haben sich nun bewahrheitet, daß unser Lager aufgelöst wird. Die Versetzungen werden nun täglich durchgeführt.

Sonntag, 8. 6.47

Am 4. 6. 47 wurden wir mit 65 Mann von Tatterschall zum Lager 262 Langar verlegt und kamen in das Seitenlager Abdelton, ca. eine Meile von Nottingham entfernt gelegen. Wir trafen gegen 12.00 Uhr im Hauptlager ein und traten am Abend die Fahrt im Lkw zum Seitenlager an. Hier traf ich alte Kameraden vom Lager Brady (USA), mit denen ich auch im Lager Fort Lawton zusammen war. Wir sind in einem kleinen Lager untergebracht, das ehemals Landmädchen als Unterkunft gedient hatte. Zur Zeit sind wir etwa 130 Mann stark. Das Lager wird von einem Sergeanten und einem Korporal geführt. Es sollte sich herausstellen, daß diese Herren einen sehr starken Druck auf uns ausübten. Ihre stärkste Waffe gegen uns, die Ausgangssperre.

Am letzten Donnerstag war ich das erste Mal in der Stadt Nottingham. Ich kam bis zur Trent-Brücke, benannt nach dem Fluß Trent, und mußte wegen Regen wieder kehrtmachen.

Am Freitag und gestern war ich wieder mit einem Kameraden in der Stadt, und wir kamen bis zum Stadtzentrum. Wir waren ca. 45 Minuten gelaufen. Was uns sehr verwirrte, war der starke Verkehr. Nun ja, seit Jahren hatten wir hinter Stacheldraht gelebt. Gestern machten wir einen Spaziergang am Trent-Ufer entlang. Vorbei an vielen Sportplätzen, auf denen Tennis und Kricket gespielt wurde. Autos hielten am Straßenrand, und die Insassen schauten dem Spiel zu. 
Unser Weg führte uns zum Schloß von Nottingham, hier saßen wir eine halbe Stunde. Wir waren beeindruckt von der Pflege der Parkanlagen, im Gegensatz zu den Straßen, die einen sehr schmutzigen Eindruck machten. Papierfetzen, Schmutz jeder Art wird vom Wind durcheinandergewirbelt. Unser Weg führte uns weiter zum Marktplatz, an dessen Ende sich der monumentale Bau der Stadthalle emporhebt. Es ist ein viereckiger Bau, die Stirnseite von einer Säulenreihe durchbrochen. Eine flache Dachkonstruktion, darüber erhebt sich eine gewaltige Kuppel. Als wir unter dem Säulengang standen und den Verkehr an uns vorüberfluten ließen, kam ein älteres Ehepaar vorüber und musterte uns. Der alte Herr trat zu uns heran und gab meinem Kameraden ein 2-Schilling-Stück mit dem Zeichen, $\mathrm{da} ß$ es für uns beide wäre.

Gestern gab es die erste Ausgangssperre. Um 14.00 Uhr kehrten wir von der Arbeit zurück, vom Rübenhacken, als wir erfuhren, daß erst um 17.00 Uhr Ausgangserlaubnis gewährt würde.

Heute morgen bei der Zählung erfahren wir, erst um 12.00 Uhr Ausgang, da die Lagerarbeiten nicht zur Befriedigung des Sergeanten ausgefallen wären. Heute wurden sogar Leute zum Kohlenschaufeln verlangt. Die Einwände, daß viele um 10.00 Uhr zur Kirche gehen wollten, wurden abgelehnt. Ich erlebe es zum ersten Mal, daß wir am Sonntag Arbeitsdienst stellen mußten, solange ich in Gefangenschaft bin. Der Lagersprecher ist der ganzen Lage nicht gewachsen.

Trotz aller Schwierigkeiten gingen wir am Nachmittag aus. Unser Weg führte uns am Trent-Uferstrand entlang über die große Trent-Brücke. Das Wetter war ausgezeichnet. Auf der Promenade herrschte ein reger Spaziergängerverkehr, meist junge Menschen. Ruderboote zogen vorbei. In Höhe des Gefallenen-Denkmals für die Toten des Ersten Weltkrieges bogen wir ein und durchschritten die gewaltige Pforte dieses Monuments. Ein wunderbarer Steingewächsgarten nahm uns auf. Vorerst war wohl nichts, was uns interessieren könnte. Wir wählten den Weg am Trent entlang, um in weitem Bogen nach der dritten Brücke stadteinwärts zu gehen. Von weitem wird das Schloß von Nottingham sichtbar, das auf steilen Sandfelsen errichtet und unser Ziel war. Nach etwa 20 Minuten Weg auf steiler Zufahrtsstraße durchschritten wir das Tor. Ein schön gepflegter Garten nahm uns auf. Von der Schloßterrasse hatten wir einen weiten Blick über das grüne Hügelland. Wir waren wohl insgesamt zwei Stunden gelaufen und bedurften der Ruhe. Gegen Abend, etwa 18.00 Uhr, gingen wir zum Marktplatz, um hier unsere Studien zu treiben. Es dauerte auch nicht lange, und eine Kapelle der Heilsarmee nahm Aufstellung. In ihrer blauen Uniform mit rot abgesetzten Biesen und Schirmmützen brachten sie mit ihren Blasinstrumenten Marschmusik. In den Pausen las irgend jemand von den uniformierten Begleitern etwas aus der Heiligen Schrift. Nach und nach wurde die Kapelle von nachfolgenden Musikanten aufgefüllt. Frauen, ebenfalls in Uniform, schlossen den offenen Halbkreis und san- 
gen Kirchenlieder. Die Zuhörer wurden immer zahlreicher und warfen nach Aufforderung Münzen in den Kreis der Musikkapelle. Es mag wohl eine Stunde gedauert haben, als sie sich zum Abmarsch formierten und mit Musik den Marktplatz verließen. Wenig später sollten wir durch Volksredner überrascht werden. Vor uns auf den Stufen stand ein junger Mann. Es war ein Vertreter einer kirchlichen Sekte. In lebhafter Sprache warb er für seine Idee. Es mögen wohl 30 Zuhörer gewesen sein. Es herrschte Schweigen. Wir konnten ernste ausdruckslose Gesichter beobachten. Doch er war nicht der einzige, der sprach; etwa $15 \mathrm{~m}$ weiter warb ein kommunistischer Redner für seine Partei. Im einfachen Arbeiteranzug stand er auf der Brüstung und schleuderte seine Worte unter die Zuhörer, die einen Kreis von ca. 100 Personen bildeten. Ich war neugierig und hörte zu. Ich konnte noch die Worte vernehmen: „Rußland, das größte Land der Welt und Paradies der Arbeiter", als mir ein älterer Herr auf den Arm tippte und uns fortzog. Er sprach sich sehr abfällig über den Redner aus, natürlich auch über Rußland. Ich erklärte ihm, daß ich das ,Arbeiterparadies" ein Jahr lang im Feldzug erlebt hätte. Ja, ich traute meinen Ohren nicht, er zitierte Worte aus A. Hitlers „Mein Kampf“, worin die Judenfrage angeschnitten wurde. Ich konnte ihm nicht beipflichten, da ich „Mein Kampf" bisher noch nicht gelesen hatte. Gegenüber dem kommunistischen Redner sprach ein Apostel einer kirchlichen Sekte. Hier hatte sich ein Kreis gebildet von jungen Menschen. Sie sangen religiöse Lieder. Man kann sich vorstellen, daß der vorgenannte Redner sich alle Mühe gab, um sich gegenüber dem Gesang zu behaupten. Ich konnte mich eines Lächelns nicht erwehren. Zwischen allen aber promenierten junge Mädchen, sie lachten und scherzten. Kaum hatte uns der alte Herr verlassen, als uns ein Herr im schwarzen Anzug ansprach. Er stellte sich als Pfarrer der Methodistenkirche vor. Er versicherte uns, daß er an die Worte Jesu glaube und an seine Wiederkehr. Er fragte uns natürlich, was wir vom Glauben halten und welcher Konfession wir angehörten. Er freute sich zu hören, daß wir uns als Konfessionsangehörige bekannten. Wir klagten ihm unser Leid, daß wir am Vormittag nicht zur Kirche gehen konnten, da wir Ausgangssperre hatten und Kohlen schippen mußten. ,Aber das können Sie nachholen“, war seine Entgegnung. ,Ich lade Sie zu einer Abendandacht ein." Wir konnten nun schlecht ablehnen und folgten ihm. Groß war unser Erstaunen, als er uns zum Gemeinschaftshaus der Methodisten führte. Er zeigte auf eine Tafel, auf der die einzelnen Räume aufgeführt waren, und ich sah: „Andacht für Taubstumme“. Das kann ja nett werden, dachte ich bei mir. Wir betraten einen kleinen Raum, eine kleine Gemeinde von ca. 15 Personen war versammelt und wartete auf ihren Pfarrer. Unser Begleiter stellte uns der Gemeinde in der Zeichensprache vor, und wir wurden durch Handschlag begrüßt. Es herrschte unter den Anwesenden eine ehrliche Freude, daß zwei deutsche Kriegsgefangene als Gäste anwesend waren. Es wurde uns die Bibel und ein Gesangbuch in die Hand 
gedrückt. Ein älterer Herr begab sich zum flachen Podium und eröffnete den Gottesdienst. Man sang gemeinsam ein Lied, d. h. wir zu dritt. Während der Herr auf dem Podium durch Zeichengebung vorlas und alle anderen folgten dem Text im Buch. Der Pfarrer hielt seine Rede in der Zeichensprache, während unser Begleiter uns den Text übersetzte. Ich tat es in Deutsch, da mein Kamerad kein Englisch verstand. Der Predigt lag das Thema „Die Liebe Gottes" zu Grunde. Eine Stunde dauerte der Gottesdienst, und anschließend folgte eine kleine Aussprache, die sich in der Hauptsache auf unsere Person bezog.

Freitag, 20.6. 47

Als ich gegen 17.30 Uhr von der Arbeit, vom Rübenhacken, heimkehrte und vom Wagen sprang, überraschte mich der Lagersprecher mit der Ankündigung, daß ich meine Sachen packen müßte. Ich habe mich morgen abmarschbereit zu halten zwecks Fahrt zum Hauptlager. Mir wurde ganz anders, wie ich die Worte „,versetzt“" hörte. „Ja, warum denn“", fragte ich zurück. „Zwecks Überführung in die Heimat“, bekam ich zur Antwort. Ich konnte es kaum glauben, ich war sprachlos. Ich hatte vorerst damit nicht gerechnet, nachdem mich der Lagerdolmetscher für den Posten als Hauptlagersprecher vorschlagen wollte. Ich hatte abgelehnt. - Das war so: Vor etwa 14 Tagen mußte ich nach Rückkehr von der Arbeit zur Schreibstube. Nun, was sollte das bedeuten, fragte ich mich. Ich hatte ja kein schlechtes Gewissen. Da empfing mich der Lagerdolmetscher, ein Pole der „Anders-Armee“, und fragte mich, wie es mir hier in England nach der Überführung aus den USA gefiele. „Nun, sehr gut, vor allen Dingen die Toleranz der Engländer.“ „Ich habe aus Ihren Personalien festgestellt, daß Sie in Westpreußen geboren sind, ich auch", gab er zur Antwort. Ich war erstaunt. „Ja, da haben wir beide unsere Heimat verloren, meine Eltern mußten unsere Heimat im Januar 1920 verlassen.“ „Ja, ich habe eine schöne Aufgabe für Sie, ich suche einen Hauptlagersprecher und halte Sie für geeignet." Nur das nicht, dachte ich mir. Ich holte tief Luft und lehnte sehr höflich ab. „Ja, warum denn? Sie bekommen ein eigenes Unterkunftszimmer, einen höheren Sold, eine bessere Verpflegung, ein Dolmetscher wird Ihnen zur Verfügung gestellt.“ Ich merkte, von diesem Posten kommst du nicht los. Aber da fiel mir plötzlich meine Einstufung in Gruppe 12 ein, die als nächste anstand zur Entlassung in die Heimat. Da gab er sich geschlagen, aber er versuchte es noch einmal mit der Bemerkung: „Wollen Sie sich nicht freiwillig auf ein Jahr verpflichten?“" „Nein, danke", gab ich zur Antwort, damit war unsere Unterredung beendet.

Montag, 23. 6. 47

Am Vormittag Vorbesichtigung durch den Quartiermeister. Am Nachmit- 
tag Besichtigung durch den Kommandanten einschließlich Seesack. Wir packten vorsichtshalber nur die zustehenden Sachen ein, so daß im allgemeinen die Säcke ziemlich zusammengefallen waren. Das fiel auch dem Kommandanten auf, und er fragte verschiedene POW, ob sie ihren zweiten Seesack unter dem Bett stehen hätten. Er stellte an jeden Fragen über Zeit der Gefangennahme, Truppenteil usw. Inzwischen war es mir aufgefallen, daß ich mich unter Kameraden befand, die in die britische und russische Zone entlassen werden sollten. Nach Rücksprache mit dem Lagersprecher erfahre ich, daß meine Entlassung in die russische Zone vorgesehen sei. Demnach wurde mein Antrag im Camp 79 nicht berücksichtigt, obwohl er als genehmigt zurückkam, daß ich in die amerikanische Zone entlassen werden möchte. Mir wurde geraten, eine Änderung im Munsterlager (britische Zone) zu versuchen.

\section{Dienstag, 24. 6. 47}

Um 9.30 Uhr mußten wir vor dem Hauptquartier stehen. Die ersten zehn POW wurden gefilzt, verschiedene hatten das Pech, ihre amerikanischen Zigaretten loszuwerden.

Wir wurden mit Lkw zum Bahnhof gefahren. 11.15 Uhr ab Bingham, 13.50 Uhr an Leicester. Nach zwei Stunden Marsch erreichten wir das Lager Nr. 34 Scraptoft, Thurnby/Leics. Am heutigen Tag herrschte sehr warmes Wetter, selbst das Handgepäck wurde zu schwer. Wir wurden zonenweise auf die Baracken eingewiesen. Empfingen ein Drittel Brot und je neun Mann eine Büchse Schinken (1 lb).

\section{Samstag, 5. 7. 47}

Die Tage wollen nicht vergehen. Man hat sich inzwischen auf die hiesigen Verhältnisse umgestellt. Wenn wir um 7.00 Uhr unseren dünnen Wasserporridge verdrückt haben, ist noch Zeit bis $8.30 \mathrm{Uhr}$, um zur Zählung zu gehen. Wenige Minuten danach hat sich alles unter die Decken verkrochen, bis kurz vor $12.00 \mathrm{Uhr}$ wird geschlafen. Nur so kann das ewige Hungergefühl herabgedrückt werden. Zur Zeit herrscht ein ungewöhnlich kühles Wetter, daß man selbst nachts mit drei Decken sich gerade warm halten kann. Haben wir den dünnen Mittagseintopf eingenommen, wird wieder bis 16.00 Uhr geschlafen. Nach der Einnahme des Abendbrots von einem Drittel Brot, $10 \mathrm{~g}$ Margarine, $56 \mathrm{~g}$ Belag fühlt man sich etwas wohler und gesättigt, daß man etwa eine Stunde ,,Runden drehen“ kann. Man sitzt dann noch im Gras und unterhält sich mit den Kameraden. Die Stimmung ist im allgemeinen sehr ernst und gefaßt. Jeder macht sich insgeheim Sorgen und Pläne, wie er den Weg in der Heimat weiter machen wird. 
Heute begehe ich meinen Jahrestag, daß ich ein Jahr in England bin. Wieder ein Jahr, das vom freien Leben abgeschnitten wurde. Im Vergleich zu denen, die bereits von den USA aus ihre Fahrt in die Heimat antreten konnten.

\section{Donnerstag, 10. 7. 47}

Bereits um 3.00 Uhr Wecken. Um 4.00 Uhr empfangen wir unseren Wasserporridge. 5.00 Uhr Abgabe der Decken und Strohsack. Überall heißt es stehen und warten. Um 6.00 Uhr müssen wir heraustreten und warten wieder bis 7.00 Uhr am Tor. Es hat in den letzten zehn Tagen fast immer geregnet. Es ist sehr frisch, und wir frieren jämmerlich. In jeweiliger Fahrzeugsbesatzung passieren wir ein letztes $\mathrm{Mal}$ das Tor und durften die ,Augen links" nehmen, denn der Kommandant stand am Tor und grüßte uns ein letztes Mal. Auf dem Bahnhof hieß es wieder warten, als wir um 9.00 Uhr den Bahnhof von Leicester verließen. Ein erregendes Gefühl. Kaum saßen wir im Zug, wurde als Mahlzeit ein Drittel Brot verdrückt. Bald fielen uns die Augen zu, denn wir hatten ja in der letzten Nacht kaum geschlafen.

Um 13.00 Uhr erreichen wir den Kai von Hull. Ein Gepäckkommando hatte bereits in Leicester die Seesäcke verladen. Jetzt marschierten wir am Gepäckwagen vorbei und schnappten uns einen Seesack. Nur 50 Schritt und wir hatten das Schiff erreicht. Die „Stamford“ der Viktoria-Klasse sollte uns heimbringen. In riesigen Netzen wurden die Säcke an Bord genommen.

Um 13.20 Uhr bestieg ich die Schiffstreppe und verließ somit englischen Boden, auf dem ich ein Jahr und fünf Tage unfreiwillig verbracht hatte. Wir mußten alle sofort unter Deck. Pünktlich um 14.00 Uhr verließ das Schiff den Hafen. Ich saß im dritten Deck und unterhielt mich mit den Kameraden, als mir gegenüber mich einer fragte, woher ich käme. Ich antwortete: „Aus Nauen.“ „Was, aus Nauen, in welcher Straße?“ „Gartenstraße", gab ich zur Antwort. Es stellte sich heraus, daß dieser Kamerad in unserer Nachbarschaft beim Tierarzt Dr. Friesicke gewohnt hatte.

Noch einmal gehen wir an Deck. Es regnete, als wir die weite Bucht von Hull verließen. Um 16.00 Uhr gibt es eine warme Mahlzeit, grüne Erbsen, zwei Salzkartoffeln, ein wenig Fleisch, drei Scheiben Brot und ein wenig Margarine. Um 21.00 Uhr gibt es noch einmal Kakao.

\section{Freitag, 11. 7.47}

Frühstück: Grießsuppe, drei Kartoffeln, ein Stück gebratene Leber, Soße, ein halber Becher Kaffee, zwei Scheiben Brot.

Das Wetter ist nach wie vor verregnet. Gegen 9.30 Uhr passieren wir Helgoland. Die vordere Hälfte ist von den Engländern weggesprengt wor- 
den, man sieht einige Grate aus dem Wasser ragen. Von der hinteren Hälfte ist der Leuchtturm zu sehen, und ganz schwach konnte man die Schattenrisse von Häusern beobachten. Gegen 11.00 Uhr: ein halber Becher Suppe, vier Salzkartoffeln, Soße, eine dünne Scheibe Rindfleisch, Reissuppe, eine Scheibe Brot.

Gegen 13.00 Uhr sollen wir Cuxhaven erreichen. Die Stimmung ist keine freudige, alles sehr ernst. Man macht sich keine falschen Vorstellungen. Wie vorgesehen erreichen wir um 13.00 Uhr Cuxhaven. 13.20 Uhr betreten wir deutschen Boden. Etwa $200 \mathrm{~m}$ sind zu laufen, und wir besteigen unseren Zug, der uns nach Munsterlager bringen soll. Sang- und klanglos betraten wir nach genau viereinhalb Jahren deutschen Boden, denn am 10. 1. 43 befand ich mich in Italien. Gegen 15.00 Uhr fahren wir ab, 19.30 Uhr Lüneburg. Bei unserer Fahrt durch Hamburg-Harburg bekommen wir einen Begriff vom Ausmaß der Zerstörung, Ruinen und nochmals Ruinen. Um 21.30 Uhr erreichen wir das Lager Munsterlager. Etwa eine dreiviertel Stunde hatten wir zu laufen. Unser Gepäck wurde gefahren. Wir werden zonenweise auf die Baracken eingewiesen und empfangen noch in der Nacht, etwa gegen 2.00 Uhr, unseren Seesack. Wir erhalten noch eine warme Suppe, ein halbes Brot, etwas Margarine, Käse und Zucker.

\section{Samstag, 12.7.47}

Am Vormittag erhalten wir unseren Bonus ausgezahlt: 178,- RM. Vor uns wird ein Transport abgefertigt, der aus Rußland kam. Ein Bild des Jammers, ein Bild ohne Worte. Man muß sie gesehen und gesprochen haben.

Am Nachmittag erhalten wir unser Entlassungsgeld, weiter werden unsere Personalaufnahmen gemacht.

\section{Dienstag, 15. 7. 47}

Heute früh verließen die Kameraden das Lager, die in der russischen Zone zu Hause sind, zur Fahrt nach Friedland, um dort den Russen übergeben zu werden.

Meine Umschreibung zur Entlassung in die amerikanische Zone vollzog sich ohne Schwierigkeiten. - Vorgestern ging ich mit dem Kameraden Werner Fenger in den Wald zum Blaubeerenpflücken.

Was war das für Gefühl, wieder die würzige Waldluft zu atmen. Vorbei an Tannen und Kiefern hatten wir eine halbe Stunde zu laufen. Es war natürlich alles von POW überlaufen, die hier auf der Suche nach Blaubeeren waren, auch viele Frauen und Kinder waren beim Pflücken. In etwa zwei Stunden hatte ich die Hälfte meines englischen Kochgeschirres vollgepflückt. Am Abend mit Zucker vermischt, gab es eine wunderbare Nach. speise.

Jetzt in den vergangenen Tagen hatten wir ausreichend Gelegenheit, mit 
den Kameraden zu sprechen, die aus Rußland zurückkamen. Sie ergaben einen erschütternden Anblick, der all ihr Leid und Elend deutlich widerspiegelte. Die meisten trugen noch ihre deutsche Uniform, die mit vielen Flicken notdürftig instand gesetzt war. Das Schuhzeug bestand meist aus selbstgefertigten Holzschuhen, der Oberschuh aus Leinen gefertigt. Sie trugen deutlich die Merkmale einer starken Unterernährung. Viele hatten Wasser, bezeichnend war ihre blasse Gesichtsfarbe, stark abgemagerte Arme und Füße, kurz geschorener Kopf. Sie strömten den üblichen Duft einer Entlassung aus (bedingt durch die Entlausung der Bekleidung).

Sie gaben uns ein Stimmungsbild vom russischen Volk und den russischen Soldaten, ein Stimmungsbild der dortigen deutschen Lagerführung. Sie steckten in den weitaus meisten Fällen mit den Posten unter einer Decke, während sie das Los ihrer Kameraden zum Teil noch verschlechterten, sich an der Verpflegung vergriffen und diese verschacherten. „Ja, für eine Suppe verkauften sie ihr Vaterland", wie einer sich ausdrückte. Auch der Herr Paulus ${ }^{31}$ (Befehlshaber der eingeschlossenen Armee in Stalingrad) stand unter dem Zeichen der Verachtung. „Der Herr hätte in Nürnberg zuerst gehängt werden müssen“, konnte man hören. Den GröBenwahn russischer Offiziere gibt folgende Äußerung eines russischen Majors wieder: „Rußland hat in diesem Krieg die stärkste Militärmacht der Welt geschlagen, und das war Deutschland, folglich wird es auch Amerika und England besiegen."

\section{Donnerstag, 17. 7. 47}

Gestern zogen wir in das Qu-Lager um. Es wird ein Transport von insgesamt 1140 Mann zusammengestellt. Am Tag zuvor kam ein A-Transport (,Demokraten“) aus England mit 600 Mann an. Diese Herren haben das Glück, mit uns zu fahren und wahrscheinlich in Dachau als erste abgefertigt zu werden. Heute früh bereits um 3.15 Uhr Wecken. Das Gepäck wird verladen. Um 6.30 Uhr marschierten wir vom Lager ab. Nach 15 Minuten werden wir vom deutschen Transportstab auf die Waggons eingewiesen. Es ist ein deutscher Lazarettzug, der ausgeschlachtet wurde. Keine Sitzflächen, wir müssen uns auf unser Handgepäck setzen. Mit 56 Mann in einem Wagenabteil. Endlich ist es soweit, 8.20 Uhr fuhr der Zug an, und wir sind im Begriff, unsere letzte Etappe dieses dornenreichen Weges zu beenden. - Celle erreichen wir gegen 10.25 Uhr - Göttingen um 15.45 Uhr Würzburg an $3.30 \mathrm{Uhr}$, ab 6.00 Uhr - Augsburg an 14.30 Uhr - München an $15.30 \mathrm{Uhr}$ - Dachau an $19.00 \mathrm{Uhr}$.

Wir durchfahren die Lüneburger Heide, nach vielen Jahren sehe ich den herrlichen deutschen Wald wieder. Mit wehmütigem Herzen muß man sehen, wie große Waldflächen kahlgeschlagen wurden, um nach England transportiert zu werden. Hinter Göttingen zieht ein herrliches Hügelland vorüber. Das Korn ist gelb und harrt der Ernte. Je weiter wir nach 
Süden kommen, um so mehr ist das Getreide schon eingefahren. Wie oft konnten wir beobachten, daß junge Frauen mit der Sense das reife Korn mähen. Überall, wo wir hinsehen, fehlt es an Männern. Frauen winken uns zu. Auf den Bahnhöfen sehen wir Massen von Menschen, wieder in der Mehrzahl Frauen. Mit Handgepäck, sie wollen oder kommen vom Hamstern. Die einzige Möglichkeit, sich am Leben zu halten. Wir sehen in abgehärmte Gesichter. Auf den Bahnhöfen, wo wir Aufenthalt haben, kommen wir mit ihnen ins Gespräch. Überall hören wir von ihnen von der großen Not. Die Ruinen der Städte, durch die wir fahren, reden eine beredte Sprache.

Wir haben vom totalen Krieg gefaselt, die anderen haben ihn geführt. Das konnte man insbesondere in England feststellen, wo ich kaum zerstörte Häuser und Fabriken feststellen konnte. Man sprach vom Ausradieren englischer Städte, ausradiert aber wurden deutsche Städte. Welch ein Gefühl. Welch ein Bild deutscher Landschaft. Welche schmucke Dörfer. Hier auf dem Lande ein Bild des Friedens, ein Bild rastloser Arbeit.

Unvergeßlich war die Fahrt durch das schöne Mainfranken mit seiner Perle, der unvergeßlichen Stadt Würzburg, die ein Opfer des Krieges wurde. Wenn ich an die verkommenen Dörfer und Häuser in England zurückdenke, dann sieht man den krassen Unterschied gegenüber den schmucken deutschen Dörfern mit den Fachwerkbauten, den bunt gestrichenen Fassaden. Alles in allem ein freundliches Bild. Jeder Quadratmeter Boden ist bestellt. - Ein hochsommerliches Wetter, im Gegensatz zu England, das hier eine gewisse Beständigkeit besitzt.

Unsere Hoffnung, Dachau in 24 Stunden zu erreichen, wird zerschlagen, zu oft hielt der Zug. Noch lange müssen wir im ehemaligen KZ Dachau herumstehen. Wir werden ärztlich untersucht. Ein Abblasen mit Läusepuder berechtigt uns zum Eintritt in das Entlassungslager. Das Einweisen auf die Baracken geht sehr langsam vonstatten und ist schlecht organisiert. Die große Masse benimmt sich unmöglich. Jeder schiebt und drängt. Leider haben die älteren Semester ein rücksichtsloses Benehmen. Ich konnte nur feststellen, daß die wenigsten Kameraden auf Grund der Dauer der Gefangenschaft entlassen werden. Es sind „Kranke“, Bergarbeiter, besondere Fälle und die ,A-Leute“. Es sind 600 von insgesamt 1140 Mann. Noch spät nachts gibt es eine Scheibe Weißbrot, etwa $10 \mathrm{~g}$ Margarine und Tee. Es wird wieder betrogen, wohin man schaut. Diese letzten Tage und Stunden geben einem den Rest dieser unrühmlichen Zeit. Es mag 2.00 Uhr nachts gewesen sein, da ich den dritten Stock im Original-KZ-Bett (blankes Holz) besteige, um zu schlafen.

Samstag, 2. 8.47

Der Tag meiner Entlassung aus der Kriegsgefangenschaft ist gekommen. Um 7.30 Uhr mußten wir am Tor des ,Cage 7“ (Käfig) stehen. Mein Ge- 
päck war innerhalb der 14 Tage in Dachau mehr geworden. Es hatte mich nur einige Zigaretten gekostet, und ich hatte drei Arbeitshosen, drei Arbeitsjacken, eine Winterjoppe, ein Paar Arbeitsschuhe, zwei Decken, zwei Hemden, zwei Tuchhosen, zwei Jacken mehr in meinem Bestand.

Es begann die Zeit des Wartens, aber es bestand die Aussicht, noch heute das Tor der Freiheit zu passieren. Wir aßen noch zum Mittag, bekamen um 14.00 Uhr unseren Bohnenkaffee, um dann endlich gegen 15.30 Uhr aufgerufen zu werden. In Trupps zu 20 Mann nahmen wir Aufstellung vor dem Tor und erhielten die letzten Anweisungen vom Vertreter des Arbeitsamtes. Dann kam der große Augenblick, da uns der Entlassungsschein ausgehändigt wurde. In Marschordnung passierten wir den Posten, eine letzte Zählung, und wir waren entlassen. Die Sonne schien heiß, und wir hatten einen Weg von etwa einem Kilometer bis zum Schlagbaum zurückzulegen. Dort sollten uns die Fuhrunternehmer (mit Handwagen) in Empfang nehmen, um unser Gepäck zum Bahnhof zu fahren. $\mathrm{Ja}$, diesen $\mathrm{Weg}$ werde ich nicht vergessen. Ich kam immer nur eine Strecke von etwa $50 \mathrm{~m}$, dann mußte ich mein Gepäck absetzen, um zu verschnaufen. Meinen Seesack hatte ich auf den Rücken geschnallt, in der linken Hand einen großen Karton mit meiner gehamsterten Bekleidung, etwa 50 Pfund. In der rechten Hand meine Handtasche mit Brot und Toilettensachen. Ich brauchte wohl eine Stunde, bis ich am Schlagbaum ankam, aber die Handwagenfahrer waren nicht mehr dort. Ich war ja der letzte. Da kam ein älterer Herr mit einem Fahrrad daher, er suchte noch einen Kunden. Der Seesack wurde über den Gepäckständer quer gelegt, vorn auf den Lenker den Karton, auf den Seesack stützte ich meine Handtasche auf. So ging es zum Bahnhof. Die Gebühren betrugen nach freiem Ermessen. Ich gab vier „Ami“ (Zigaretten) und 1,- RM. Auf dem Bahnhof half mir noch der Zugführer mein Gepäck zu verstauen, das kostete eine „Ami", aber ich war im Abteil.

Um 17.00 Uhr verließ der Zug den Bahnhof Dachau, und gegen 17.30 Uhr erreichte ich den Hauptbahnhof von München. Was ich auf dieser Strecke an Ruinen zu sehen bekam, hatte ich in England nicht in einem Jahr gesehen. So stand ich vor dem Hauptbahnhofsgebäude. Vor mir die Ruinen des Telegrafenamtes. Was tun?

Ich fragte einen älteren Herren nach einer Taxe. Ich stellte fest, daß ich zur falschen Seite hinausgegangen war. Er half mir liebenswürdigerweise, mein Gepäck zur anderen Seite tragen, und das kostete wieder eine "Ami“" (Zigarette). Auf Grund meines Entlassungsscheines konnte ich eine Taxe beanspruchen, mußte aber warten, bis mindestens noch zwei Personen beisammen waren. Sie erschienen nach einer halben Stunde Wartezeit in der Person eines ,Fräuleins“ und eines Ami-Soldaten. Ich mußte kräftig schlucken. Aber was sollte man sagen.

Während meines Englandaufenthaltes korrespondierte ich mit einem ehemaligen Kriegskameraden S.-T. Er war einer meiner drei Geschützfüh- 
rer einer Flakeinheit während des Rußlandfeldzuges. So hatten wir vereinbart, daß ich einige Tage in seiner Wohnung absteigen könnte. Bald hatte ich mein Ziel im Süden von München erreicht. Mit letzter Kraftanstrengung schleppte ich mein Gepäck bis zum dritten Stock. Ich drückte voll Erwartung auf den Klingelknopf. Es öffnete die Schwiegermutter meines Kameraden. Die Eheleute waren gerade abwesend. Nun, es dauerte nicht lange, und es gab eine freudige Begrüßung.

Ich spendierte meinen mitgebrachten Bohnenkaffee aus England, der im Gegensatz zum Tee nicht rationiert war, eine Stange Pall Mall, Toilettenseife für das neugeborene Baby.

Nun bat ich um eine kleine Schüssel, öffnete meine Kakaobüchse, schüttete den Inhalt in die Schüssel und zog meine wohlverpackte ZeissIkon-Kamera $6 \times 9$ heraus. Dann bat ich um ein scharfes Messer, schlitzte meine selbstgebastelte Schreibmappe an den Seiten auf. Zuerst die eine Hälfte und brachte meine so getarnten $6 \times 9-$ Negative und aus der anderen Hälfte die $6 \times 9$-Positive heraus. Vier Jahre, zwei Monate und 23 Tage hatte ich um meine Kamera erfolgreich gekämpft. Wenn ich zurückdenke, dann waren es zu fünfzig Prozent Glück und fünfzig Prozent blitzschnelle Reaktion, um bei „99 Filzungen“ dem Ami ein Schnippchen zu schlagen.

\section{Schlußwort:}

Ich genehmigte mir selbst einen „Urlaub“ bis zum 18. 8. 47, um am 19.8. 47 bei der Firma Ph. Holzmann AG eine einjährige Umschulung zum Facharbeiter für das Maurerhandwerk anzutreten. Da ich keine Bleibe hatte, mußte ich wohl oder übel in das Barackenlager der Firma Holzmann in München-Obersendling einziehen. Mit 16 Mann auf der „Bude“ bezog ich meinen mit Papierschnitzel gefüllten Strohsack im „,II. Stock“. Mein erster Arbeitseinsatz erfolgte im Justizpalast in München am Stachus. Hier gab es viel Arbeit. Eingedrückte Wände und abgefallener Putz an den Wänden. Eine Folge der vielen Luftangriffe auf München. Eines Tages hatte ich in einem Hauptgang des Gebäudes einen Türbogen zu verputzen. Ein älterer Herr, mit einem Aktenbündel unter dem Arm, kam mit mir ins Gespräch. „Na“, sagte er, „,Sie sind doch auch nicht vom Bau?" „Nein", sagte ich, ,ich war Berufssoldat, und seit der Stunde ,Null' bin ich Umschüler."

„Ja“, sagte der Herr, ,ich war hier vor der Stunde ,Null“ der Präsident im Hause! Und jetzt bin ich Amtsbote." - Das gab mir zu denken. Wer war wohl tiefer gefallen? 


\section{Anmerkungen}

${ }^{1}$ Weder die Türkei noch Spanien traten in den Krieg ein, beide Staaten verfolgten eine Neutralitätspolitik. Die Türkei erklärte lediglich am 23. Februar 1945 Deutschland und Japan pro forma den Krieg. Der spanische General Franco erklärte zu Beginn des Krieges seine Neutralität und war auch nicht durch Hitlers Drängen zu einem Kriegseintritt zu bewegen. Nach dem Abschluß des „Iberischen Pakts" mit Portugal am 20. Dezember 1942 kühlten sich die Beziehungen zu Deutschland merklich ab. Japan hatte am 13. April 1941 einen vierjährigen Nichtangriffspakt mit der Sowjetunion geschlossen, der von der Sowjetunion aber 1944 gekündigt wurde. Japan machte Eroberungen im asiatischen Raum (Burma, Philippinen, Hongkong, Singapur), marschierte jedoch nicht in der Sowjetunion ein.

${ }^{2}$ Es ist erstaunlich, daß die gefangenen deutschen Soldaten diesen nach der Kapitulation von Stalingrad am 31. Januar 1943 doch sehr unrealistischen Berichten Glauben schenkten. Keine der angegebenen Informationen traf zu.

${ }^{3}$ POW $=$ Prisoner of War (Kriegsgefangener).

${ }^{4}$ Dem am 22. August 1864 in Genf abgeschlossenen internationalen Abkommen zum Schutz der Verwundeten, der Kriegsgefangenen und der Zivilbevölkerung in Kriegszeiten folgte am 27. Juli 1919 eine neue weitgehende Regelung zur Behandlung der Kriegsgefangenen, die von allen bedeutenderen Staaten mit Ausnahme von Japan und der Sowjetunion ratifiziert wurde.

${ }^{5}$ Italien hatte am 3. September 1943 ein zunächst noch geheimes Waffenstillstandsabkommen mit den Alliierten geschlossen, das formal der Forderung des amerikanischen Präsidenten Roosevelt nach einer bedingungslosen Kapitulation entsprach, Italien aber gewisse Rechte ließ. Der Waffenstillstand wurde erst am 8. September bekanntgegeben.

${ }^{6}$ Nach dem Bekanntwerden des Waffenstillstands wurde im Zuge der deutschen Gegenmaßnahmen Rom von deutschen Truppen besetzt, der Regierung Badoglio und der königlichen Familie gelang die Flucht zu den Alliierten. Nach der Befreiung Mussolinis durch die Deutschen trat er am 12. September an die Spitze der am 9. September gebildeten Gegenregierung, der Repubblica Sociale Italiana, die unter deutscher Kontrolle stand und ihren Regierungssitz in Saló am Gardasee hatte.

'Der „Stellvertreter des Führers“, Rudolf Heß, flog am 10. Mai 1941 nach Schottland, wo er wenige Kilometer vom Sitz des Herzogs von Hamilton entfernt mit einem Fallschirm absprang. Er beabsichtigte, die britische Regierung mit Hilfe des ihm flüchtig bekannten Herzogs davon zu überzeugen, daß Hitler keineswegs plane, eine gleichfalls nordische Rasse zu vernichten. Er wolle lediglich freie Hand im Osten. Sollte Großbritannien dies aber verhindern wollen, würde es vollständig zerstört werden. Heß wurde jedoch gefangengenommen und im Nürnberger Hauptkriegsverbrecherproze $B$ zu lebenslanger Haft verurteilt, die er bis zu seinem Tod am 17. August 1987 in Berlin-Spandau absaß. Durch seine lange Haft wurde er von neonazistischen Gruppen zum Märtyrer hochstilisiert.

${ }^{8}$ Jedes Jahr fand am 9. November das Treffen der ,Alten Kämpfer“" im Münchner Bürgerbräukeller statt, um der Opfer des fehlgeschlagenen Hitlerputsches am 9. November 1923 zu gedenken, eben der "Gefallenen der Bewegung“.

${ }^{9}$ Hitler hielt die Rede am Nachmittag des 8 . November im Löwenbräukeller in München. Abends wurde sie im Rundfunk übertragen.

${ }^{10}$ Rommel war bis 21 . November 1943 Befehlshaber der Heeresgruppe B in Norditalien. Verbände der 71. Infanterie-Division besetzten in der Adria zwar die Inseln Lussino, Cherso und Krk, eroberten aber keine Schlüsselstellungen. Während des gesamten Novembers fanden heftige Kämpfe um den Dnjepr statt, die Krim wurde aber noch gehalten, Kiew allerdings war am 6 . November von den Sowjets erobert worden. 
1 Die 6. deutsche Armee unter General d. Art. de Angelis räumte Odessa am 10. April 1944.

${ }^{12}$ Am 15. April 1944 hatte Badoglio ein neues Kabinett gebildet, in dem der Kommunist Palmiro Togliatti vertreten war.

${ }^{13}$ Die Deutschen hatten am 2. Oktober 1940 für alle Juden Warschaus und die jüdischen Flüchtlinge aus der Umgebung ein Ghetto errichtet, das etwa 400000 bis 500000 Menschen umfaßte. Als die Deutschen am 19. April 1943 das durch Deportationen, vornehmlich nach Treblinka, bereits stark dezimierte Ghetto liquidieren wollten, leisteten einige Bewohner organisierten bewaffneten Widerstand. Die Deutschen, die mit wenig Gegenwehr gerechnet hatten, mußten ihre Vorgehensweise ändern; sie vermieden jetzt direkte Auseinandersetzungen auf der Straße und brannten statt dessen die Häuser ab, warfen Handgranaten und setzten Gas ein. Am 8. Mai fiel das Hauptquartier der Widerstandsbewegung in deutsche Hände, wodurch der Widerstand gebrochen war, vereinzelt gab es aber noch bis Juni Kämpfe.

${ }^{14}$ Vgl. Die Wehrmachtberichte 1939-1945, Bd. 3, Köln 1989, S. 94.

${ }^{15}$ Die Invasion begann am 6. Juni 1944 mit der alliierten Landung in der Normandie.

${ }^{16}$ Während des ganzen Jahres 1944 griffen deutsche Flugzeuge London an. Am 12./13. Juni begann das Flak-Regiment 155 mit dem Abschuß von V1 (unbemannte Flugkörper) auf den Großraum London; am 15./16. Juni erreichte diese Aktion einen Höhepunkt.

${ }^{17}$ Die Alliierten zogen am 4. Juni 1944 in Rom ein. Die Deutschen erlitten beim Rückzug schwere Verluste durch nachstoßende amerikanische Panzerverbände.

${ }^{18}$ London stand während dieser Tage unter starker Bombardierung durch V 1-Waffen.

${ }^{19}$ Nach dem mißlungenen Attentat vom 20. Juli 1944 löste Heinz Guderian General Zeitzler als Chef des Generalstabes des Heeres ab. Ebenfalls eine Folge des Attentats war die Berufung Heinrich Himmlers zum Oberbefehlshaber des Ersatzheeres und Chef der Heeresrüstung.

${ }^{20}$ Am 25. Juli 1944 ernannte Hitler - auf Vorschlag von Hermann Göring - Reichsminister Goebbels zum „Reichsbevollmächtigten für den totalen Kriegseinsatz“. Daraufhin hielt dieser am Abend des 26. Juli eine lange Rede, die über alle deutschen Sender übertragen wurde, in der er seine ,fast religiöse, andächtige Dankbarkeit" über das fehlgeschlagene Attentat auf Hitler betonte und den ,totalen Krieg“" zum „Gebot der Stunde" erhob.

${ }^{21}$ Die Deutschen räumten am 28. Juli nach der Zerstörung aller wichtigen militärischen Anlagen die Städte Lemberg, Brest-Litowsk, Bialystok und Dünaburg.

${ }^{22}$ Seit 14. September standen die Amerikaner südlich bzw. südöstlich von Aachen. Von dort aus gelangen ihnen Einbrüche in Vorfeldstellungen des Westwalles. Etwa einen Monat lang fanden dort heftige Kämpfe statt. Trier war von August bis Dezember 1944 immer wieder Ziel alliierter Bombenangriffe. Kämpfe um die Stadt gab es aber erst im März 1945.

${ }^{23}$ Seit dem 12. Oktober wurde in der Gegend um Tilsit gekämpft, am 15. des Monats erlitt die Stadt einen schweren Bombenangriff. Die US-Armee eroberte Aachen am 21. Oktober 1944.

${ }^{24}$ Das Winterhilfswerk (WHW) war eine unter beträchtlichem Propagandaaufwand betriebene Sammel- und Spendenaktion, die ab 1933 jeweils in den Wintermonaten durchgeführt wurde, und zwar von der "Nationalsozialistischen Volkswohlfahrt“" (NSV) unter Aufsicht des Propagandaministeriums.

${ }_{25}$ Adolf Hitler hatte am 30. April, zusammen mit seiner langjährigen Geliebten Eva Braun, die er am Tag zuvor noch geheiratet hatte, Selbstmord begangen. Eva Braun hatte Gift genommen, Hitler sich mit einer Pistole in den Mund geschossen. Er 
hatte testamentarisch Großadmiral Karl Dönitz zu seinem Nachfolger ernannt. Dessen Regierungszeit währte vom 1. bis 23. Mai 1945, als ihn die Briten absetzten und gefangennahmen. Vom Internationalen Militärgerichtshof in Nürnberg wurde er zu zehn Jahren Haft verurteilt.

${ }^{26}$ Am 8. Mai 1945 erfolgte die bedingungslose Kapitulation der Deutschen Wehrmacht. General Jodl unterzeichnete am 7. Mai im US-Hauptquartier in Reims die Kapitulationsurkunde, Generalfeldmarschall Wilhelm Keitel am 9. Mai im sowjetischen Hauptquartier in Berlin-Karlshorst.

${ }^{27}$ Die ,Deutsche Arbeitsfront" (DAF) war nach der Zerschlagung aller freien und unabhängigen Gewerkschaften am 2. Mai 1933 als Einheitsorganisation aller Arbeitnehmer und Arbeitgeber gegründet worden. Unter ihrem Leiter Robert Ley war sie mit bis zu 25 Millionen Mitgliedern die größte Massenorganisation des Dritten Reiches. Sie sollte die Arbeiterschaft für den NS-Staat gewinnen, kontrollierte die Einstellung und Entlassung der Arbeitskräfte, ihre Entlohnung und Sozialversicherung. Auch die ,nationalsozialistische Gemeinschaft Kraft durch Freude“ (KdF), die für Millionen von deutschen Arbeitern die Freizeit organisierte, unterstand der DAF.

${ }^{28}$ Im November 1945 begann der Prozeß gegen die Hauptkriegsverbrecher vor dem Internationalen Militärgerichtshof in Nürnberg. Zwölf sog. Hauptkriegsverbrecher wurden zum Tode verurteilt (darunter Göring, Streicher, Ribbentrop, Frank, Keitel und Jodl), sieben zu Freiheitsstrafen und drei freigesprochen (Urteilsverkündung: 30. 9. - 1. 10. 1946). Zwölf sog. Nachfolgeprozesse unter US-Gerichtshoheit u. a. gegen Diplomaten, Militärs und Vertreter der Wirtschaft folgten.

${ }^{29}$ Gemeint ist das Konzentrationslager Bergen-Belsen, das in der Nähe von Hannover lag. Errichtet wurde das ,,Aufenthaltslager“, das ursprünglich dem Gefangenenaustausch mit im Ausland festgehaltenen Deutschen dienen sollte, im Juli 1943. Deshalb waren dort anfänglich auch die Bedingungen etwas besser als in anderen Lagern. 1944 aber herrschten fürchterliche Zustände. 37000 Menschen starben durch Zwangsarbeit, Mißhandlungen und Epidemien vor der Befreiung des Lagers durch die Briten am 15. April 1945, darunter auch Anne Frank. Nach dem Krieg wurde Belsen das größte Lager für Displaced Persons in der britischen Besatzungszone.

${ }^{30}$ In einer Note vom 14. Januar 1947 bat die französische Regierung die USA um ihre Zustimmung zu dem Vorhaben, die deutschen Kriegsgefangenen selbst entscheiden zu lassen, ob sie nach Deutschland entlassen oder als „Freie Zivilarbeiter" in Frankreich bleiben wollten. Am 28. Januar gaben die USA ihr Einverständnis. Die Übernahme in das Arbeitsverhältnis - eine raschere Entlassung war die Folge begann im Juli 1947 und umfaßte 137987 fast ausschließlich deutsche Kriegsgefangene. Vgl. Kurt Böhme, Die deutschen Kriegsgefangenen in französischer Hand, München 1971, S. $133 \mathrm{ff}$.

${ }^{31}$ Generalfeldmarschall Friedrich Paulus hatte den Oberbefehl über die 6. Armee, deren Überreste am 31. Januar 1943 bei Stalingrad kapitulieren mußten. Paulus geriet in sowjetische Kriegsgefangenschaft. 1946 sagte er als Zeuge der sowjetischen Anklage vor dem Internationalen Militärgerichtshof in Nürnberg aus, blieb aber bis November 1953 in sowjetischer Kriegsgefangenschaft. Er hatte sich dort dem „Bund Deutscher Offiziere" angeschlossen, der das Ende des NS-Regimes und des Krieges propagierte. Danach zog er in die DDR und starb am 1. Februar 1957 in Dresden. 

